\title{
DUE/ER/T5700-.TH
}

\section{An artificial neural network}

\author{
fault-diagnostic adviser for a nuclear power plant \\ with error prediction \\ by DE93 010305 \\ DOE/ER/75700--T4
}

Keehoon Kim

A Thesis Submitted to the

Graduate Faculty in Partial Fulfillment of the

Requirements for the Degree of

MASTER OF SCIENCE

Department: Mechanical Engineering

Major: Nuclear Engineering

Approved:

Member of the Committee:

In Charge of Major Work

For the Major Department

For the Graduate College

FGO2-92ER75 700

Iowa State University

Ames, Iowa

1992

Copyright $\odot$ Keehoon Kim, 1992. All rights reserved.

The Government reserves for itself and

others acting on its behalf a royalty free,

nonexclusive, irrevocable, world-wide

license for goverrmental purposes to publish,

distribute, translate, duplicate, exhibit,

and perform any such data copyrighted by

the contractor. 
TABLE OF CONTENTS

ACKNONLEDGELENT . . . . . . . . . . . . . . . . . ix CHAPTER 1. IMTRODUCTIOA . . . . . . . . . . . . 1 Nuclear Power Plant Fault Diagnostics . . . . . . . . 1 Artificial Neural Network Fault-Diagnostic Adviser . . . 2 Error Analysis for ANN Diagnostic Results . . . . . . . 4 CHAPTER 2. BACRPROPAGATIOA MEURAL METWORK THEORY . . . . . 6 Introduction . . . . . . . . . . . . . . 6 Backpropagation Neural Network Architecture . . . . . . 7 Backpropagation Algorithm . . . . . . . . . . . 9 Feedforward flow ............... 9 Backward error propagation ........... 12

Chapter 3. gemeralization . . . . . . . . . . . 15 Introduction . . . . . . . . . . . . . . 15 Generalization . . . . . . . . . . . . 16 Generalizer . . . . . . . . . . . . 18

Generalizer criteria . . . . . . . . . . 19 CEAPTER 4. ERROR PREDICTION OF A BINGLE GENERALIZER . . . . 24 Introduction . . . . . . . . . . . . . . . . . 24 Nonparametric statistics . . . . . . . . . . . . 24 Cross Validation . . . . . . . . . . . . . 27 
Stacked Generalization . . . . . . . . . . . . . 31

Cross validation partition set . . . . . . . . . 33 stacked generalization for multple generalizers . . 35 stacked generalization for a single generalizer . . . 39 Error prediction . . . . . . . . . . . . . . 42

CHAPTER 5. METHOD OF SOLUTION . . . . . . . . . . . . 43

Introduction . . . . . . . . . . . . . . .43

Data Analyzed . . . . . . . . . . . . . . . 44

Data . . . . . . . . . . . . . . . . . 44 4

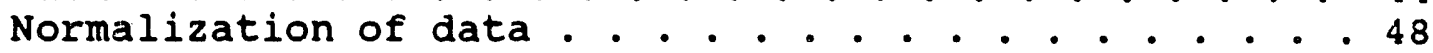

Development of an ANN Fault-Diagnostic Adviser . . . . . . 49

Learning set and learning process of the ANN adviser .. 49

Error Prediction in the ANN Fault Diagnostics for a NPP .. 53

Generating a level 1 learning set. . . . . . . . 54

Training of a level 1 generalizer... . . . . . . . 56

Predicted error . . . . . . . . . . . . . . 57

CHAPTER 6. RESULTS OF THE REBEARCH . . . . . . . . . . 58

Diagnostic Results of the Adiviser . . . . . . . . . 58

Error Prediction on the Adviser Diagnosis . . . . . . 60

CHAPTER 7. CONCLU8IONB . . . . . . . . . . . . . 80

Possible Future Work . . . . . . . . . . . . . 81

BIBLIOGRAPHY . . . . . . . . . . . . . . . 82

APPENDIX A. COMPUTER CODES . . . . . . . . . . . . . 87

NORMAL.FOR . . . . . . . . . . . . . . 87

MR10.FOR . . . . . . . . . . . . . . . 89

RCLN1-.FOR . . . . . . . . . . . . . . . 97

APPENDIX B. BAMPLE DATA SET . . . . . . . . . . . 100 


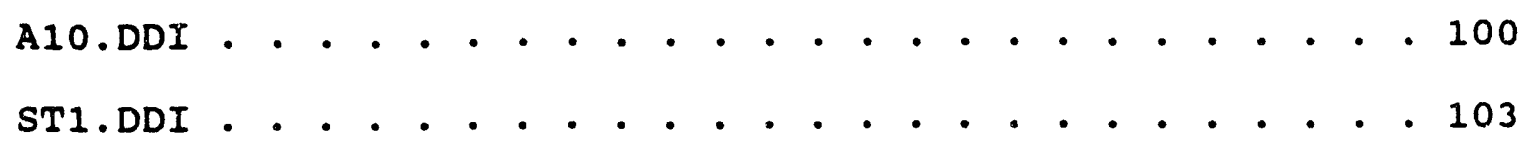


LIBT OF TABLES

Table 5.1 : List of 10 accident scenarios with transient onset time and desired ANN output layer

activation............... 45

Table 5.2 : Plant variables . . . . . . . . . . 46

Table 6.1 : Summary of the ANN adviser results . . . . . 59

\section{DISCLAIMER}

This report was prepared as an account of work sponsored by an agency of the United States Government. Neither the United States Government nor any agency thereof, nor any of their employees, makes any warranty, express or implied, or assumes any legal liability or responsibility for the accuracy, completeness, or usefulness of any information, apparatus, product, or process disclosed, or represents that its use would not infringe privately owned rights. Reference herein to any specific commercial product, process, or service by trade name, trademark, manufacturer, or otherwise does not necessarily constitute or imply its endorsement, recommendation, or favoring by the United States Government or any agency thereof. The views and opinions of authors expressed herein do not necessarily state or reflect those of the United States Government or any agency thereof. 


\section{LIBT OF FIGURES}

Figure 2.1 : An example of a 4 layer neural network . . 8

Figure 2.2 : Feedforward activation for a neural network ............... . . 11

Figure 4.1 : Illustration of set $Q=\{q \mid$ all questions $\}$ and the cross validation partition set (CVPS) . . . . . . . . . . . . . . 34

Figure 4.2 : Illustration of generating a new learning set (level 1) by stacked generalization for multiple generalizers . . . . . . . 36

Figure 4.3 : Illustration of level 1 generalizer with a question . . . . . . . . . . . . 38

Figure 4.4 : Illustration of generating a level 1 learning set by stacked generalization for a single generalizer... . . . . . . . . 40

Figure 4.5 : Illustration of a level 1 generalizer with a question... . . . . . . . . . . . 41

Figure 6.1 : Recall performance for the transient of Turbine Trip / Reactor Trip . . . . . 61

Figure 6.2 : Recall performance for the transient of Loss of Main Feedwater Pumps . . . . . 61

Figure 6.3 : Recall performance for the transient of Closure of Both Main Steam Isolation Valves . . . . . . . . . . . . 62

Figure 6.4 : Recall performance for the transient of Trip of All Reactor Coolant Pumps . . . . 62

Figure 6.5 : Recall performance for the transient of Trip of a Single Reactor Coolant Pump . . . 63 
vii

Figure 6.6 : Recall performance for the transient of Turbine Trip From 50\% Power . . . . . 63

Figure 6.7 : Recall performance for the transient of Loss of Coolant Accident (LOCA) with Loss of off-Site Power. . . . . . . . . 64

Figure 6.8 : Recall performance for the transient of Main Steam Line Break . . . . . . . . 64

Figure 6.9 : Recall performance for the transient of Stuck open Pressurizer Safety with High Pressure Injection Inhibited . . . . 65

Figure 6.10: Recall performance for the transient of Single Turbine Governor Valve Closure . . . .65

Figure 6.11: Prdicted error on the diagnosis for the Turbine Trip / Reactor Trip . . . . . . 67

Figure 6.12 : Classification of the diagnosis for the Turbine Trip / Reactor Trip. . . . . . 667

Figure 6.13 : Predicted error on the diagnosis for the Loss of Main Feedwater pumps . . . . . . 68

Figure 6.14 : Classification of the diagnosis for the Loss of Main Feedwater Pumps . . . . . . . 68

Figure 6.15 : Predicted error on the diagnosis for the Closure of Both Main Steam Isolation Valves.............. 69

Figure 6.16 :- Classification of the diagnosis for the Closure of Both Main steam Isolation Valves............ . . . 69

Figure 6.17 : Predicted error on the diagnosis for the Trip of All Reactor Coolant Pumps . . . . . . 70

Figure 6.18 : Classification of the diagnosis for the Trip of All Reactor Coolant Pumps . . . . . 70

Figure 6.19 : Predicted error on the diagnosis for the Trip of a Single Reactor Coolant Pump . . . . . 71

Figure 6.20 : Classification of the diagnosis for the Trip of a Single Reactor Coolant Pump. . . . . 71 
Figure 6.21 : Predicted error on the diagnosis for the Turbine Trip From 50\% Power . . . . . . 72

Figure 6.22 : Classification of the diagnosis for the Turbine Trip From 508 Power . . . . . . 72

Figure 6.23 : Predicted error on the diagnosis for the Loss of Coolant Accident (LOCA) with Loss of offSite Power ................ . 73

Figure 6.24 : Classification of the diagnosis for the Loss of Coolant Accident (LOCA) with Loss of off-site Power ................. 73

Figure 6.25 : Predicted error on the diagnosis for the Main Steam Line Break . . . . . . . . . . . 74

Figure 6.26 : Classification of the diagnosis for the Main Steam Line Break . . . . . . . . . . . 74

Figure 6.27 : Predicted error on the diagnosis for the stuck Open Pressurizer Safety with High Pressure

Injection Inhibited....... . . . 75

Figure 6.28 : Classification of the diagnosis for the stuck Open Pressurizer Safety with High Pressure

Injection Inhibited . . . . . . . . 75

Figure 6.29 : Predicted error on the diagnosis for the Single Turbine Governor Valve Closure . . . . . 76

Figure 6.30 : Classification of the diagnosis for the single Turbine Governor Valve Closure . . . . . 76 


$$
\text { ix }
$$

\section{ACKNOWLEDGEMENTS}

First, I would like to thank my God for His love and for His helping me surmount all difficulties in my life, and in future. I am grateful to the supports of the United states Department of Energy under Special Research Grant No. DE-FGO292ER75700 and NETROLOGIC Inc. under SBIR project of Nuclear Regulatory Commission. I wish to thank the San onofre Nuclear Generating station for their cooperation in providing the training simulation data. Special thanks to Dr. Eric Bartlett for his enthusiasm and encouragement that inspired me through this endeavor. I thank Dr. Danofsky and Dr. Udpa for being on my program committee. Finally, I wish to thank my parents, my wife Gyeongsook, my daughter Somang, for their love and support. 
CHAPTER 1. IMTRODUCTION

\section{wuclear Power Plant Fault Diagnostics}

Since the accidents at the Three-Mile Island (TMI) and Chernobyl nuclear power plants (NPPs), the safety of NPPs has become an even more important concern to both the nuclear power industry and the general public. The demand for safer plants has increased ever since. Responding to the demand, many scientists have investigated augmenting NPP safety in various ways. For example, innovative reactor designs, better safety system designs, human factor studies, stricter safety regulations, and so on, have been developed and implemented in the years since the above-mentioned accidents.

It is, however, imprudent to assume that the possibility of an accident can be totally eliminated. Despite continual technical innovation and knowledge accumulation, the possibility of an accident is never zero. Human error factors, such as misdiagnosis, misinterpretation, or intentional human error (sabotage), are involved. Concentrating efforts on obtaining 
accurate diagnoses, and prescribing corrective actions when undesirable situations evolve, may be a more important and tractable approach than trying to remove completely all such possibilities case by case. This kind of approach will ameliorate NPP safety with less cost.

In order to control a potentially unsafe situation or condition properly and in a timely manner, accurate diagnoses should be made as soon as possible. Such accurate and rapid diagnoses will allow more time for the operators to respond to unsafe situations. They can concentrate on remedying or mitigating them rather than spending time determining the plant operating status. If the exact diagnosis can be performed by $a$ computer-aided adviser, the possibility of human error would be eliminated. In addition, other advantages that the computeraided adviser can offer include; fast diagnoses of anomalies, enumeration of the causes of anomalous conditions, and assistance for the operators in their decision process. Consequently, a computer-aided, fault-diagnostic adviser, used in the NPP control room or technical support center, requires the capability of early detection and accurate classification of operating transients in the NPP.

\section{Artificial Neural Network Fault-Diagnostic Adviser}

An artificial neural network (ANN) is one of many different 
artificial intelligence (AI) techniques that can be used as a fault-diagnostic adviser [7] [8]. In applications of AI to classification and pattern recognition, the ANN paradigms may be the most appropriate.

An ANN falit-diagnostic adviser uses given examples as its model. It learns similarities among complex and multifarious input information. During the learning process, the ANN adviser generalizes the characteristics of the given examples so that it is able to identify unfamiliar or novel input information based on similarities of that inputs with the known examples. The generalization characteristic enables the ANN to interpolate (or extrapolate) new input information and also gives it a degree of robustness against noisy or faulty input information. These noise- and fault-tolerance capabilities enable the ANN adviser to correctly diagnose a symptom even under a corrupted input condition.

Mathematically, the generalization characteristic is analogous to inferring an exact function from a given, limited sample set [13] [25] [36] [37]. In other words, an ANN generalizes a relationship between general input and output information by inferring a multidimensional and nonlinear mapping based on the given samples (or examples). However, the mapping in an ANN scheme is done by weight interconnections which cannot be delineated into a simple mathematical form. After an ANN establishes the relationship satisfactorily through 
the learning process, its classification or diagnosis is immediately determined when a question is asked of it. It doesn't go through the learning process again.

A number of scientists have investigated the application of an ANN to enhance NPP safety. Uhrig [29] (1989) has proposed the utilization of an ANN to identify causes of perturbations in a steam generator. Roh, Cheon and Chang [23] (1991) have applied an ANN to predict reactor thermal power. Upadhyaya and Eryurek [30] (1992) have used an ANN as an estimator of process variables and a method of sensor validation technique in a NPP. Guo and Uhrig [12] (1992) have applied an ANN to analyze the thermodynamic behavior of the Tennessee Valley Authority's Sequoyah NPP. Bartlett [4] [5] (1992) has investigated application of an ANN to NPP status diagnostics.

\section{Exror Analysis for ANN Diagnostic Results}

One drawback of the ANN is its inability to validate its diagnosis for the input conditions that are not in its training examples. This validation concern restricts the application of the ANN to areas where the input conditions are not notably different from the training examples, where the verification of the results is not a great concern, or where the ANN has other means of authentication.

In NPP fault diagnostics, the validation process is crucial 
in order to implement an ANN fault-diagnostic adviser in a real NPP [5]. The ANN diagnosis for a symptom in the plant, which is not validated, may mislead operators in the control room to analyze nonexisting or incorrect plant conditions during corrective and mitigative actions. Such a misdirection is contrary to the objectives of the original ANN fault-diagnostic adviser. Thus, a validation or an error estimation on an ANN's result must be provided to the NPP operators. Error analysis for ANNs is a relatively new field that will significantly contribute to improving both the credibility of the ANN faultdiagnostic adviser and NPP safety.

In this thesis, an ANN fault-diagnostic adviser for a NPP has been developed, and an error prediction method, suitable for the fault-diagnostic adviser, has been applied to validate the diagnostic results of the adviser. 


\section{CHAPTER 2 - BACKPROPAGATION MEURAL NETWORK THEORY}

\section{Introduction}

Backpropagation is the most widely applied and investigated ANN paradigm. In 1969, backpropagation was proposed by Bryson and Ho [2] and separately introduced by Werbos in 1974 [33], but it was largely ignored and unappreciated. Rumelhart rediscovered backpropagation with his research group members in 1985 [24]. Since Rumelhart's rediscovery, backpropagation has become one of the classic ANN paradigms and has been applied to various fields.

A backpropagation ANN is made of simple computational units (or nodes) connected to one another by weights. A gradient descent method is used to build a set of weight connections in the typical feedforward, multi-layered network used in backpropagation [13] [25] [34]. In this chapter, the theory of the backpropagation learning algorithm will be illustrated. 
Backpropagation Neural Network Architecture

Backpropagation is designed to determine weights in a hierarchial and fully interconnected ANN architecture (see Figure 2.1). The interconnections are structured to fan out between nodes and between layers. The backpropagation architecture contains one or more hidden layers between the input layer and the output layer. The interconnections of the nodes in the layers are accomplished through variable weights. In other words, the processing elements or nodes, interconnected by the weights, constitute the parallel, distributed information-processing structure [13] [19]. The backpropagation neural network of the parallel, distributed informationprocessing structure carries out an approximation or inference of a bounded mapping (multidimensional, linear, or nonlinear mapping) .

Mathematically, the network information-processing mapping may be expressed as a functional relationship $f$ from a subset $A$ of a m-dimensional Euclidian vector space to a bounded subset $f\{A\}$ of a n-dimensional Euclidean vector space [13], where

$$
f: A \subset R^{m} \rightarrow R^{n}
$$

such that 


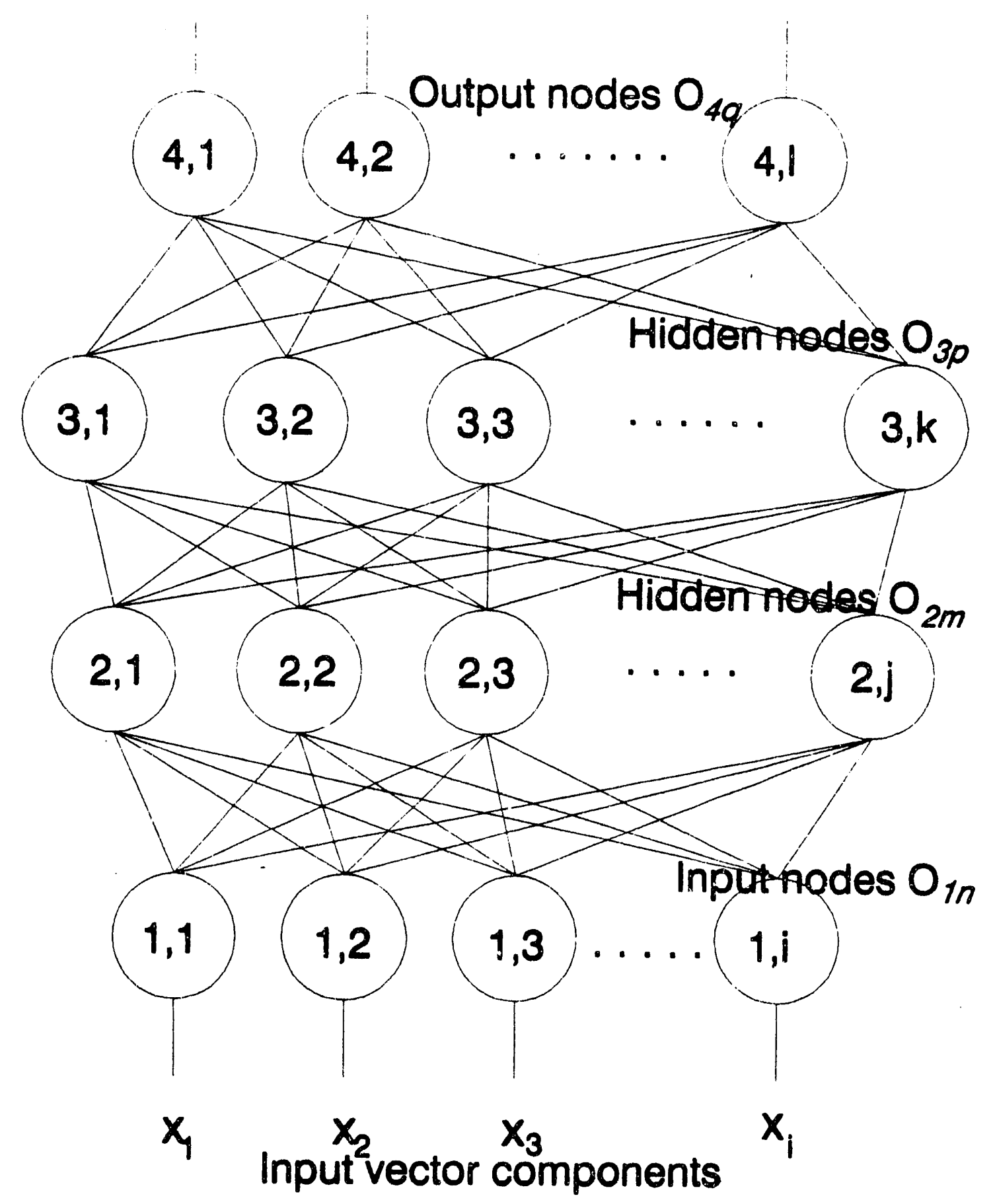

Figure 2.1 : An example of a 4-layer neural network 


$$
\vec{Y}_{k}=f\left(\vec{x}_{k}\right)
$$

A learning set consisting of $k$ examples, $\left(x_{1}, y_{1}\right),\left(x_{2}, y_{2}\right), \ldots$, $\left(x_{k}, y_{k}\right)$, is used to infer $f$. Each example contains an input pattern $x_{k}$ and an desired output (or target) pattern $y_{k}$. Note that those input-output patterns having $m$ and $n$ components, respectively, are equivalent to vectors in hyperspace.

The examples are generated by selecting the $x_{k}$ vectors randomly from the subset $A$ with a fixed probability distribution. The $Y_{k}$ vectors in the subset $f(A\}$ correspond to the selected $x_{k}$ vectors. In general, the more appropriate the selection of the $k$ examples, the more accurate the approximation of $f$. During the learning process, examples (patterns) are presented in turn, randomly, or all at once as in batch learning, to the network.

\section{Backpropagation Algorithm}

\section{Feedforward flow}

As illustrated in the previous section, the backpropagation architecture contains one or more hidden layers between the input layer and the output layer. In the feedforward activation flow [19], the input layer, consisting of input nodes, simply receives the individual components of a presented example, an 
input vector. Each component of the input vector is distributed to each of the nodes in the second layer with weight multiplication (see Figure 2.2). Note that there is no sigmoidal activation of the nodes in this input layer since the input to an input node is the output of that node.

After the input layer, the individual nodes of a next layer carry out the summation of each output of the nodes in the preceding layer, multiplied by their associated weights. This mechanism, delineated in Figure 2.2 , is referred to as feedforward activation. The activation of each node is determined by using a sigmoidal activation function, or transfer function. The activations and distributions continue in a forward or upward manner. The final output, or decision at the

output layer, is produced after all successive upward activations in previous layers are completed. Details of the feedforward activation follow.

Let $o_{p i}$ denote the output of node $i$ in layer $p$. Weight $w_{i j}$ connects from node $j$ in layer $p-1$ to node $i$. $\theta_{i}$ is a bias for node $i$. See Figure 2.2. The activation of the node $i$ is calculated using the following rule,

$$
O_{p i}=f\left(\sum_{j} w_{1 j} O_{p-1} f+\theta_{i}\right)
$$

where $f$ is the logistic activation (or sigmoid) function,

$$
f(x)=\frac{1}{1+\exp (-x)}
$$




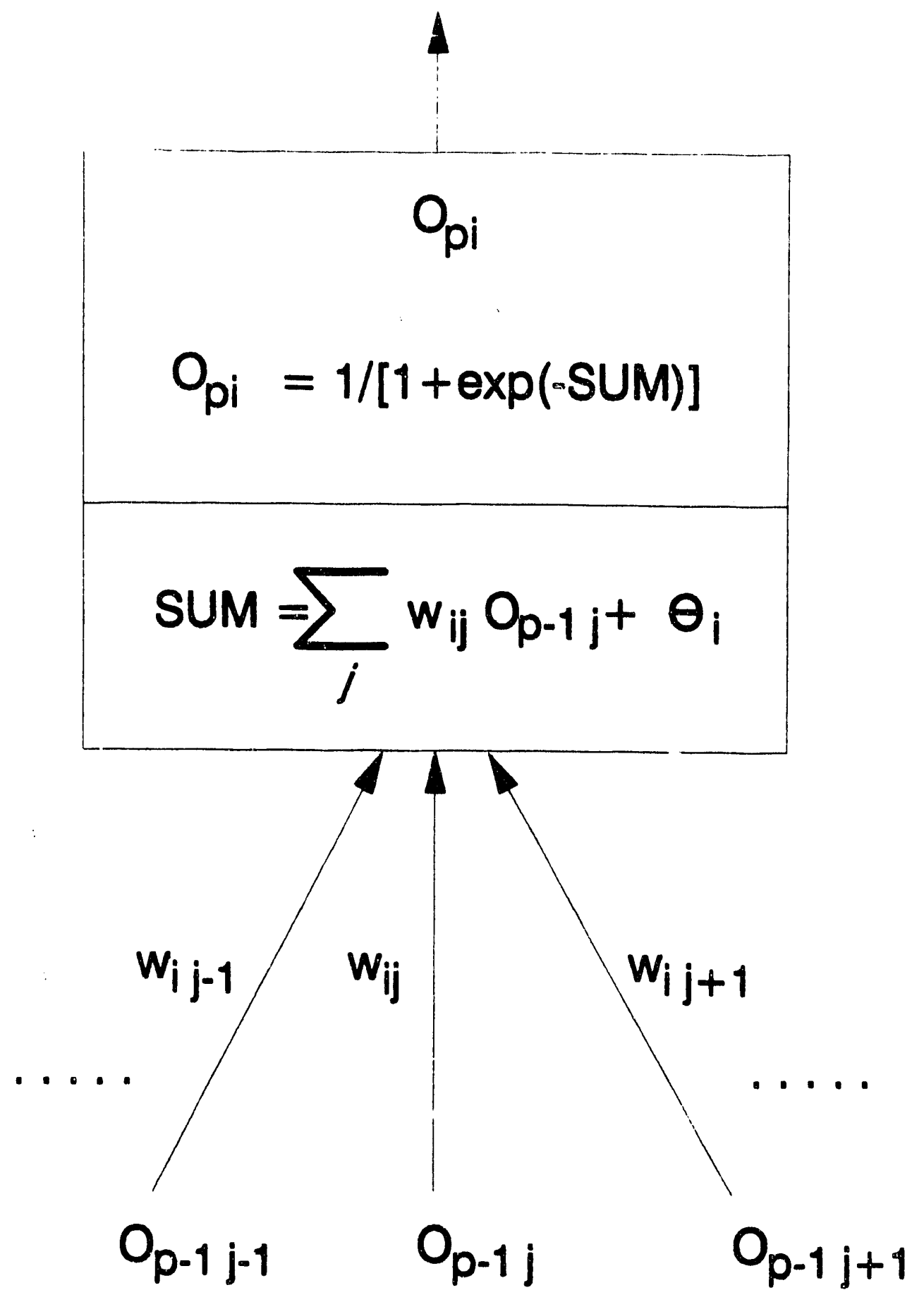

Figure 2.2: Feedforwäd activation for a neural network 
Namely, the activation of node $i$ is calculated using the sigmoid function on the sum of the weighted inputs to the node.

once the feedforward activation flow is accomplished, the output of the network may not be the desired result for a given input. Thus, the network needs a learning process to produce the desired output. This learning process is performed by backward error propagation [13] [25].

\section{Backward error propagation}

The backward error propagation (BEP) adjusts the weights connected between two successive layers in order to provide the desired results. The weights are updated recursively in accordance with

$$
w_{i j}(n+1)=w_{i j}(n)+\eta \delta_{p i} o_{p j}+\alpha\left(w_{i j}(n)-w_{i j}(n-1)\right)
$$

where $\eta$ is the learning rate, $n$ is the training number, $\alpha$ is the momentum coefficient, and $\delta_{p i}$ is the error of node $i$. The error $\delta_{p i}$ is calculated by the delta rule in the final layer and by the generalized delta rule in the hidden layers. Thus, first step of the BEP process is to calculate the error of each output node, and to adjust the connected weights by the backpropagation learning laws.

Delta rule A weight, connecting the output node and a 
hidden node in the uppermost hidden layer, is adjusted by Eq. 5 coupled with the delta rule [25] [34]. The delta rule is used to compute the error $\delta_{p i}$ at the output node $i$ as follows.

$$
\delta_{p 1}=\left(t_{1}-O_{p 1}\right) O_{p 1}\left(1-O_{p 1}\right)
$$

where $t_{i}$ is the desired (or target) output. Namely, the error is calculated based on the difference between the desired output and the actual output for the node, multiplied by the derivative of the node. Note that $O_{p i}\left(1-O_{p i}\right)$ is the derivative of the sigmoid function.

Generalized delta rule The next step is to adjust the weights connected between two successive hidden layers. For the weight adjustments, the error $\delta_{\mathrm{pi}}$ of a hidden node in the upper hidden layer must be known. However, the desired output of the hidden node is not explicitly known. To resolve the difficulty, Widrow and others have developed the generalized delta rule to infer the error of the hidden node [19] [34]. The error is estimated by propagating the computed errors of the output layer in the backward direction.

The error $\delta_{p i}$ for a hidden node $i$ between two successive hidden layers, $p$-th and $(p+1)$-th layers, is displayed as 


$$
\delta_{p i}=O_{p i}\left(1-O_{p i}\right) \sum_{k} \delta_{p+1} w^{w_{i k}}
$$

The $\delta_{p i}$ is associated with the errors of those $k$ hidden nodes in the upper hidden layer, multiplied by the weights connected to the node $i$. The derivative of the sigmoid function is then applied to the summed value. This estimated error is used in updating the weight according to Eq. 5. The generalized delta rule can be applied repeatedly to the next lower hidden layers when the ANN architecture has multiple hidden layers. According to these rules, weights are adjusted to learn a set of presented examples.

The feedforward and the BEP processes continue until the network's learning error becomes less than a predetermined value (or target learning accuracy). A set of weights, obtained from the learning procedure, represents the mapping that the network has approximated.

The backpropagation paradigm is not only one type of ANN, but also a generalizer as will be explained in the next chapter [35] [36] [37]. The backpropagation ANN will be employed in a stacked generalization scheme to predict the generalization error of a generalizer, described in Chapter 4 [37]. 
CEAPTER 3. GENERAIIZATION

\section{Introduction}

Generalization is one of the most desirable characteristics in various scientific applications. For example, in the fields of statistics, AI, and ANNs, generalization from given experimental data is essential in solving the problem of determining the best model for a given data set. The best, generalized, model will be able to predict (interpolate or extrapolate) a group of variables as closely as possible.

In addition, generalization enables a system to cope with noises and faults caused by irregular and novel environmental factors in real-world applications, such as in speech recognition, pattern recognition, image reconstruction, control optimization, and so on. Usually, noises and faults come from outside the system. Therefore, a well generalized system (the best model) will respond correctly even to novel or degraded inputs. Memorization, in contrast to generalization, cannot provide proper responses to novel or degraded information. A 
system that has memorized a given data set will fail to show correct responses to novel input information.

In real-world problems, a system faces external noises or novel information frequently. Without the generalization capability, noisy and novel inputs degrarie the abilities of the system to perform its intended function. These degraded solutions are undesirable and unreliable. Obviously, generalization is an important consideration in solving the real-world problems in order for the system to produce a wellbehaved solution.

In NPP fault diagnostics, when a novel or unidentified plant condition is presented to an ANN fault-diagnostic adviser, the adviser has to be capable of detecting and diagnosing the unidentified condition. Early and accurate diagnoses should be provided to the plant operators even under noisy- and faultyinformation. Typically, the noisy- and faulty-information come from the plant variable monitoring system at the NPP. Thus, even under the noisy- and faulty-information, fast and accurate fault-diagnoses must be realized. Consequently, generalization is a significant factor in designing a fault-diagnostic adviser for a NPP.

\section{Generalization}

One of the goals of AI is to create a human-like system 
that possesses two kinds of logical inference abilities. Namely, the human-like system has both the deductive inference ability and the inductive inference ability. Each inference ability yields different kinds of knowledge [10]. The deductive inference corresponds to a rule- or data-based intelligence, similar to memorization. In the same way, the inductive inference corresponds to generalization. For example, suppose that a teacher lectured a student on how to solve a problem in a textbook. If, in an exam, the same type of problem is asked of the student, the exam will measure the student's deductive inference ability (or memorization). If a problem, made up by applying the acquired knowledge from solving the taught problem, is asked of the student, the exam will measure the student's inductive inference ability (or generalization). Thus, the generalization is the inductive inference that is more essential element to simulate the functions of human intelligence. Generalization is difficult to achieve in AI.

Mathematically speaking, generalization is analogous to inferring an objective function from a given sample set. Many times, the objective function is referred to as a parent function [36] [37]. The given set consisting of input-output vector pairs, used in the above inference process, is referred to as a learning set. Wolpert [36] defines generalization as the ability of a system to make a good guess as to the output vector for an input vector not included in the learning set. Since 
generalization takes piace without a priori knowledge of novel input information, it is analogous to educated guessing. This kind of intelligent guessing is performed by looking for similarities between the novel input information and previously learnec nnowledge.

From a statistical viewpoint generalization can also be regarded as simply a statistical curve fitting [36]. In other words, the acjuiring the generalization characteristic from a given learning set is analogous to the searching for the best model that rits experimental data in statistics. In ANN paradigms, the best model fitting is performed by searching for the best weight.s combinations from infinite sets of weights.

In addition, generalization (or generalization accuracy) is used $a=$ a measure of the intelligence of a system [36]. As an application to ANN learning, a system can be evaluated by generalization accuracy rather than by learning accuracy. Using this measure, a system can also be optimized to have the least generalization error for a given data set.

\section{Generalizers}

An algorithm, which infers a parent function from a limited learning set, is called a generalizer [36] [37]. A generalizer is trained, or taught, with a learning set, $\left\{\left(x_{1}, y_{1}\right),\left(x_{2}, y_{2}\right)\right.$, ..., $\left.\left(x_{k}, y_{k}\right)\right\}$, consisting of $k$ pairs of input-output patterns. 
The input vector $x_{k}$ and the output vector $y_{k}$ have $m$ and $n$ components, respectively. When a question vector $q$, having $m$ components, is asked of the generalizer, the generalizer will guess the corresponding output that is induced from its internal knowledge.

The generalizer is defined more precisely as follows. Suppose that each pair, $\left(x_{p}, Y_{p}\right)$ in a data space of $\mathbf{R}^{m} \times \mathbf{R}^{n}$, constitutes a learning set in data space $\mathbf{B}^{\mathrm{k}(\mathrm{m}+\mathrm{a})}$, such that \{ $\left(x_{p}, y_{p}\right) \mid 1 \leq p \leq k, x_{p}=\left(x_{1}, x_{2}, \ldots, x_{m}\right) \in \mathbf{R}^{m}, Y_{p}=\left(y_{1}, Y_{2}, \ldots, y_{n}\right)$ $\left.\epsilon \mathbf{R}^{\mathbf{n}}\right\}$, where $\mathbf{R}$ represents the space of real numbers. Thus, $\boldsymbol{x}_{\mathbf{p}}$ and $y_{p}$ represent input and output vectors (patterns) in $\mathbf{R}^{m+n}$, respectively. $\mathbf{R}^{k(m+n)}$ represents the $k$-th order data space of $k$ input-output pairs in the learning set. The order of the learning set is then defined to be $k$, the number of patterns in the data space. Wolpert defines an m-dimensional generalizer \{ $G \mid G_{i}, 0 \leq i<\infty ; i$ is integer $\}$ to be a countably infinite set of continuous mappings from a subset of $\mathbf{R}^{\mathrm{k}(\mathrm{m}+\mathrm{n})+m}$ to $\mathbf{R}^{\mathrm{n}}$ [36]. The $\mathbf{R}^{\mathbf{m}}$ in the $\mathbf{R}^{\mathbf{k}(\mathbf{m}+\mathbf{a})+\mathrm{m}}$ term represents a question data space. $\mathbf{R}^{\mathrm{n}}$ represents the n-dimensional output vector space. Note that the dimension of a generalizer is defined to be the dimension of input data space, $m$ in this case.

\section{Generalizer criteria}

To complete the definition of a generalizer, several restrictions must be imposed. Hence, a generalizer should 
satisfy the following criteria [36]:

The first restriction pertains to the order of the patterns in the data space. The order of the presentation of data to a generalizer must be irrelevant. Namely, a generalizer is invariant to the presentation order of the data. Thus,

1. Every generalizer $G_{i}$ is invariant under permutation of the data space.

The second restriction pertains to the reproduction of the learning set. When a generalizer $G_{i}$ is asked a question from the learning set, the generalizer $G_{i}$ must reproduce an output vector from the learning set, corresponding to the input question vector. This criterion is subject to learning accuracy.

2. When the $G_{i}$ is asked a question that is the same as an input vector in the data space, the $\dot{G}_{i}$ generates the same output vector in the data space, corresponding to the input vector.

The third restriction states that the domain of $G_{i}$ is single-valued. In other words, two or more outputs corresponding to a single input vector cannot be allowed. 
3. For any $G_{i}$, if any input vector in the data space is identical to another input vector in other data space, then they must have the same output vector.

The next restriction refers to the least number of inputoutput patterns in a learning set. Hence, a generalizer needs sufficient input-output vectors (learning examples) in the learning set in order to possess generalization characteristic.

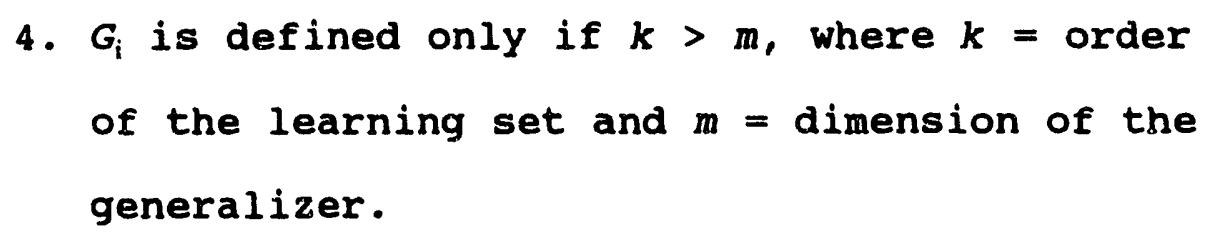

The last criteria refers to a necessary dimensionality of the input vectors in a learning set. For examl e, assume $m=2$. In this case an input vector in the learning set has two components. If all input vectors are colinear (i.e., the 1dimensional hyperplane is identical to a line), then this learning set provides information about the line to be generalized. Hence, the learning set cannot provide sufficient information about the points not on the line (i.e., generalization is not possible with such a limited learning set). A generalizer requires the components of all input vectors in a learning set to lie on, at least, the same dimensional 
hyperplane as that of the generalizer. This is expressed as follows.

5. Even if $k>m, G_{i}$ is not defined if the components of all input vectors in the learning set, $\left(x_{1}, x_{2}, \ldots x_{m}\right) \in \mathbf{R}^{\mathrm{m}}$, lie on the same $(m-1)$-dimensional hyperplane.

There are many generalizers that satisfy these criteria. For example, generalizers include backpropagation neural networks [25] [35], Holland's classifier system [14], Rissanen's minimum description length principle [22], memory-based reasoning schemes [26], regularization theory [21], and surface fitters of a parent function [9] [20] [36]. Of course none of these generalizers cannot infer with infinite certainty an entire parent function from a learning set.

Intuitively, if a generalizer is trained on a subset of the learning set, the generalizer should be able to make an educated guess at the rest of learning set. This is called self-guessing [36]. Furthermore, by applying this self-guessing property, the generalizer can estimate its own self-performance for untaughted examples. Self-guessing can be considered as a different kind of reproduction of the learning set and can be used to observe the behavior of a generalizer for novel inputs. This self-guessing of the remainder of the learning set is an application of the 
23

second criteria of generalization described in the previous section. Self-guessing appears as cross-validation in statistics [36]. 
CHAPTER 4. ERROR PREDICTION OF GENERALIZER

\section{Introduction}

One obstacle to the application of ANNs to a real-world situation has been the inability to assign error bounds to the ANN results. An ANN result that contains a large error cannot be reliable. Thus, ANNs can not be used in NPP fault diagnostics without providing error bounds, figure of merits, or confidence levels, on the ANN results. Validation of ANN results is crucial in NPP fault diagnostics. This chapter will address the validation concern for ANN results by applying the stacked generalization technique [37]. In this chapter, stacked generalization will be illustrated as a tool to define and measure generalization error.

\section{Nonparametric statistics}

As described in the previous chapter, self-guessing is related to cross validation. Cross validation is one of many 
methods in nonparametric statistics developed by statisticians since 1950 [31]. Therefore, it is advantageous to discuss nonparametric statistics. But, first, a short discussion of statistics in general will be presented.

Statistics is used to compare a set of experimental data, or a theoretical model, with other data or models. Suppose that there is two models, $A$ and $B$. The question of which model fits a set of given data better can be converted statistically to a question of which one has better statistical parameters.

For example, the question of whether or not the average of the elements in set $A$ is larger than a similar average in set $B$ can be addressed in statistics as follows. Before the emergence of nonparametric statistics, the standard statistical answer would be obtained by using the t-statistic, which is the difference between the average of the set $A$ and the average of the set $B$, divided by a certain quadratic function of all the data. The divisor scales the difference between the two averages for comparison with a single table. The computed $t$ is compared with its theoretical distribution calculated under the assumption that all the given data were randomly drawn from the same normal (Gaussian) distribution. For the normal distribution, a standard table, called $t$-table, is tabulated. By comparing a value in the table with the calculated value $t$ from the given data, the question of whether the set $A$ is bigger than set $B$ is answered. Additionally, the question that set $A$ is not 
just accidentally bigger than set $B$ can be answered by using the $t$-table. Unfortunately, t-statistic is too idealized, based on normal or Gaussian distribution, to apply it to many real-world situations. If an observed data set does not follow normal distribution, $t$ is not quite an appropriate parameter to be used for a statistical test. The statistical decision by this parameter would not be accurate.

Nonparametric statisticians has developed ways to find answers to questions of the sort discussed above for those data sets that do not depend upon normal distribution [28] [26] [27] [31] [34]. As the price for nondependence on normal distributions, nonparametric statistics requires a huge computational effort because a significance table must be constructed for each set of data.

For example, let set $A$ and set $B$ have $n$ and $m$ elements, respectively. Assume that we want to determine that set $A$ has a larger average than set $B$ as before. First, in the nonparametric metnod, the two sets are combined into a single set, $C$, containing $n+m$ elements. Then, a partition of set $C$ is arbitrarily made yielding two subsets. One of the subsets has $n$ elements, and another one has m elements. Note that there are a total of $(n+m) ! /(n ! m !)$ ways of partitioning the set $c$ into two subsets having $\mathrm{n}$ and $\mathrm{m}$ elements respectively. For a given partition, the difference between the average of each partitioned subset (the average of one subset minus the average 
of another subset) is computed. For all possible partitions, there are $(n+m) ! /(n ! m !)$ computed differences. Notice that among the computed $(n+m) ! /(n ! m !)$ differences, one of these differences is the difference between the averages of set $A$ and set $B$. These $(n+m) ! /(n ! m !)$ differences constitute a significance table for this set $c$, corresponding to the $t$-table in normal distribution statistics. Thus, the significance table is used to decide which set has a statistically larger average. If the difference between the averages of $A$ and $B, i . e .$, the average of $A$ minus the average of $B$, is in the upper $5 \%$ of the $(n+m) ! /(n ! m !)$ difference values in the significance table, the set $A$ has a statistically larger average than the set B [28].

The statistical decision by this nonparametric method is much more accurate and appropriate for cases depending upon nonnormal distributions, or an unknown distribution.

\section{Cross Validation}

Selection of the best model for a given experimental data set is an important consideration in many scientific applications [18]. Additionally, how well the model performs and how it is able to predict an experimental result is also of crucial importance for the model. In nonparametric statistics, cross validation addresses this concern. Cross validation has been proposed by stone [27] and Geisser [11] in order to solve 
the problem of selecting appropriate models to fit observed or experimental data.

The following discussion explains cross validation. Consider the selection of the best model for a given data set amongst many possible models. In cross validation, an arbitrary model is chosen amongst available others. The given data set is then randomly partitioned into two subsets, subset $\theta_{2}$ having one element and another subset $\theta_{1}$ having the remaining of the data. Then any method is used to fit the model to the partitioned subset $\theta_{1}$. The model fitted to $\theta_{1}$ is tested to see how well it predicts the subset $\theta_{2}$. This is why the term is named cross validation since the partitioned subset $\theta_{2}$ is used to cross validate the model developed by the another partitioned subset $\theta_{1}$. The main objective of the cross validation is to choose the best model of many possible models by observing the behavior on one part of the partitioned subsets, while the other part is used to fit the model. The behavior of each model is compared with that of different models, and then the best model is selected. This is sometimes referred to as a winner-takes-all strategy because only the best model is selected for use by the technique. A mathematical explanation of cross validation follows [31].

Let $\mathrm{N}$ data points $\left(x_{\mathrm{i}}, Y_{\mathrm{i}}\right)$ be generated by a parent function $y(x)$ on the interval $[a, b]$ such that $y_{\mathrm{i}} \equiv y\left(x_{\mathrm{i}}\right)+\varepsilon_{\mathrm{i}}$ where the $\varepsilon_{\mathrm{i}}$ are independent normal random variables with mean 0 and a given 
standard deviation, and $x_{i}=a+i \cdot(b-a) / N, i=1,2, \cdots, N$. Suppose that $h(x, \alpha)$ is a class of curves $h(x)$ fitted to the given $\mathrm{N}$ data with a choice of the non-negative parameter $\alpha[31]$. Hence, $h(x, \alpha)$ is defined to be the curve minimizing [31]

$$
\frac{1}{N} \sum_{i=1}^{N}\left[y_{1}-h\left(x_{1}\right)\right]^{2}
$$

constrained by the following equation,

$$
\int_{a}^{b}\left[\frac{d^{2} h(x)}{d x^{2}}\right]^{2} d x=\alpha
$$

The constraint Eq. 9 is a smoothness condition: if $\alpha=0$, the fitted curve $h(x, \alpha)$ is so smooth that the curve is a straight line, as if it is fitted by the ordinary least squares method. If $\alpha$ is large enough, $h(x, \alpha)$ will go through every data point. This fits all the given data perfectly, but it is a very irregular curve. Thus, the selection of the best fitted curve to the parent function is dependent upon the parameter $\alpha$. Cross validation provides the best value of $\alpha$ among the given choices. Selecting the best $\alpha$ means the minimization of the error of a fitted curve, compared to the true parent function. In other words, $\alpha$ is selected such that a curve $h(x, \alpha)$ for the selected 
$\alpha$ is the closest to the true parent function. Cross validation is performed as follows.

Let the given data set be $L=\left\{\left(x_{i}, y_{i}\right) \mid i=\right.$ integers, $0 \leq$ $i \leq N\}$. First, consider a partition of $L$. The partition splits L into two subsets, a pair $\left(x_{i}, Y_{i}\right)$ and the remainder of $L$. For each choice of a partition $i$, let $h_{(i)}(x, \alpha)$ be a curve $h(x)$ satisfying constraint Eq. 9, and minimizing

$$
\frac{1}{N-1} \sum_{\substack{i=1 \\ j \neq 1}}^{N-1}\left[y_{i}-h\left(x_{i}\right)\right]^{2}
$$

Now, $h_{(i)}(x, \alpha)$ is a curve fitting the $N-1$ data points that satisfies the constraint in Eq. 9 by minimizing Eq. 8 without the selected pair, $\left(x_{i}, y_{i}\right)$. Next, in order to choose the best $\alpha$, $\left(x_{i}, y_{i}\right)$ is used to predict an expected error involved in fitting the curve $h_{(i)}(x, \alpha)$. Note that the prediction of an error corresponds to the observation of the behavior of the model on one of partitioned subsets, when the model is fitted on the other partitioned subset. Hence, for all partitions, define

$$
Q^{+}(\alpha)=\frac{1}{N} \sum_{i=1}^{N}\left[y_{i}-h_{(1)}\left(x_{1}\right)\right]^{2} .
$$

Select the best $\alpha, \alpha^{\dagger}$, minimizing $Q(\alpha)$ for all partitions. Now, 
the curve $h\left(x, \alpha^{+}\right)$is the best solution or model suggested by cross validation in the class of $h(x, \alpha)$.

The selection of the best fitted curve $h\left(x, \alpha^{+}\right)$by cross validation can be viewed as the choice of the generalizer $G_{i}$ that shows the highest generalization capability in a class of generalizers. Similarly, the given data set in the cross validation scheme corresponds to a learning set in generalization. Note that the self-guessing characteristics of generalization, described in the preceding chapter, is used in cross validation.

Cross validation is a winner-takes-all strategy by which the best model is selected. As an application, cross validation can be used as a method to pick the best generalizer $G_{i}$ among possible generalizers. Additionally, cross validation can be employed to estimate the average generalizing accuracy of a generalizer for an unknown parent function which generated a learning set. Wolpert has developed these ideas into stacked generalization [37].

\section{stacked Goneralization}

Stacked generalization can be thought of as an extension application of cross validation. It was proposed by Wolpert [37] to achieve a generalization accuracy that is as high as possible for one or more generalizers. When used with multiple 
generalizerj, stacked generalization can be viewed as a scheme collecting and combining all the advantages of each gerieralizer, rather than choosing only the best one, with respect to a particular learning set. In other words, stacked generalization maximizes the benefits from each generalizer by synthesizing different advantages of the multiple generalizers to achieve generalizaion accuracy that is as high as possible. stacked generalization is not a winner-takes-all strategy. When used with a single generalizer, stacked generalization can bri used to estinate the error of a generalizer which is asked a novel question or presented with a novel il.put.

stacked generalization is concerned with the problem of inferring a parent function (mapping) from a given learning set. In contrast with ANNs, generalizers, and cross validation, stacked generalization tell us the way to maximize the generalization capabilities of a generalizer or multiple generalizers. Stacked generalization, as a sophisticated version of cross validation, uses the following ideas.

First, create a partition of a learning set, train a generalizer on one partitioned subset, then observe the performance of the generaliztr on the other partitioned subset. The performance data from the partitioned subset constitutes a new learning set. A new generalizer that is called a level 1 generalizer is then trained on the new learning set of the performance data. The new generalizer can evaluate the 
performance of the first generalizer by this stacking procedure.

There are several different ways to implement stacked generalization. In the next sections, the stacked generalization scheme will be described in detail for both the cases of multiple generalizers and of a single generalizer [37].

\section{Cross validation partition set}

Let set $Q$ be the set of all questions $q$ of interest. $Q$ corresponds to the universal set. From set $Q$, a subset $L$ is chosen to be a learning set used to train generalizers. Let $I=$ $\left\{\left(x_{1}, y_{1}\right),\left(x_{2}, y_{2}\right), \ldots,\left(x_{k}, y_{k}\right)\right\}$ consisting of $k$ pairs of inputoutput vectors, $x \in \mathbf{R}^{m}$ and $y \in R^{*}$. Figure 4.1 shows an illustration of these ideas. When asked a novel question $q \varepsilon\{$ Q - I \}, a generalizer can show how well it has generalized a parent function with respect to the learning set $L$.

To employ staciked generalization, first, a set of $r$ partitions is chosen from the learning set $L$. For a partition $i$ where $i$ is integer and $1 \leq i \leq r, L$ is split into two disjointed sets, $\theta_{i 1}$ and $\theta_{i 2}$. The cross validation partition set (CVPS) is defined to be $r=k$ so that for all $i, \theta_{i 2}$ consists of a single chosen element of $I$, and the corresponding $\theta_{i 1}$ consists of the rest of $L$. Therefore, for all $i, \theta_{i 2}$ consists of a single pattern of $\left(x_{i}, y_{i}\right)$, the corresponding $\theta_{i 1}$ consists of the remainder of $L$, $\left\{L-\left(x_{i}, y_{i}\right)\right\}$. Since $r=k$, the set of all $\theta_{i 2}$ covers the learning set $\mathrm{L}$. A partition is shown in Figure 4.1 by dividing $\mathrm{L}$ into two 


\section{$Q=\{q\}$ : Set of All Questions}

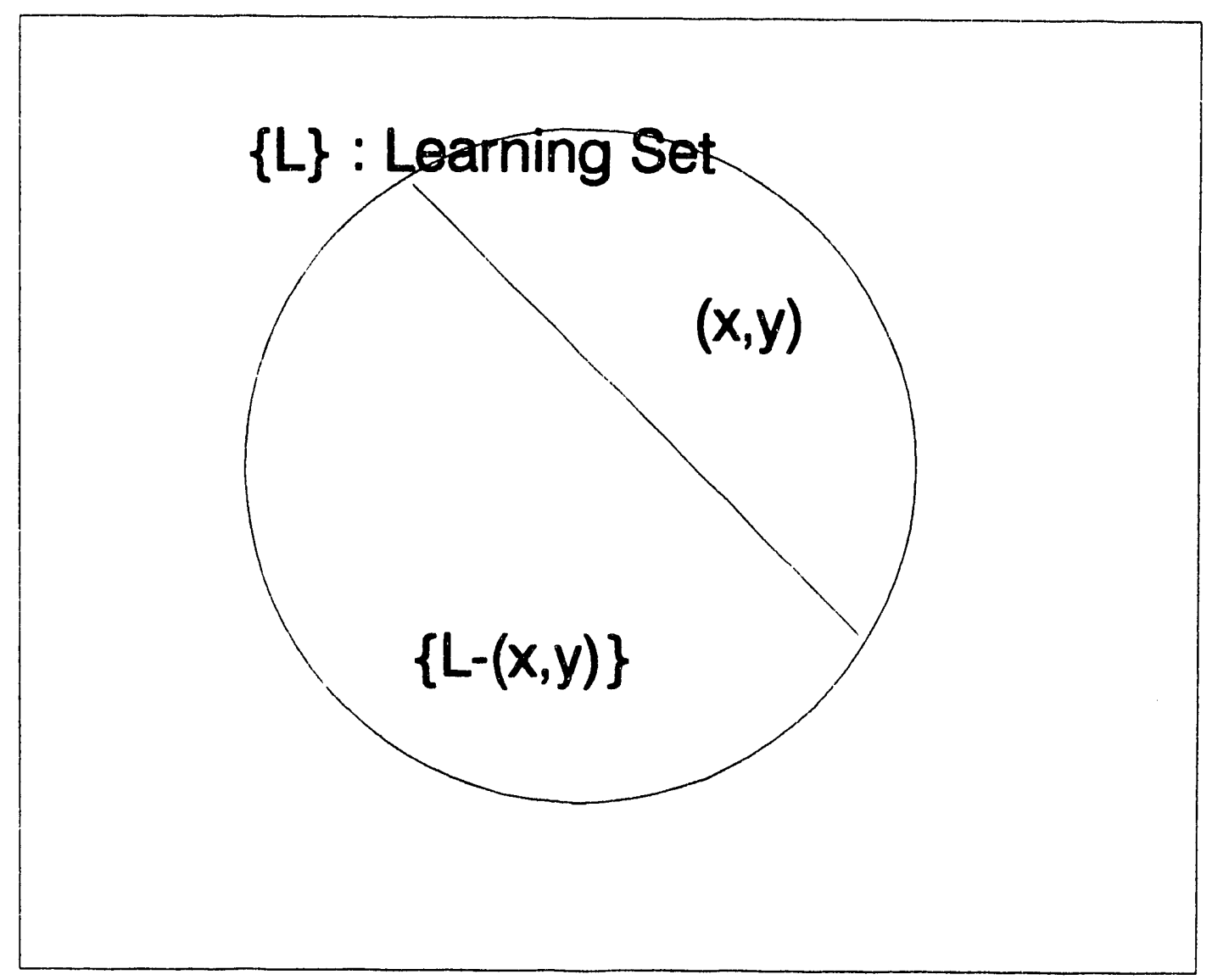

Figure 4.1: Illustration of set $Q=\{q \mid$ all questions $\}$ and the cross validation partition set (CVPS) 
subsets, $\theta_{i 2}=\left(x_{i}, y_{i}\right)$ and $\theta_{i 1}=\left\{L-\left(x_{i}, y_{i}\right)\right\}$. Wolpert defines the space of the original learning set $L, \mathbf{R}^{m} \times \mathbf{R}^{\mathrm{n}}$, as the level 0 space. Any generalizer applied directly to $L$ in the level 0 space is then referred to as the level 0 generalizer.

\section{stacked generalization for multiple generalizers}

Suppose there is a set of $p$ generalizers that we are interested in, $G_{1}, G_{2}, \ldots, G_{p}$. For a particular partition $i$, a partitioned subset $\theta_{i 2}$ consists of $(x, y)$, and the other subset $\theta_{i 1}$ consists of $\{L-(x, y)\}$. Note that the subscript for the input-output pair is dropped for convenience. Given this partition, the $p$ generalizers are trained on the $\{L-(x, y)\}$ so that the generalizers learn the elements of $\theta_{i 1}$ except for $(x, y)$. Then, all generalizers are asked the question $x$. For the question $x$, a generalizer $G_{n}$, where $1 \leq n \leq p$, produces an answer $g_{n}$. Generally, since the pair $(x, y)$ is not used in training the generalizer, the answer given by the generalizer is different from the desired output $Y$.

Now, we have just obtained from the generalizers $G_{1}, G_{2}, \ldots$ , $G_{p}$, the answer $g_{1}, g_{2}, \ldots, g_{p}$, respectively, but the correct answer is $Y$ (see Figure 4.2). This new information about the level 0 generalizers' answers for a given question provides knowledge of their generalization behaviors or accuracy. This new information space is called the level 1 space. This information is cast as a new learning set in the level 1 space, 
New Learning Set L'

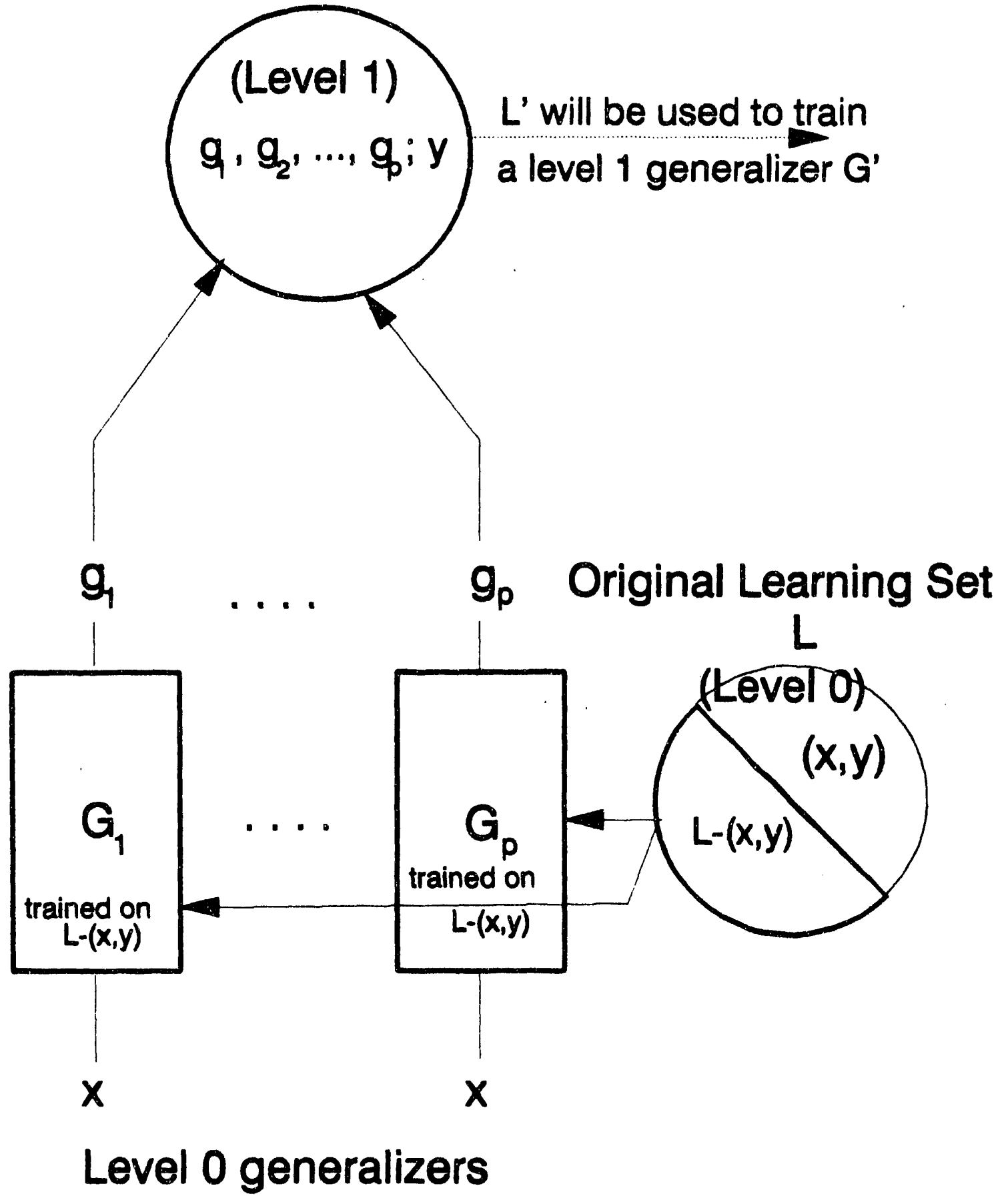

Figure 4.2: Illustration of generating a new learning set (level 1) by stacked generalization for multiple generalizers 
illustrating the generalizers' generalization accuracy in the level 0 space. Hence, a new level 1 learning set $L^{\prime}$ consists of an input $\left(g_{1}, g_{2}, \ldots, g_{p}\right)$ and the output $y$ (or the correct answer for the question). For other partitions of the original learning set $\mathrm{L}$, the generalizers will give other such pairs. Taken together, these pairs constitute the new learning set $L^{\prime}$. A new generalizer $G^{\prime}$, referred to as the level 1 generalizer, is trained on the level 1 learning set $L^{\prime}$ to provide a better answer to the question $q$.

Next, train the level 0 generalizers $G_{1}, G_{2}, \ldots, G_{\mathrm{p}}$ on all of $L$ and then ask them a novel question $q \in\{Q-L\}$. The answers from the level 0 generalizers are fed as a question into the level 1 generalizer $G^{\prime}$. The level 1 generalizer's answer is the final, and hopefully best, answer for the desired output $y$ (see Figure 4.3). In this stacked generalization scheme for multiple generalizers, an answer given by the level 1 generalizer is determined by combining the answers of the original $p$ level 0 generalizers. In other words, the level 1 generalizer performs filtration of generalization errors on the level 0 generalizers which are involved in each level 0 question.

The process of stacked generalization can be used recursively (i.e. multiple stacking). The multiple stacking results in level 2 , level 3 , and so on, higher level generalizers. Sometimes, multiple stacking is not practical when 


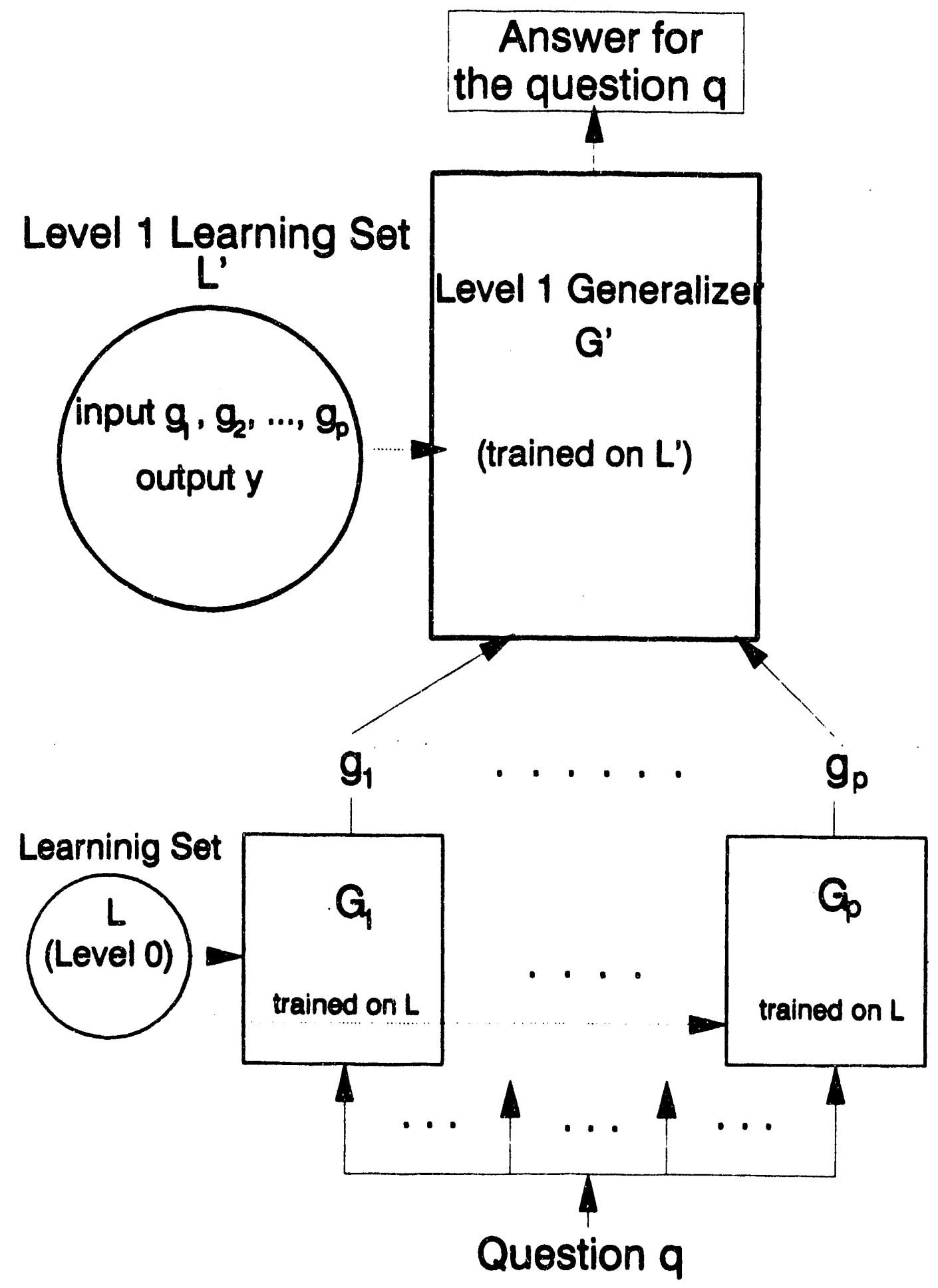

Figure 4.3: Illustration of a level 1 generalizer with a question 
computation time for learning is large.

\section{Stacked generalization for a single generalizer}

Let $G$ be a single generalizer and the original learning set be the same one, $L$, described in the previous section (see Figure 4.4). A question $q \epsilon Q$ lies outside of $L$. As in Figure 4.4, for a partition $i, L$ is split into two subsets $\{L-(x, y)$ \} and $(x, y)$. Given the partition, the level 0 generalizer $G$ is trained on the subset $\{L-(x, y)\}$. Then $G$ is asked $x$ as a question which is not used in training $G$. An answer, $g$, given by $G$ for the question $x$ will be, in general, different from the correct answer (output) $y$. In addition to this information, the vector $\mathbf{x}^{\prime}$ defined as the distance from $x$ to its nearest neighbor in $\{L-(x, y)\}$ is computed. Now, when the question is $x$, and the vector from $x$ to its nearest neighbor in the learning set is $x^{\prime}$, the correct answer differs from the level 0 generalizer's answer by $g$ - $y$. The error information along with $x$ and $x^{\prime}$ defines the level 1 information space for this case of a single generalizer. This information forms a new learning set $L^{\prime}$ in the level 1 space. Hence, the new level 1 learning set $L^{\prime}$ consists of an input $\left(x, x^{\prime}\right)$ and an output $g$ - $y$ for the particular partition. For the other partitions of $L$, the generalizer $G$ will give such pairs. Those pairs constitute the level 1 learning set $L^{\prime}$. A new generalizer $G^{\prime}$ (level 1 generalizer) is then trained on the level 1 learning set $L^{\prime}$ (refer to Figure 4.5). 


\section{Level 1 Learning Set}

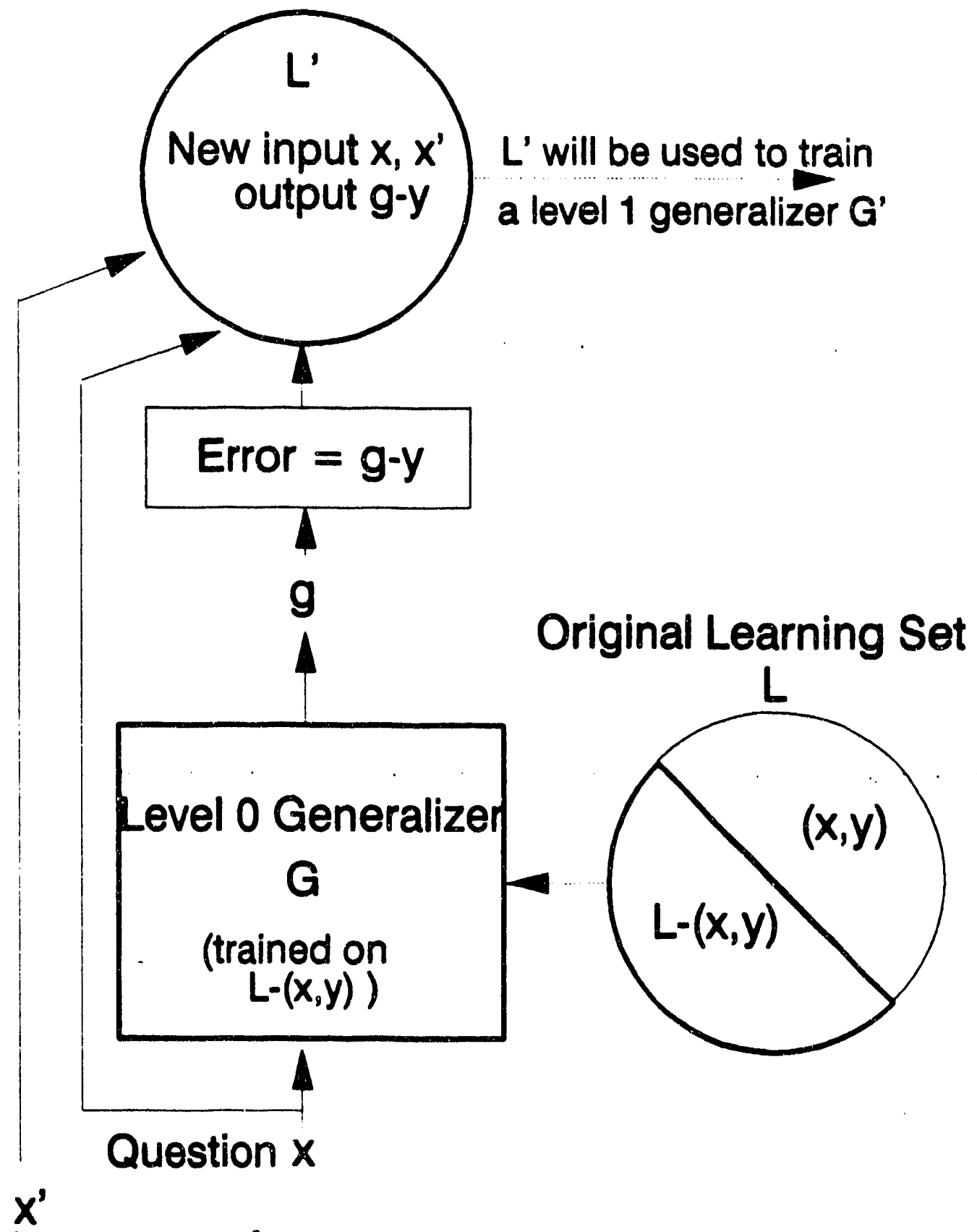

Distance vector from

$x$ to its nearest neighbor pattern in $L-(x, y)$

Figure 4.4: Illustration of generating a level 1 learning set by stacked generalization for a single generalizer 


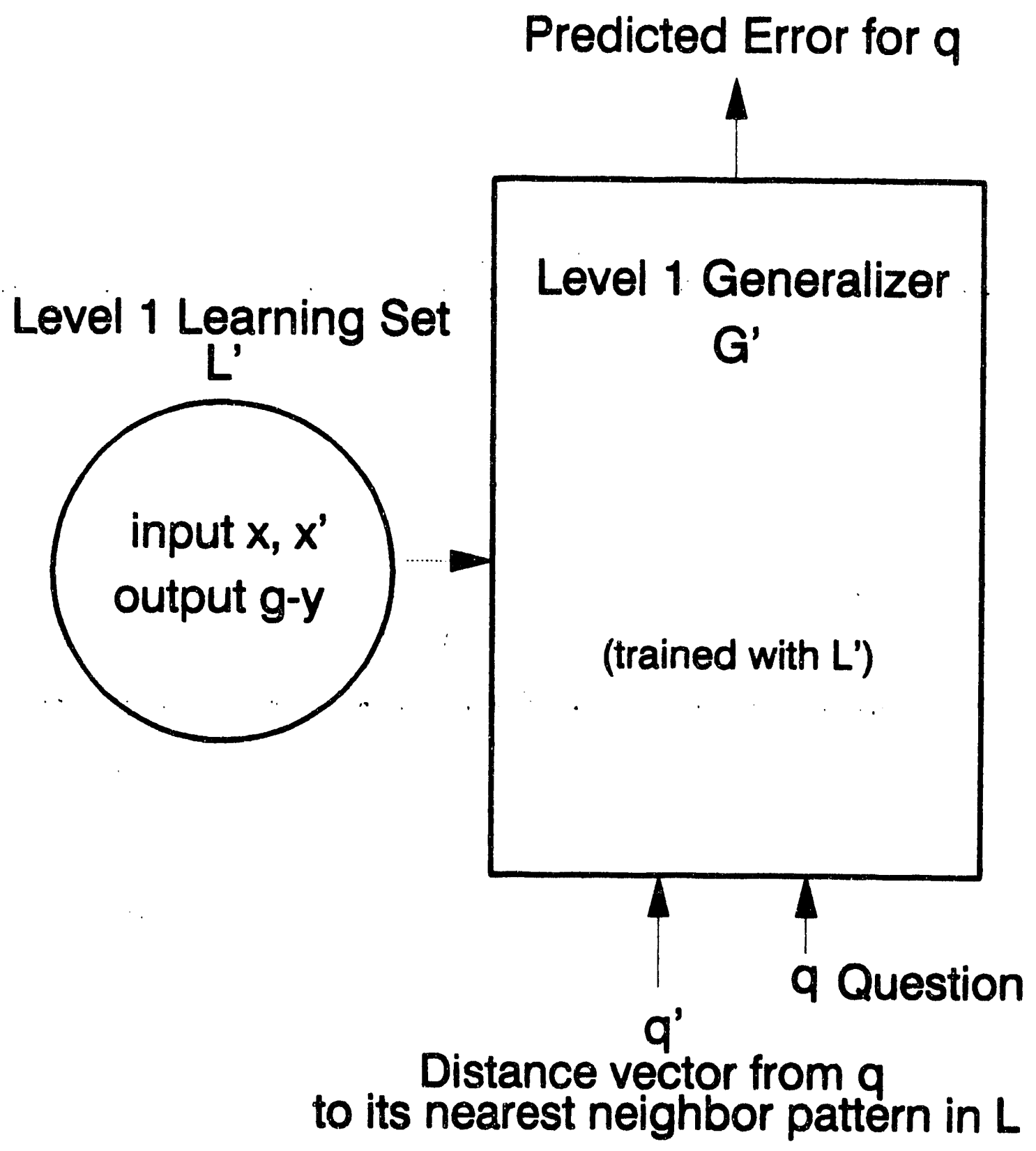

Figure 4.5: Illustration of a level 1 generalizer with a question 
Next, train the level 0 generalizer $G$ on all of $L$ and then ask the generalizer a question $q \epsilon\{Q-L\}, q$ is fed into the trained level 1 generalizer $G^{\prime}$ as a question with the vector $q^{\prime}$ from $q$ to its nearest neighbor in $L$. The answer (output) of the level 1 generalizer is the error of the level 0 generalizer in answering the question $q$.

\section{Error prediction}

A generalizer has a capability to learn a given set of examples, and then to generalize the behavior of a parent function or mapping. When a generalizer is asked a question that is not in a learning set, the generalizer can provide its answer. The error involved in the generalizer's answer can be predicted by the stacked generalization scheme for a single generalizer.

In Nuclear Power Plant fault diagnostics, if a transient or accident occurs, the ANN fault-diagnostic adviser should diagnose the transient, and provide the error bound of the ANN diagnosis. In this thesis, stacked generalization is applied to predict an error bound on a diagnosis performed by an ANN faultdiagnostic adviser for a NPP. The predicted error bound of the adviser provides the degree of reliability indicating how much error in the diagnosis is implicated. 


\section{CHAPTER 5. METHOD OF 8OLOTION}

\section{Introduction}

In this chapter, an ANN fault-diagnostic adviser for the San Onofre Nuclear Generating Station (NGS) is developed. This ANN adviser is a generalizer as defined by the criteria from Chapter 3. This chapter describes the method used to develop an ANN adviser that detects and classifies various operational transients at the nuclear power plant in an accurate and timely manner. Stacked generalization is then applied to predict generalization exrors involved in the ANN diagnoses. With predicted errors on the diagnoses of anomalous conditions, the plant operators can assess the accuracy of the diagnoses. The operators can therefore compare the error-measured diagnoses of the ANN adviser with their own determination of the plant conditions. The operators can then incorporate the information provided by the ANN in order to promptly rectify or mitigate the anomalous plant conditions.

The following sections will explain the data used in this 
research, the ANN fault-diagnostic adviser and its training process, and the error prediction method.

\section{Data Analyzed}

\section{Data}

The data used for training the ANN fault-diagnostic adviser, were obtained from san onofre Nuclear Generating Station (NGS), owned by Southern California Edison Co. and San Diego Gas \& Electric Co [38]. San Onofre NGS is a pressurized water reactor (PWR) plant.

The San Onofre NGS training simulator generated the data used. These data simulate various plant operational transients to address Nuclear Regulatory Commission (NRC) certification requirements for the training simulator [38]. Ten transient scenarios (see Table 5.1) were selected among an assortment of accident scenarios, typically used for training the operators of San Onofre NGS. The scenarios include design-basis accidents and less severe transients. (Note that the stuck Open Pressurizer Safety Valve with High Pressure Injection Inhibited is the same type of Three-Mile Island accident). The data of the ten transients obtained from the training simulator contain 33 plant-monitoring variables. These variables are listed in Table 5.2 .

For each of the ten scenarios, each of the 33 plant 
Table 5.1 : List of 10 accident scenarios with transient onset time and desired ANN output layer activation

\begin{tabular}{|c|c|c|c|c|c|}
\hline \multirow[t]{2}{*}{ Scenario } & \multirow{2}{*}{$\begin{array}{l}\text { Transient } \\
\text { Onset Time } \\
\quad(\mathrm{sec})\end{array}$} & \multicolumn{4}{|c|}{$\begin{array}{l}\text { Desired Output } \\
\text { Node Activation }\end{array}$} \\
\hline & & 1 & 2 & 3 & 4 \\
\hline $\begin{array}{l}\text { Turbine Trip/Reactor } \\
\text { Trip }\end{array}$ & 6 & 1 & 0 & 0 & 0 \\
\hline $\begin{array}{l}\text { Loss of Main Feedwater } \\
\text { Pumps }\end{array}$ & 47 & 0 & 1 & 0 & 0 \\
\hline $\begin{array}{l}\text { Closure of Both Main } \\
\text { Steam Isolation Valves }\end{array}$ & 7 & 0 & 0 & 1 & 0 \\
\hline $\begin{array}{l}\text { Trip of All Reactor Coolant } \\
\text { Pumps }\end{array}$ & 16 & 0 & 0 & 0 & 1 \\
\hline $\begin{array}{l}\text { Trip of A Single Reactor } \\
\text { Coolant Pump }\end{array}$ & 14 & 1 & 1 & 0 & 0 \\
\hline Turbine Trip From 508 Power & 50 & 1 & 0 & 1 & 0 \\
\hline $\begin{array}{l}\text { Loss of Coolant Accident } \\
\text { (LOCA) With Loss of } \\
\text { Off-Site Power }\end{array}$ & 7 & 1 & 0 & 0 & 1 \\
\hline Main Steam Line Break & 6 & 0 & 1 & 1 & 0 \\
\hline $\begin{array}{l}\text { Stuck Open Pressurizer safety } \\
\text { with figh Pressure } \\
\text { Injection Inhibited }\end{array}$ & 15 & 0 & 1 & 0 & 1 \\
\hline $\begin{array}{l}\text { Single Turbine Governor } \\
\text { valve Closure }\end{array}$ & 7 & 0 & 0 & 1 & 1 \\
\hline $\begin{array}{l}\text { Normal Operation (before } \\
\text { a transient onset) }\end{array}$ & -- & 0 & 0 & 0 & 0 \\
\hline
\end{tabular}


Table 5.2 : Plant variables

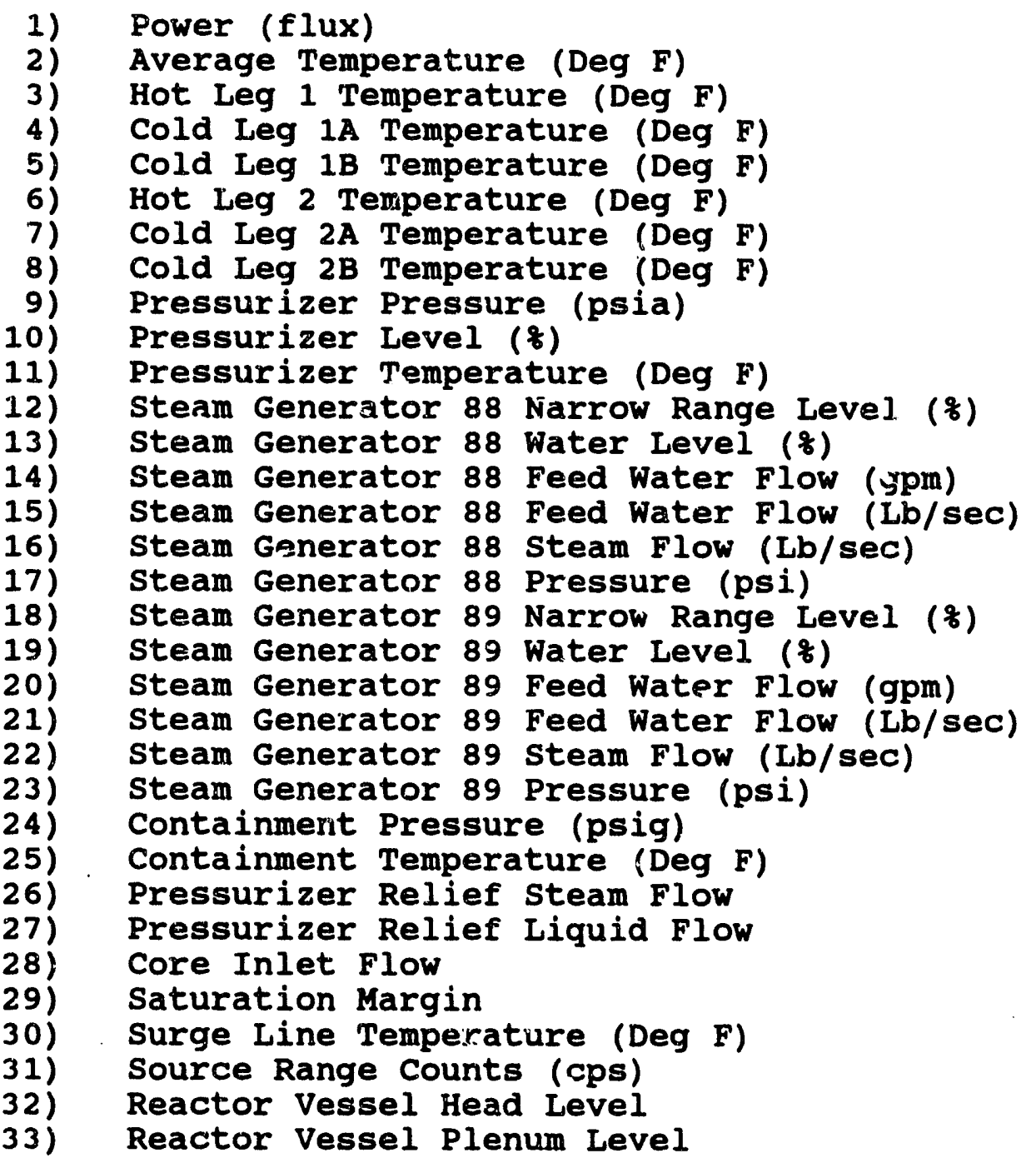


variables was collected for a total time of about ten minutes. The 33 plant variables were collected at time step intervals of one second. A single time step containing the 33 variables was used to train the ANN adviser. This time snap shot of data (a single time slice) does not constitute temporal information. The main advantage of this approach of the single time step is simplicity of execution and training. Thus, the ANN adviser can diagnose transients at very instance of the data presentation. The ANN do not need to observe trends of the temporal information of data. The simulated data contained no noise.

Each data set of a transient is divided into two parts, normal operation data for a short time period, followed by transient-condition data after the onset of the transient. The transient onset times for the ten scenarios are shown in Table 5.1. Notice that with the exception of the Turbine Trip From $50 \%$ Power, all of the transient scenarios start from the full power normal operating conditions.

To distinguish the ten transient conditions and one normal condition, a distinct 4-bit binary code of 1's or 0's for the ANN adviser's output was used. Four output nodes were therefore needed. Each combination of the 4-bit binary code is assigned to a transient (see Table 5.1). Of course, 33 input nodes were assigned to the input layer of the ANN adviser, corresponding to the 33 plant variables. 


\section{Normalization of data}

Typically, ANNs require values that are scaled from 0 to 1 as inputs. However, the values of the 33 plant variables are not in the same range. Therefore, the different ranges of the 33 plant variables should be adjusted. The adjusted values are then fed into an input layer of the ANN adviser. This adjustment process is accomplished in a linear fashion and is referred to as normalization.

In order to normalize the plant variables from 0 to 1 , the minimum and maximum values for each of the 33 variables were found over the entire ten scenario data set. Then, each variable is normalized by the following equation for an $i$-th plant variable:

$$
X_{\text {normalized,i }}=\frac{X_{i}-X_{\min , i}}{X_{\max , i}-X_{\min , i}}
$$

A normalized value of 0 corresponds to the smallest meterreading of a plant variable. A normalized value of 1 corresponds to the maximum meter-reading. A FORTRAN code called "NORMAL" was written to normalize the data (refer to Appendix B). The normalized data for each transient scenaxio constitute the recall set for the transient. The recall set will be used to observe the generalization accuracy of a trained ANN adviser later in this thesis. 


\section{Developeent of an MN Fault-Diagnostic Adviser}

As illustrated in Chapter 3, the backpropagation ANN paradigm is one of algorithms that satisfies the generalizer criteria [36] [37]. The backpropagation ANN paradigm is therefore employed here to develop the ANN fault-diagnostic adviser for the San Onofre NGS.

Learning set and learning process of the ANN adviser

In order for the ANN fault-diagnostic adviser to function well for the San Onofre NGS, the ANN adviser must learn how to classify the ten transients. This is accomplished by training the ANN adviser on a given learning set (or training set) of data. The ANN adviser will then generalize the smaller training data set to the lager recall set.

one might try to expand the learning set to as large as possible in an effort to accomplish higher generalization efficacy. However, superfluous learning examples require more computation time which is expensive. Thus, it is important to choose a training data set that represents the necessary characteristics of the transients of interest and simplifies the training process as much as possible.

Additionally, the optimization of the number of inputs (or 
the proper selection of plant variables) is considered in a learning [12] [17]. Such optimization of the input node number will contribute to establishing a simpler ANN architecture and to achieving a faster learning. This architecture optimization is however not the topic of this thesis and will not be discussed further.

Selection of level o learning set As a first step, a total of 20 input-output patterns was chosen as an initial learning set. Two patterns from each transient, one input-output pattern of normal operation at one second, and another inputoutput pattern (post-accident pattern) for the stabilized transient condition at the end time (when data collection had ceased), were included in the initial learning set.

The next step is the selection of an appropriate architecture of the ANN adviser. The architecture selection was performed on a trial-and-error basis. In this work, an architecture of 33-22-10-4 was chosen after investigating many others. Thus, the ANN adviser has 33 nodes in the input layer, 22 nodes in the first hidden layer, 10 nodes in the second hidden layer, and 4 nodes in the output layer. The ANN adviser begins the learning process with initial weights whose values are randomly assigned.

The ANN adviser is trained until it achieves a predetermined value of learning accuracy (error). The learning 
error is expressed as a root-mean-square (RMS). The RMS error, for all presented patterns that were used during the learning process, is calculated in accordance with Eq. 13, below [4].

$$
R M S=\left[\frac{1}{k \cdot n} \sum_{i=1}^{k}\left(\sum_{j=1}^{n}\left(t_{f, 1}-o_{f, 1}\right)^{2}\right)\right]^{1 / 2}
$$

where $t_{j, i}$ is the desired output and $o_{j, i}$ is the ANN output of the $j-t h$ output node for the $i$-th training pattern. The $k$ in the above equation is the total number of patterns in the learning set, and $n$ is the total number of output nodes. Sometimes, in other contexts, the learning error is referred to as the cost function. Later, in this thesis, the RMS error is interpreted as an actual diagnostic error when the ANN adviser is presented a novel input condition of a NPP operational transient.

The training process of the adviser on the initial learning set was continued until a target learning error (RMS error) of 0.01 was obtained. After obtaining the target learning error, the next step is adding new patterns to the original learning set. This process is illustrated as follows.

The trained ANN adviser is recalled each of the ten normalized recall sets. For each recall set, an RMS error at each single time step data is calculated, and is plotted versus time. In the RMS error versus time plot for each scenario, several peaks of large RMS values are typically observed. These 
peaks indicate that the ANN adviser doesn't learn enough to show generalization characteristic at those data points. The peak usually arises when a presented pattern at the peak has distinct or unusual features that are not contained in the initial learning set. Of course, the initial learning set of the 20 examples contains insufficient information to instruct the adviser to perform the correct classification.

Hence, the unfamiliar patterns exhibiting the peaks on the RMS error plot are added to the initial learning set. The expanded learning set will furnish the adviser more information adequate to performing a correct classification.

with the expanded learning set, the learning process is repeated. When the target learning error is attained once again, the RMS versus time plots are re-drawn. Then the patterns corresponding to the error peaks on the plots are added to the learning set. The above procedures are repeated until such peaks do not appear on the RMS versus time plots. The training, recalling, and expanding of the learning set, was iterated so that all peaks fell below 0.1 or less of the RMS exror except for those peaks very close (in time) to the failure which initiates the transient. Typical plots are Figure 6.1 through 6.10 on page 61 through 65.

The ANN adviser For the San onofre scenarios of ten transients, a total of 113 training input-output patterns was 
obtained by the above procedure. Note that this learning set includes ten different initial conditions due to a different initial power flux level. The remaining 103 input-output patterns correspond to abnormal conditions at the NPP. The finalized learning set of 113 patterns, which is designated as set $I$, is displayed in Appendix B. Consequently, this finalized learning set $L$ is the level 0 learning set which is used to train the ANN fault-diagnostic adviser.

Hence, the ANN fault-diagnostic adviser for the san Onofre NGS (a level 0 generalizer) was developed by training on the finalized learning set $L$ (the level 0 learning set). The ANN fault-diagnostic adviser was then recalled on data which the adviser was not trained, in order to examine the adviser's responses to novel input conditions. Results will be shown in Figure 6.1 through Figure 6.10 on page 61 through 65 of the next chapter.

\section{Brror Prediction in the ANN Pault Diagnostics for d MPP}

In order to validate results of the ANN fault-diagnostic adviser, errors bounds on the ANN diagnoses should be given. In this thesis, the error prediction is performed by applying stacked generalization for a single generalizer to the ANN adviser developed in the preceding sections. How the stacked generalization is applied to this research will be illustrated 
in the following sections.

\section{Generating a level 1 learning set}

In the above sections the ANN adviser was trained on the level 0 learning set $L$. The level 0 learning set $L$ with $k=113$ input-output patterns constitutes information space of level 0 .

Using the CVPS, $r=k=113$ partitions were created such that $\theta_{i 2}=$ an input-output pattern of $(x, y)$ and $\theta_{i 1}=\{L$ $(x, y)$ \} containing 112 patterns, for a partition $i$, where $1 \leq i$ $\leq r$, and $i$ is an integer. $x$ is an input pattern of the 33 plant variables, and $y$ is the desired output pattern assigned the 4bit binary code. Note that $x$ and $y$ are vectors in multidimensional vector space.

The next step is to generate the level 1 learning set to be used for the error prediction of the developed ANN adviser. In order to generate the level 1 learning set, another backpropagation ANN having the same architecture of the developed ANN adviser was used as a level 0 generalizer.

For each partition, the level 0 backpropagation ANN was trained on $\theta_{i 1}$ (until it obtained the same target learning error of 0.01 as that of ANN adviser), and then presented an input pattern $x$ of $\theta_{i 2}$, as a question. The error $\varepsilon$ of the generalizer for the question was computed by subtracting the generalizer output from the desired output, as follows: 


$$
\varepsilon_{j}=\left|0_{j}-y_{j}\right|, \quad 1 \leq j \leq 4
$$

where $o_{j}$ is an value of the $j$-th output node of the generalizer, and $y_{j}$ is a $j$-th component of the desired output $y$ corresponding to the question $x$. The next step is to calculate vector $x^{\prime}$ from $\mathbf{x}$ to its nearest neighbor vector $\mathbf{x}_{\mathrm{m}}$.

First, nearest neighbor vector $x_{\mathrm{m}}$ from $x$ was chosen in the $\theta_{i 1}=\{L-(x, y)\}$ such that $x_{m}$ has the smallest distance $\left|x_{m}-x\right|$. And the vector $x^{\prime}$ from $x$ to its nearest neighbor $x_{m}$ can be determined by a vector equation $x^{\prime}=x_{m}-x$. However, some components of the vector $x^{\prime}$ calculated by the equation, may have negative values that are not appropriate as an input to an ANN. Therefore, a transformation was applied to constrain all components of $x^{\prime}$ positive without loss of any information content by imposing a transformation. The transformation used here is expressed as

$$
x_{i}^{\prime}=\frac{\left[\left(x_{1}-x_{n n i}\right)+1\right]}{2}
$$

for $i$-th component of the vector. Additionally, this transformation formula also insure that all components are within the interval $[0,1]$.

The procedures outlined above, were repeated for all other 
partitions. Now, for the 113 partitions, a total of 113 trios of $\mathbf{x}, \mathbf{x}^{\prime}$, and $\varepsilon$, were acquired. Therefore, the level 1 learning set $I^{\prime}$ consisted of these 113 trios. Note that $\mathbf{x}$ and $\mathbf{x}^{\prime}$ constitutes a new input pattern which has been expanded into $R^{33+33}$ space of the new learning set $L^{\prime}$. And $\varepsilon \in \mathbf{R}^{4}$ constitutes a desired output pattern in $L^{\prime}$. These new input-output patterns in $L^{\prime}$ were used to train the level 1 generalizer to predict errors on the results of the level 0 generalizer.

Training of a level 1 generalizer

The next step is to train a level 1 generalizer on the level 1 learning set $L^{\prime}$. The level 1 generalizer that learned the associations between level 0 generalization and its related error, will predict the error bounds on the level 0 generalizer. The level 1 generalizer was chosen to be another backpropagation neural network.

Since the level 1 information space is expanded from $\mathbf{R}^{33}$ into $\mathbf{R}^{66}$, the number of input nodes of the level 1 generalizer should be extended into 66 nodes. The architecture of the level 1 generalizer was selected to be 66-30-20-10-4. This architecture was schosen after several attempts were made to attain a suitable architecture. The level 1 generalizer was trained on the level 1 learning set $L^{\prime}$ until a target learning error (RMS) of 0.01 was reached. 


\section{Predicted Error}

The developed ANN adviser will categorize (classify) the novel input-conditions at the plant into a normal condition or a specific transient (or accident). This classification is the diagnosis of the ANN fault-diagnostic adviser, for an unknown symptom in the plant operational status. For the diagnosis, the developed level 1 generalizer will provide an error bound on the diagnosis. The novel input-condition that is fed into the ANN fault-diagnostic adviser (level 0), plus the vector from the input-condition (pattern) to its nearest pattern, are presented as an input condition to the level 1 generalizer. For the level 1 input condition, the level 1 generalizer will predict the error on the diagnosis of the level 0 ANN adviser. For the ten transients, the predicted error bounds on the ANN adviser's diagnoses are shown in Figure 6.11 through Figure 6.30 in the next chapter. 
CHAPTEK 6. REBULTB OP THE REBEARCH

\section{Diagnostic Results of the Adviser}

The ANN fault-diagnostic adviser for the San onofre NGS was trained on the level 0 learning set consisting of 113 example patterns. The number of the examples in the level 0 learning set was about $2 \%$ out of the 6203 patterns of the entire recall sets. Each of the ten recall sets was then used in the recall process of the ANN fault-diagnostic adviser. Results shows that the ANN faut-diagnostic adviser classified the plant input conditions correctly.

Table 6.1 shows the results of the ANN adviser classifications. The first column shows the transients onset times. The second column shows the time needed for the adviser to make a diagnosis with the actual diagnostic RMS error of below 0.1. The ANN adviser classifies most of the abnormal conditions correctly within 30 seconds after transient onset, and even immeiately in the case of the stuck open Pressurizer Safety with High Pressure Injection Inhibited. One exception is 
Table 6.1: Summary of the ANN adviser results

\begin{tabular}{|c|c|c|}
\hline Scenario & $\begin{array}{l}\text { Transient } \\
\text { Onset Time } \\
\text { (sec) }\end{array}$ & $\begin{array}{c}\text { Time, after the } \\
\text { onset, needed to } \\
\text { diagnose the transient }\end{array}$ \\
\hline $\begin{array}{l}\text { Turbine Trip/Reactor } \\
\text { Trip }\end{array}$ & 6 & 30 \\
\hline $\begin{array}{l}\text { Loss of Main Feedwater } \\
\text { Pumps }\end{array}$ & 47 & 3 \\
\hline $\begin{array}{l}\text { Closure of Both Main } \\
\text { Steam Isolation Valves }\end{array}$ & 7 & 28 \\
\hline $\begin{array}{l}\text { Trip of All -teactor } \\
\text { Coolant Pumps }\end{array}$ & 16 & 2 \\
\hline $\begin{array}{l}\text { Trip of a single Reactor } \\
\text { Coolant Pump }\end{array}$ & 14 & 62 \\
\hline Turbine Trip From $50 \%$ Power & 50 & 1 \\
\hline $\begin{array}{l}\text { Loss of Coolant Accident } \\
\text { (LOCA) with Loss of } \\
\text { off-site Power }\end{array}$ & 7 & 14 \\
\hline Main Steam Line Break & 6 & 4 \\
\hline $\begin{array}{l}\text { Stuck Open Pressurizer safety } \\
\text { with High Pressure } \\
\text { Injection Inhibited }\end{array}$ & 15 & Immediate diagnose \\
\hline $\begin{array}{l}\text { Single Turbine Governor } \\
\text { Valve Closure }\end{array}$ & 7 & 16 \\
\hline
\end{tabular}

the Trip of A single Reactor Coolant Pump for which the correct classification takes about 62 seconds. This transient is characteristically similar to the Trip of All Reactor Coolant Pumps. It is understandable that the adviser may need more time 
to distinguish that transient from this similar one. Note that the diagnosing time of the Trip of All Reactor coolant pumps after the onset is only 2 seconds.

Figure 6.1 through Figure 6.10 show the typical recall performance of the trained ANN adviser for the ten transients. The ordinate value of the figures is the diagnostic RMS error for the ANN output versus time. The diagnostic RMS error is interpreted as an actual error as compared with the true solution involved in the ANN diagnosis. As seen in these figures, the adviser responds very quickly to the onset of the transients. However, since the plant input variables are, dynamically and suddenly, changing during a short transitory period after the onset, the adviser diagnoses are inconclusive or incorrect for this period. This transitory period for each transient is shown in the figures as well as in the second column of Table 6.1. After the transitory period passes, the ANN adviser diagnoses the plant transients correctly.

\section{Error Prediction on the Adviser Diagnosis}

The error prediction on diagnoses of the ANN faultdiagnostic adviser was performed by applying stacked generalization to the adviser. The results of the error prediction are shown in the odd numbered figures 6.11 through 6.30. For edch transient scenario, there is an even and odd 


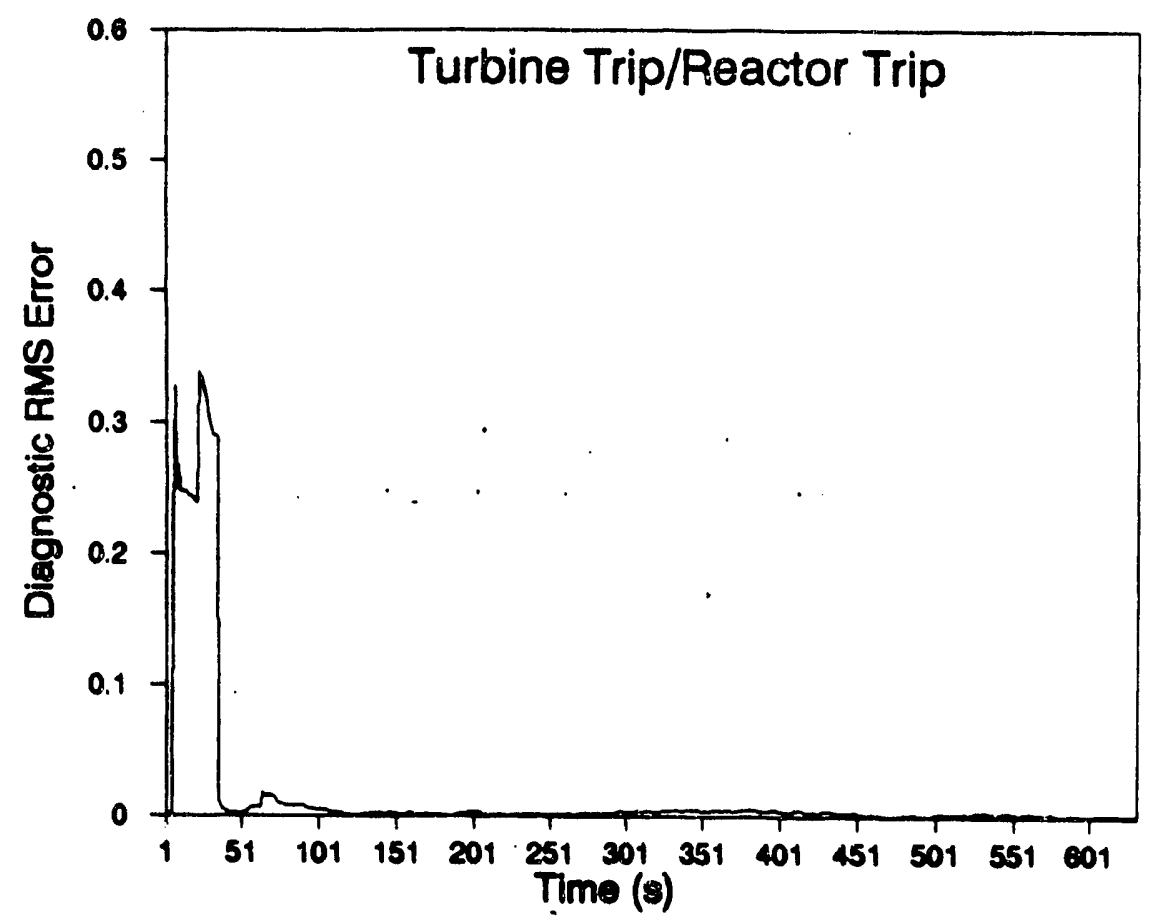

Figure 6.1 : Recall performance for the transient of Turbine Trip / Reactor Trip

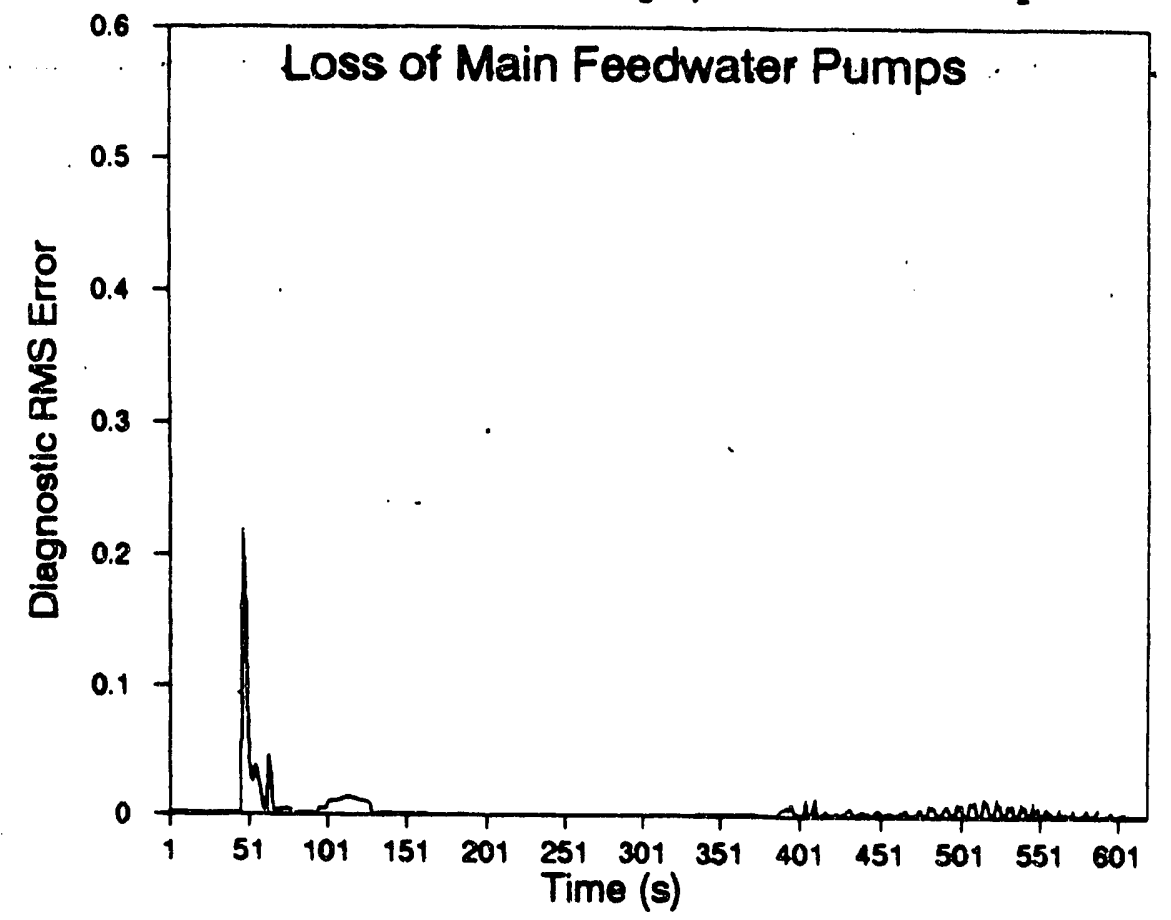

Figure 6.2 : Recall performance for the transient of Loss of Main Feedwater Pumps 


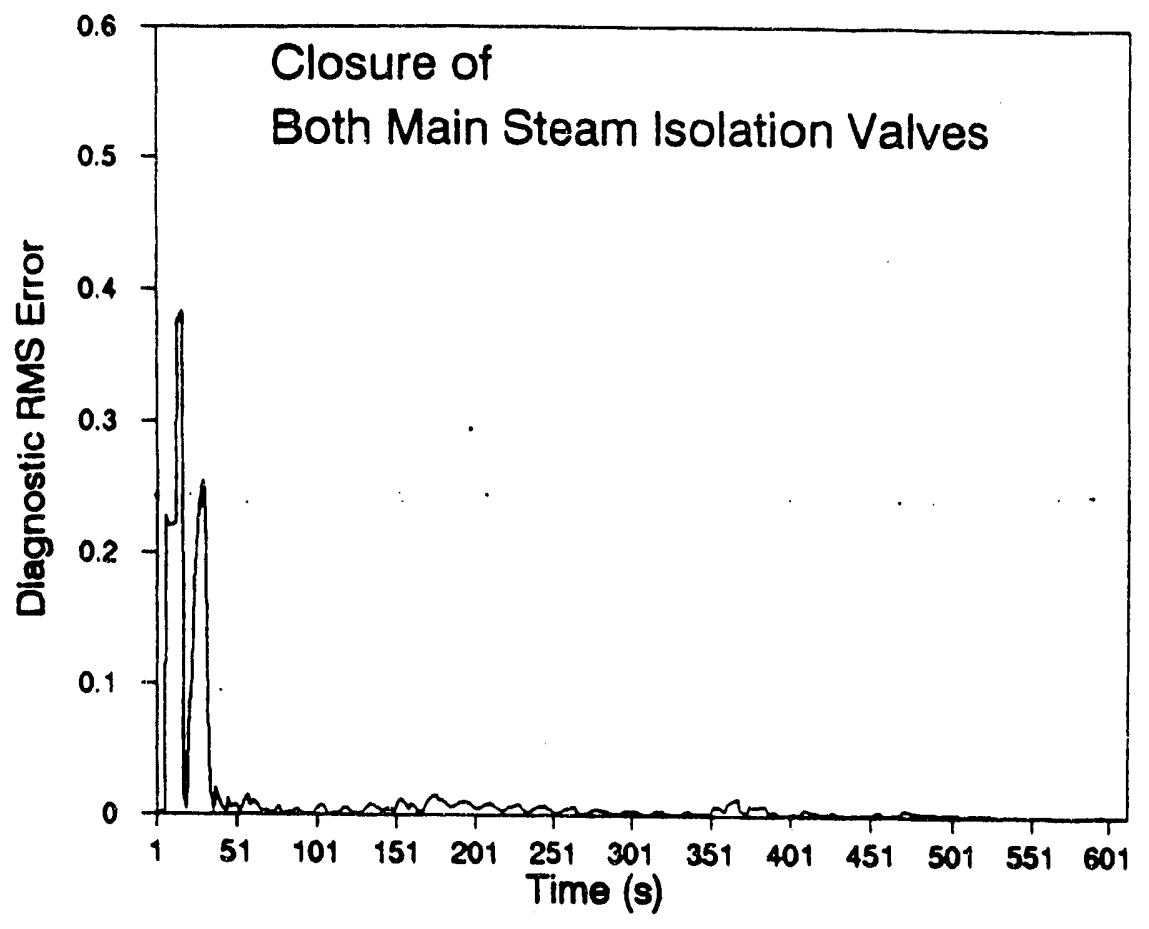

Figure 6.3 : Recall performance for the transient of closure of Both Main steam Isolation Valves

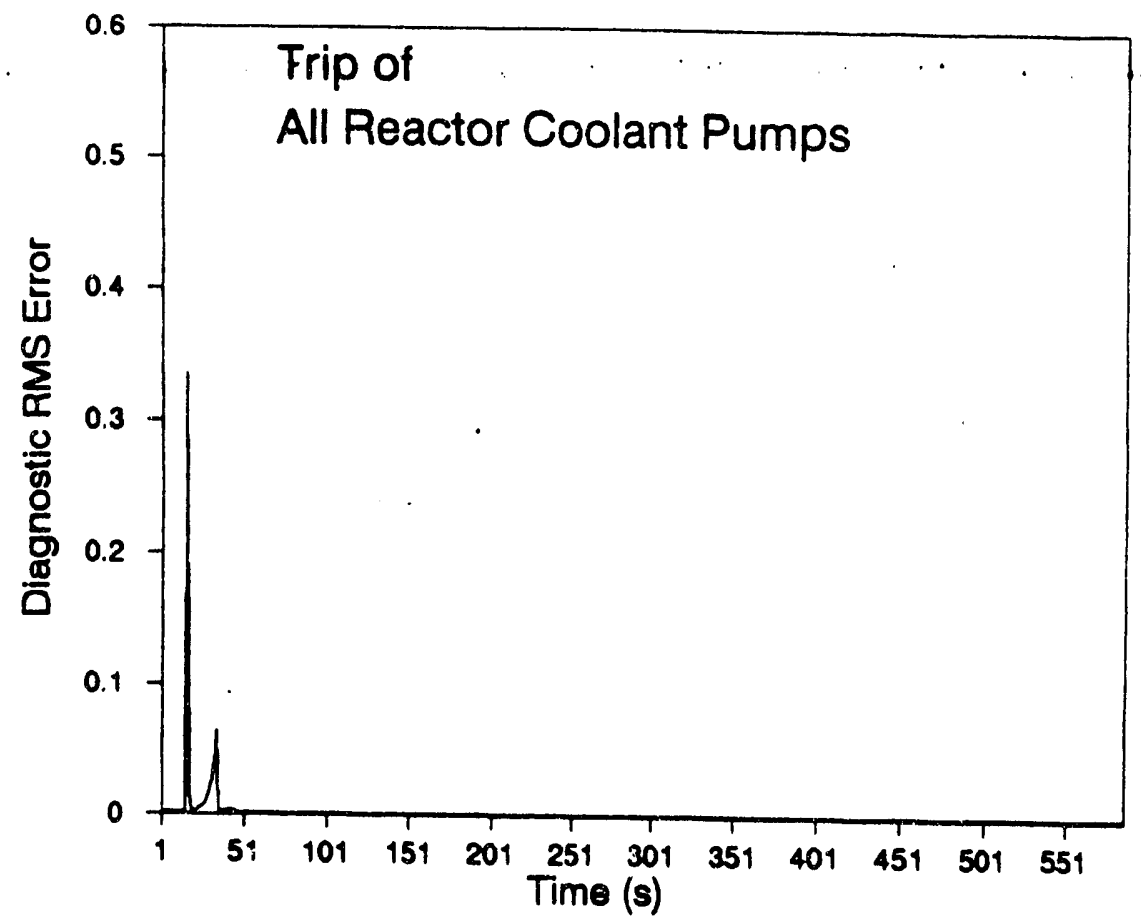

Figure 6.4 : Recall performance for the transient of Trip of All Reactor Coolant Pumps 


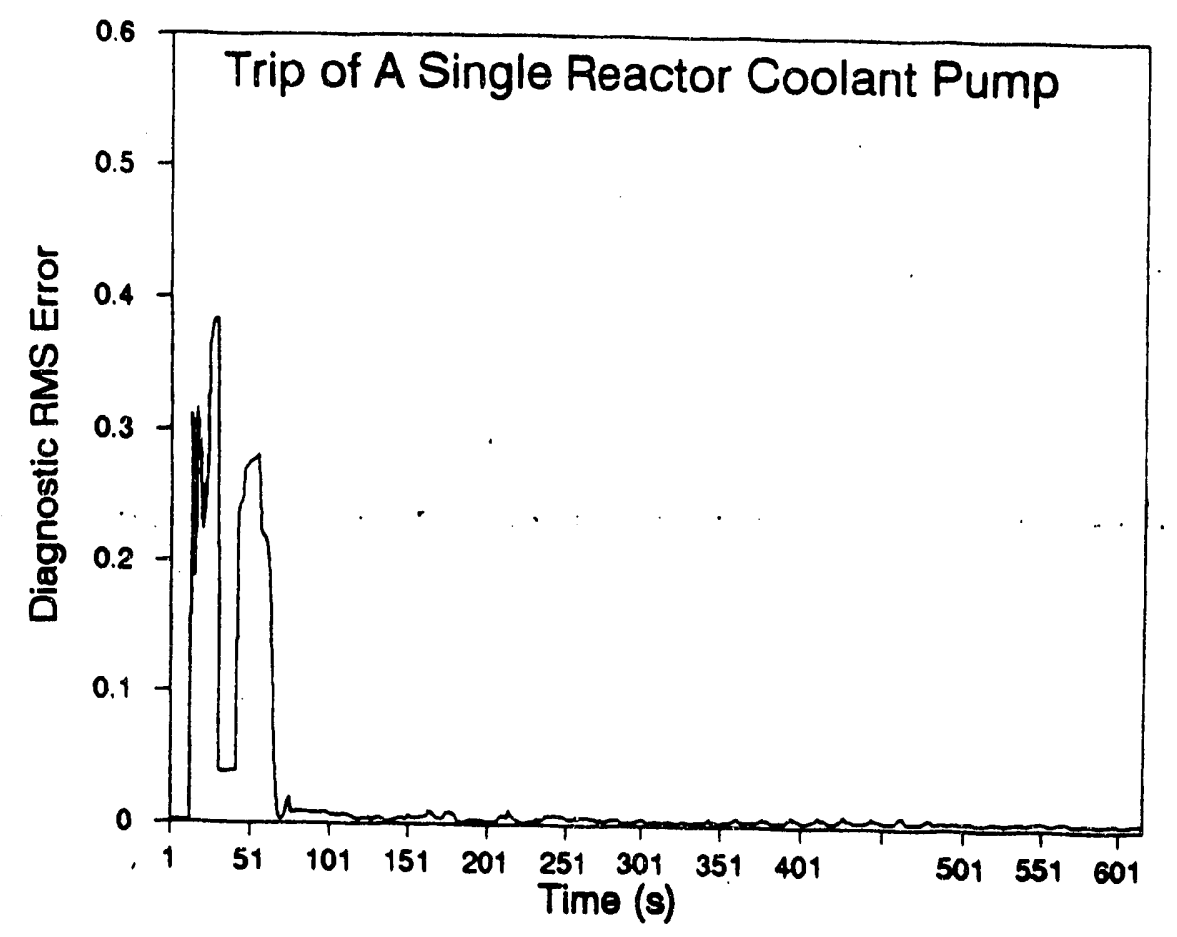

Figure 6.5 : Recall performance for the transient of Trip of a single Reactor Coolant pump

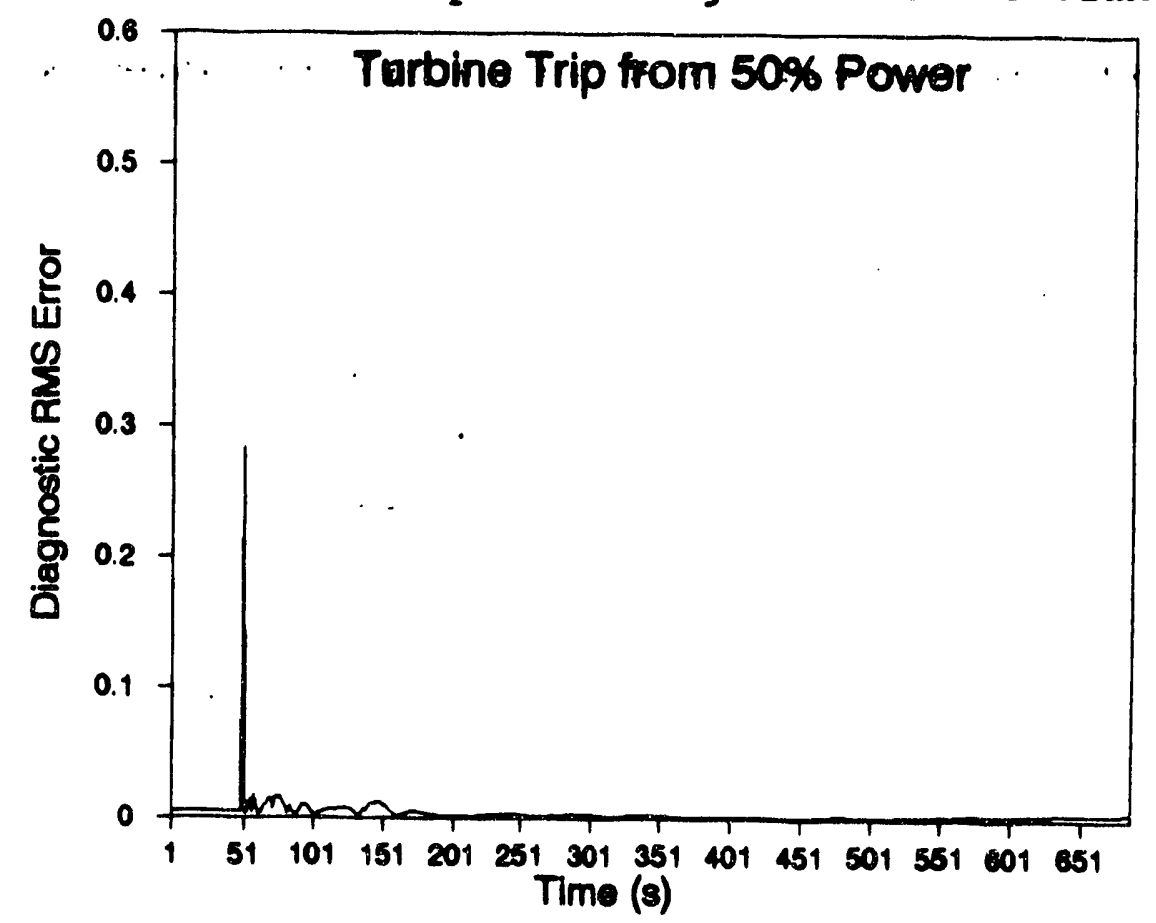

Figure 6.6 : Recall performance for the transient of Turbine Trip From 508 Power 


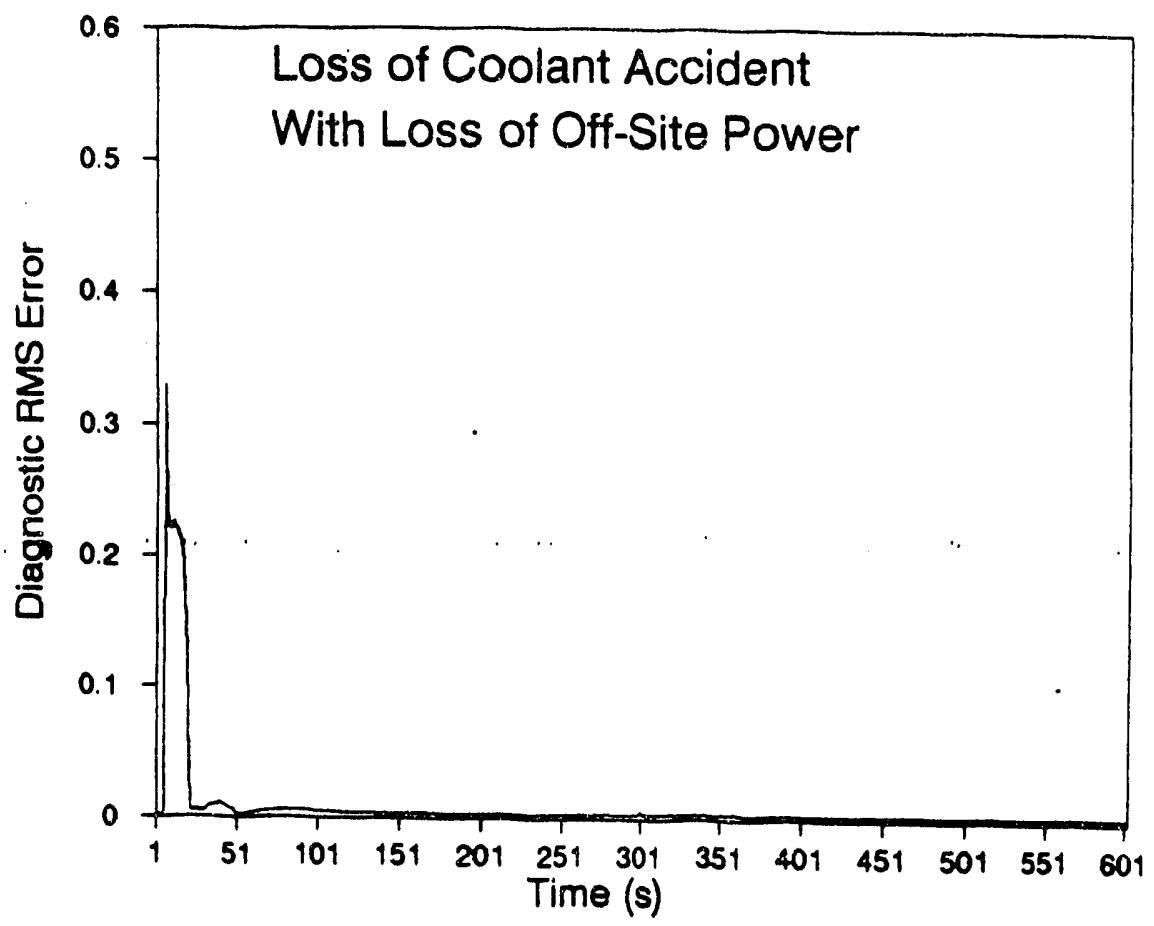

\section{Figure 6.7 : Recall performance for the transient of Loss of Coolant Accident (LOCA) with Loss of off-site Power}

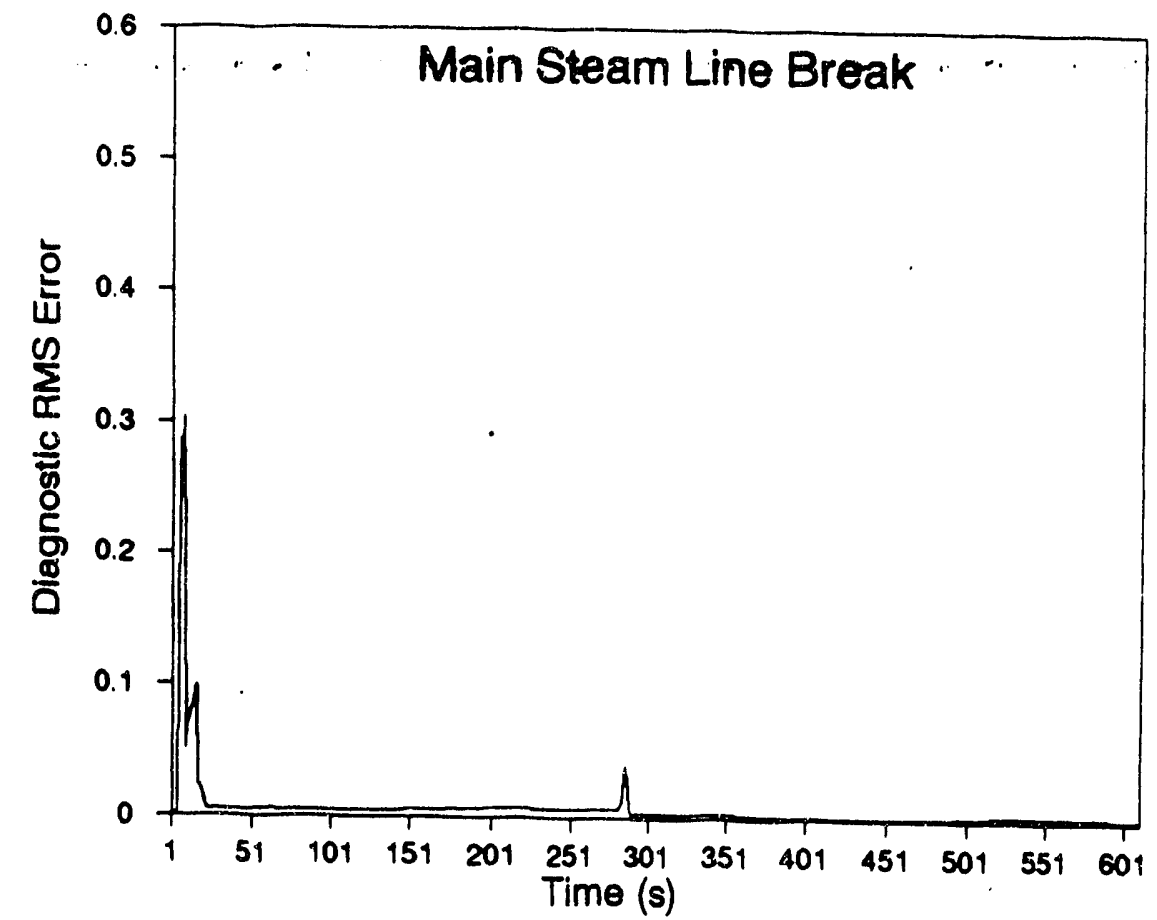

Figure 6.8 : Recall performance for the transient of Main Steam Line Break 


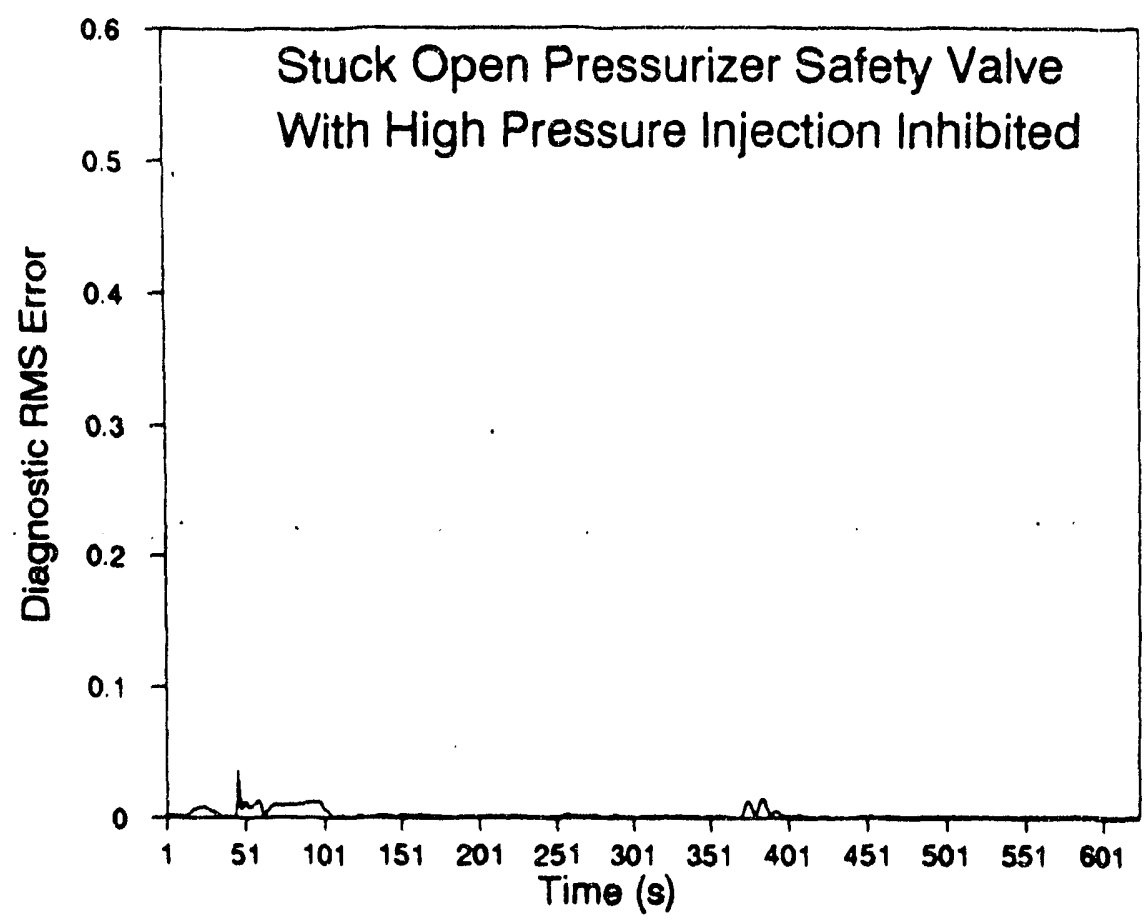

Figure 6.9 : Recall performance for the transient of stuck open Pressurizer safety with High Pressure Injection Inhibited

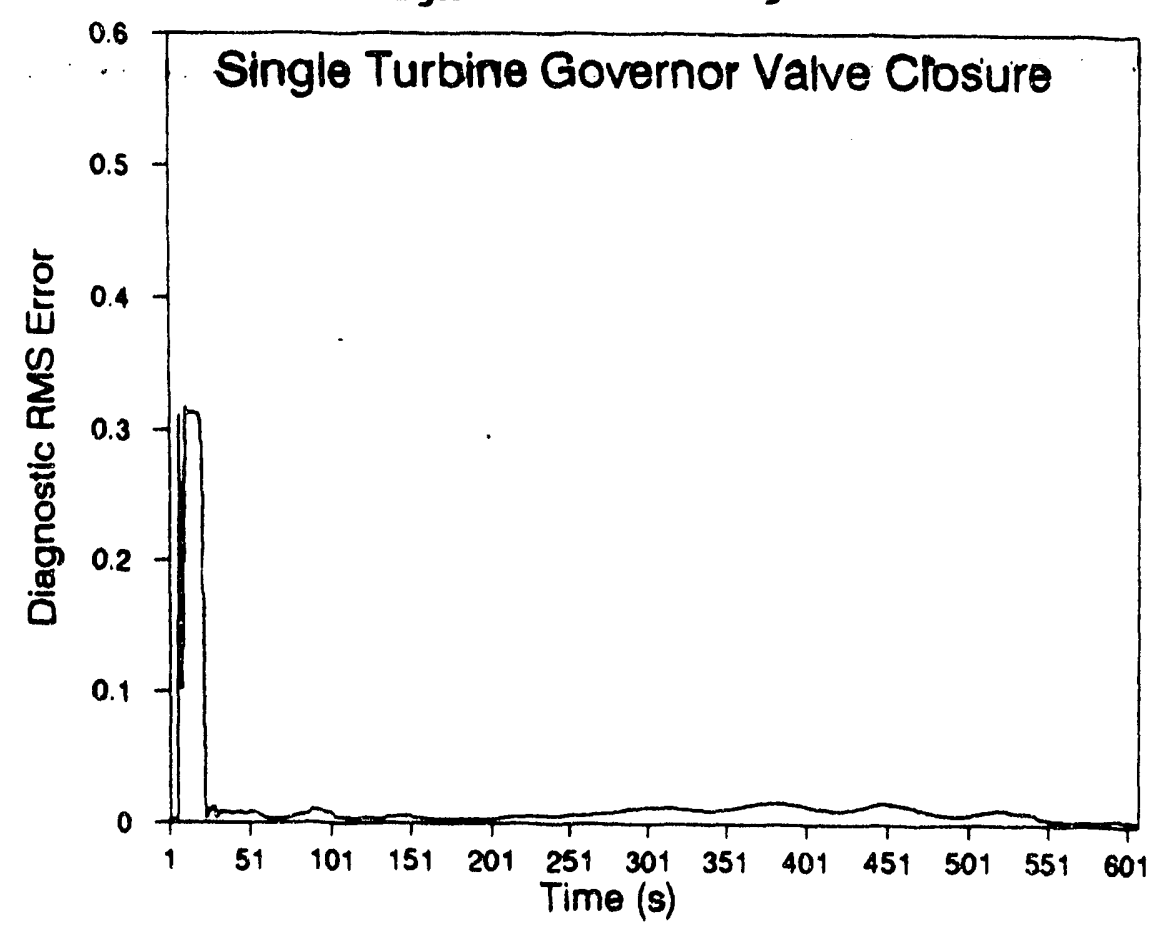

Figure 6.10 : Recall performance for the transient of single Turbine Governor Valvè Closure 
numbered pair of figures.

For the Turbine Trip and Reactor Trip, Figure 6.11 shows the predicted errors on the diagnoses of the ANN adviser given from the stacked generalization technique. Figure 6.12 displays the classification of the diagnosis that resulted from the combination of the predicted errors with the diagnoses of the ANN adviser. This error-combined classification will be provided as a final result to the operators at the NPP since the true solution will be unknown. Note that when a predicted error fall below 0.05 , the diagnosis is considered to be acceptable or reliable.

In Figure 6.15, the predicted errors indicate the estimated uncertainty in the ANN adviser diagnoses. During the transitory period (in this case, from 7 seconds through 28 seconds), the predicted errors are so large that the diagnosis for this transitory period is unreliable. Hence, the classification is undetermined for the transitory period as seen in Figure 6.16 . since the diagnoses are undetermined, the plant operators should keep monitoring the plant for further anomalous conditions. The operators must wait for a more certain diagnosis from the ANN adviser. After the transitory period passes, the predicted errors are less than 0.05 . The diagnosis of the adviser is then reliable and Figure 6.16 shows that the classification is the Closure of Both Main steam Isolation Valves. Thus, the operators perceive diagnosis, and then take their responses to the 


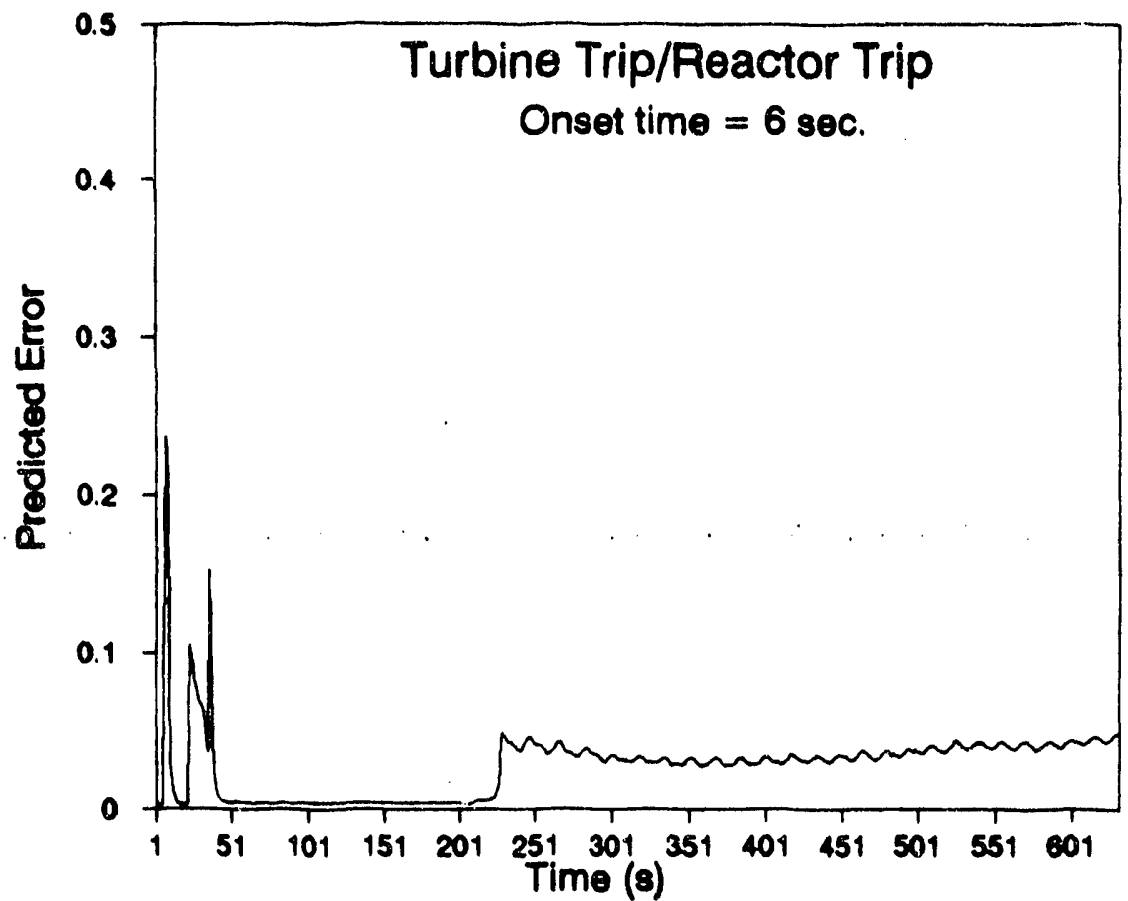

Figure 6.11 : Predicted error on the diagnosis for the Turbine Trip / Reactor Trip

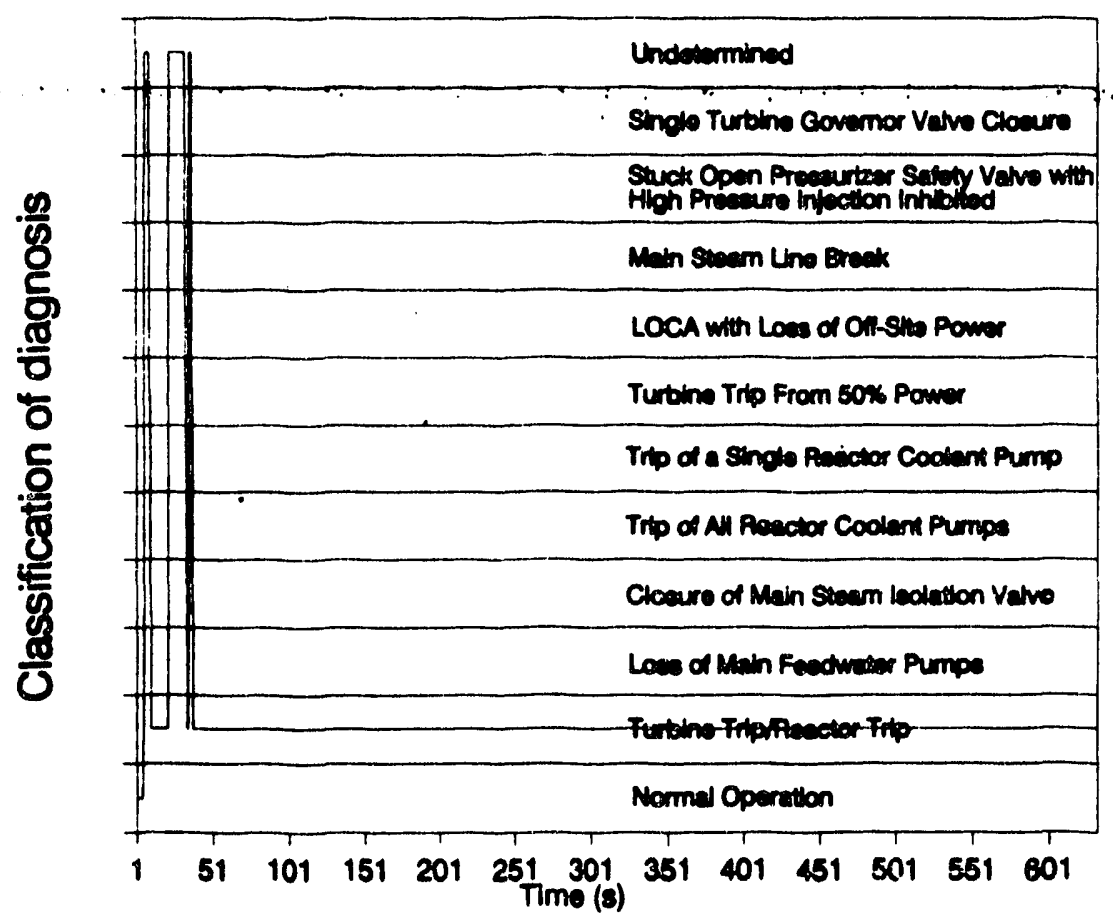

Figure 6.12 : Classification of the diagnosis for the Turbine Trip / Reactor Trip 


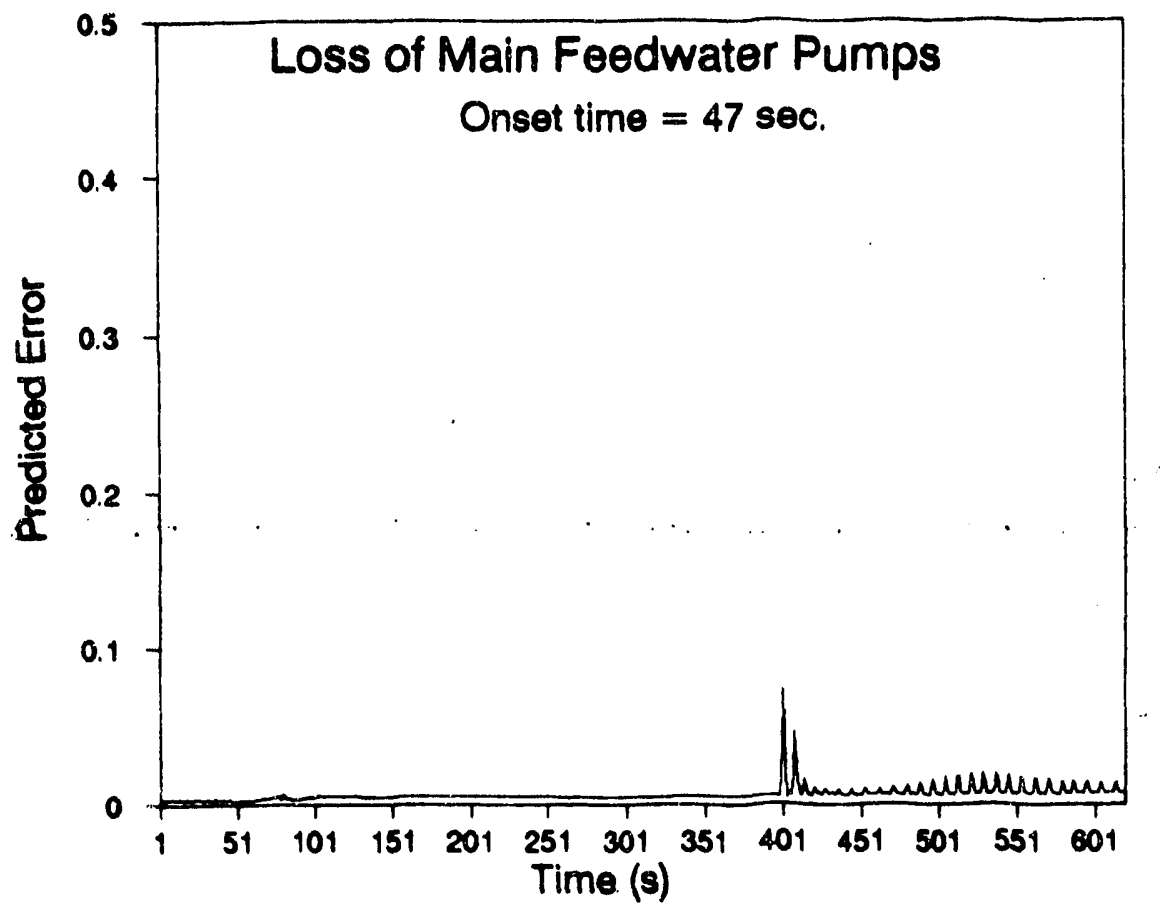

Figure 6.13: Predicted error on the diagnosis for the Loss of Main Feedwater Pumps

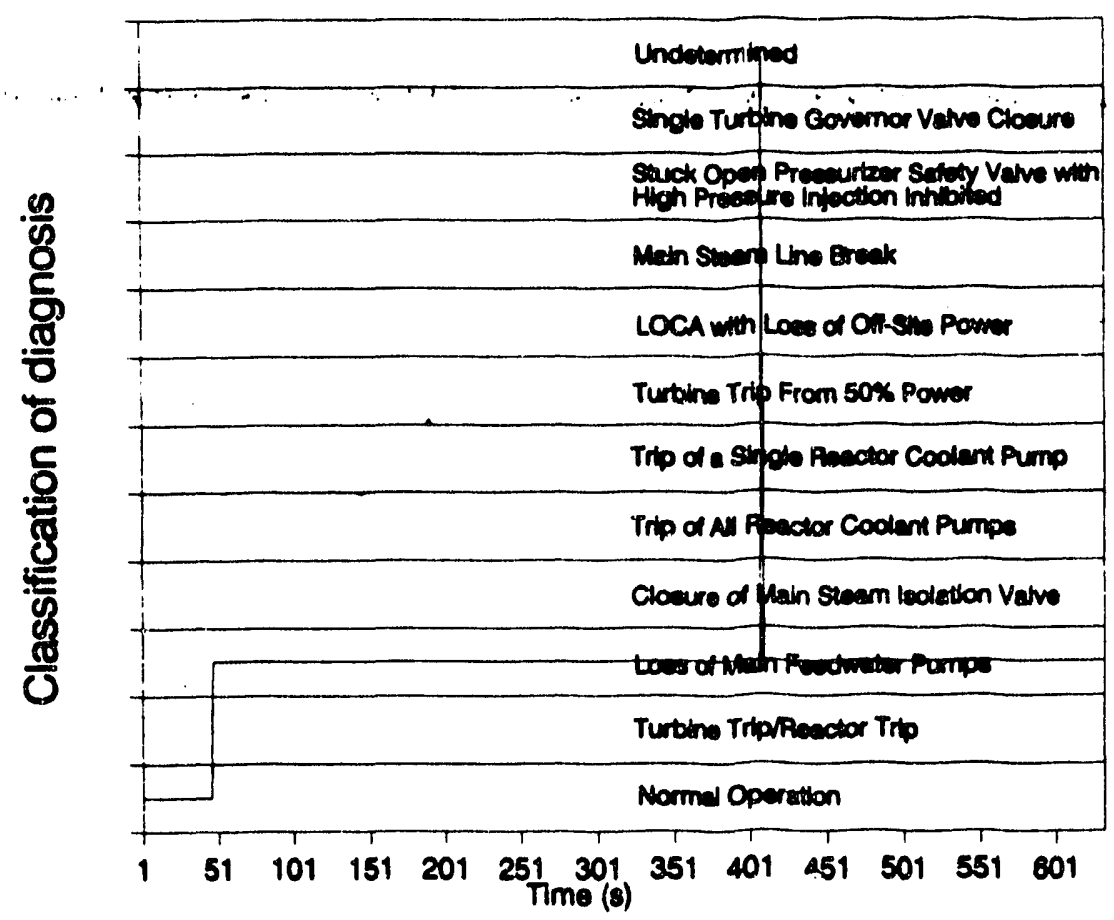

Figure 6.14 : Classification of the diagnosis for the Loss of Main Feedwater Pumps 


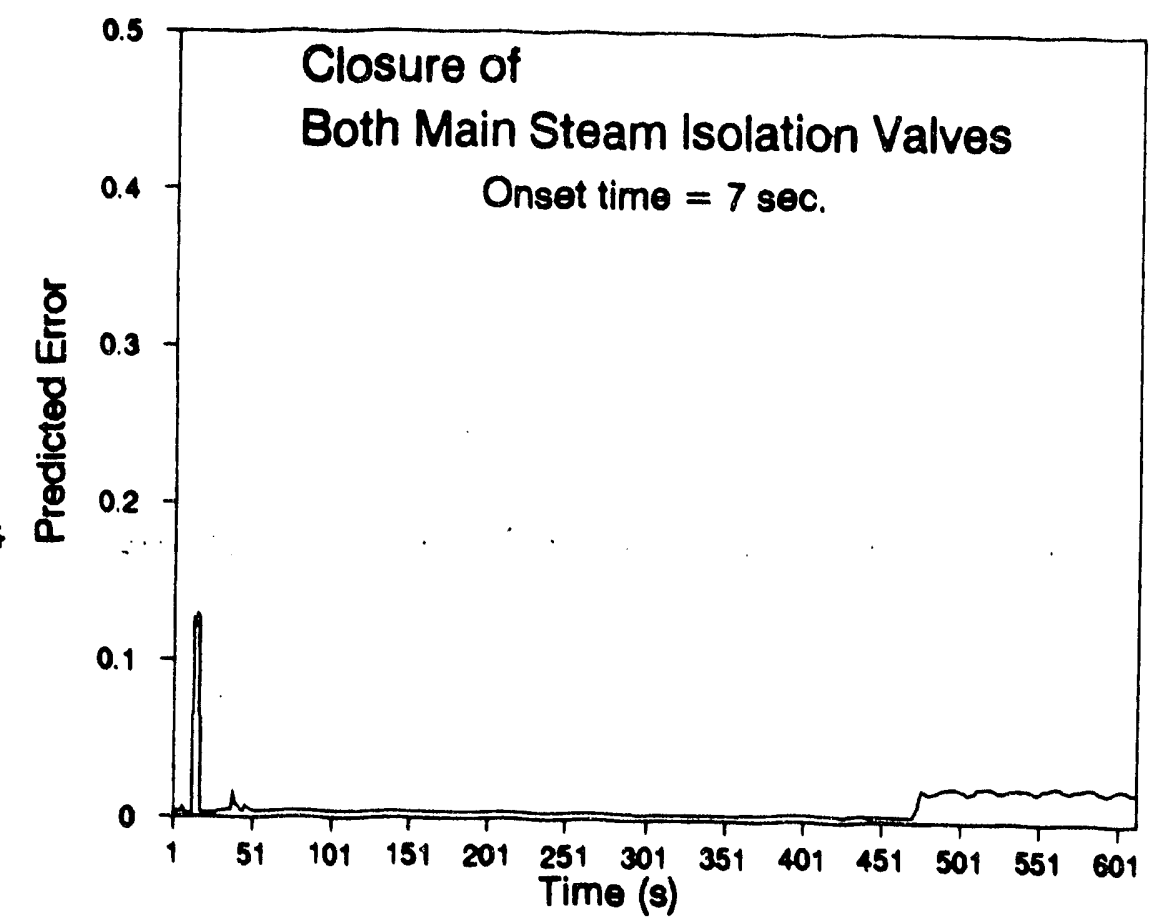

Figure 6.15 : Predicted error on the diagnosis for the closure of Both Main steam Isolation Valves

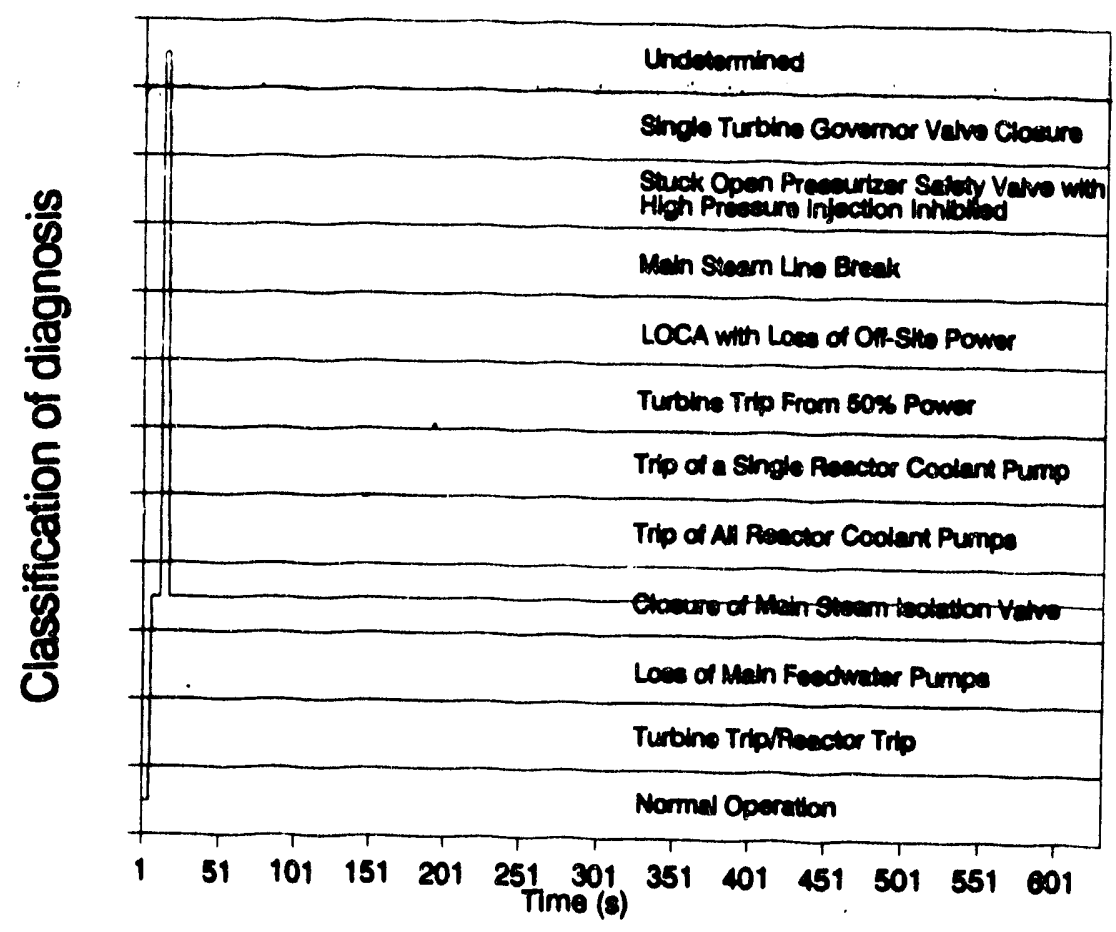

Figure 6.16 : Classification of the diagnosis for the Closure of Both Main Steam Isolation Valves 


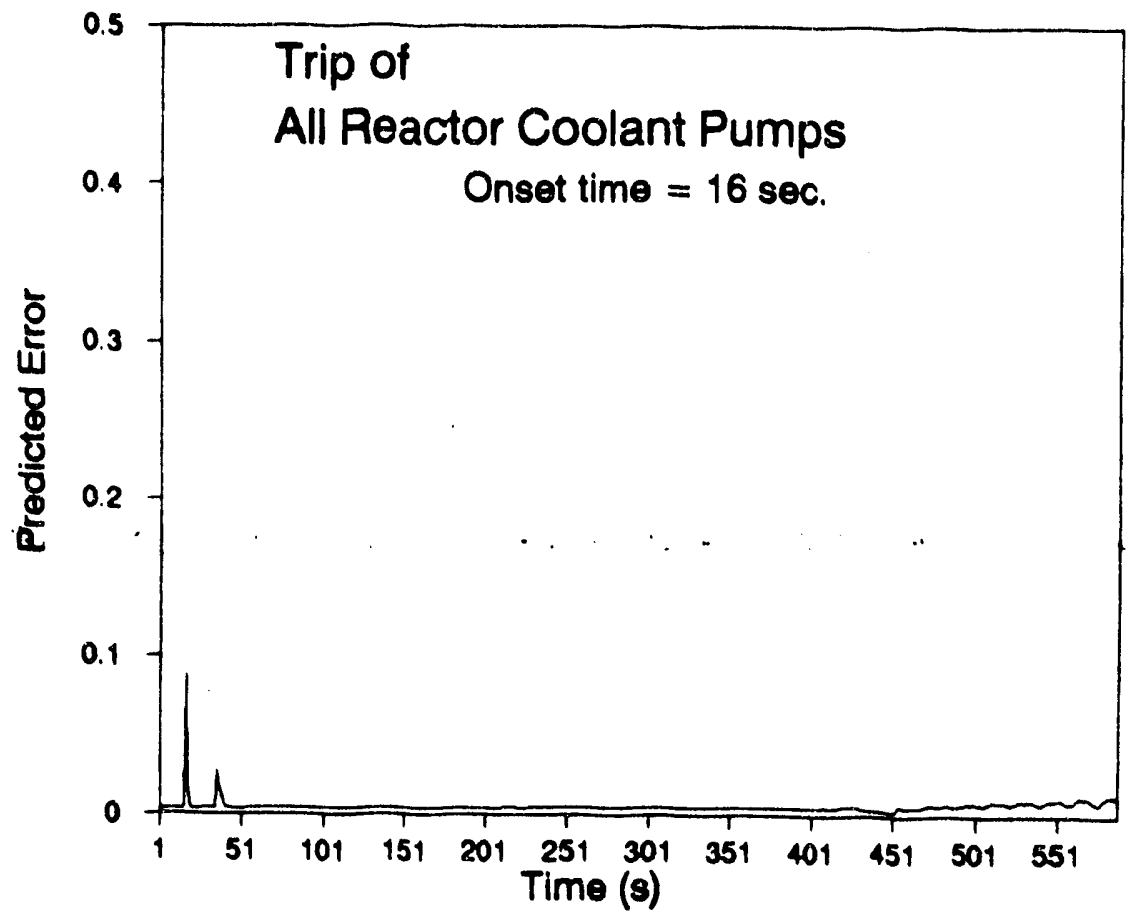

Figure 6.17 : Predicted error on the diagnosis for the Trip of All Reactor Coolant Pumps

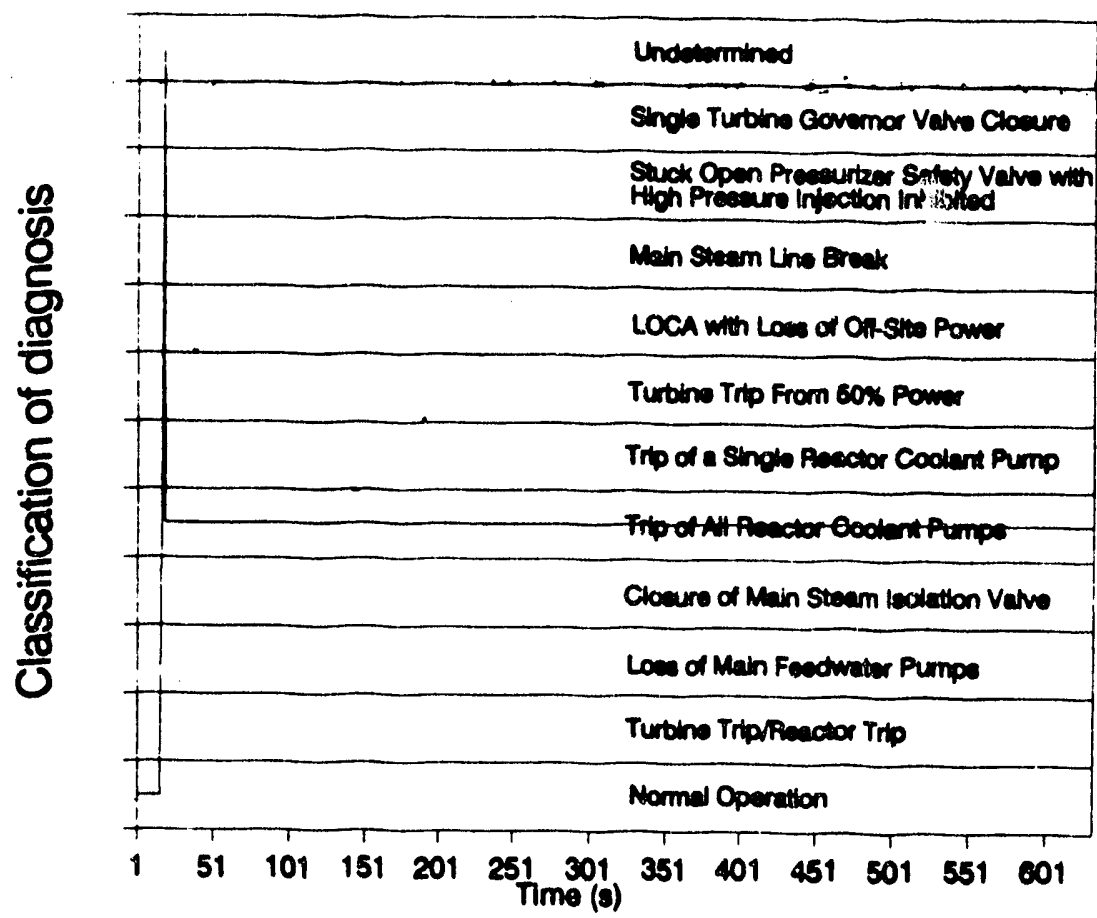

Figure 6.18 : Classification of the diagnosis for the Trip of All Reactor Coolant Pumps 


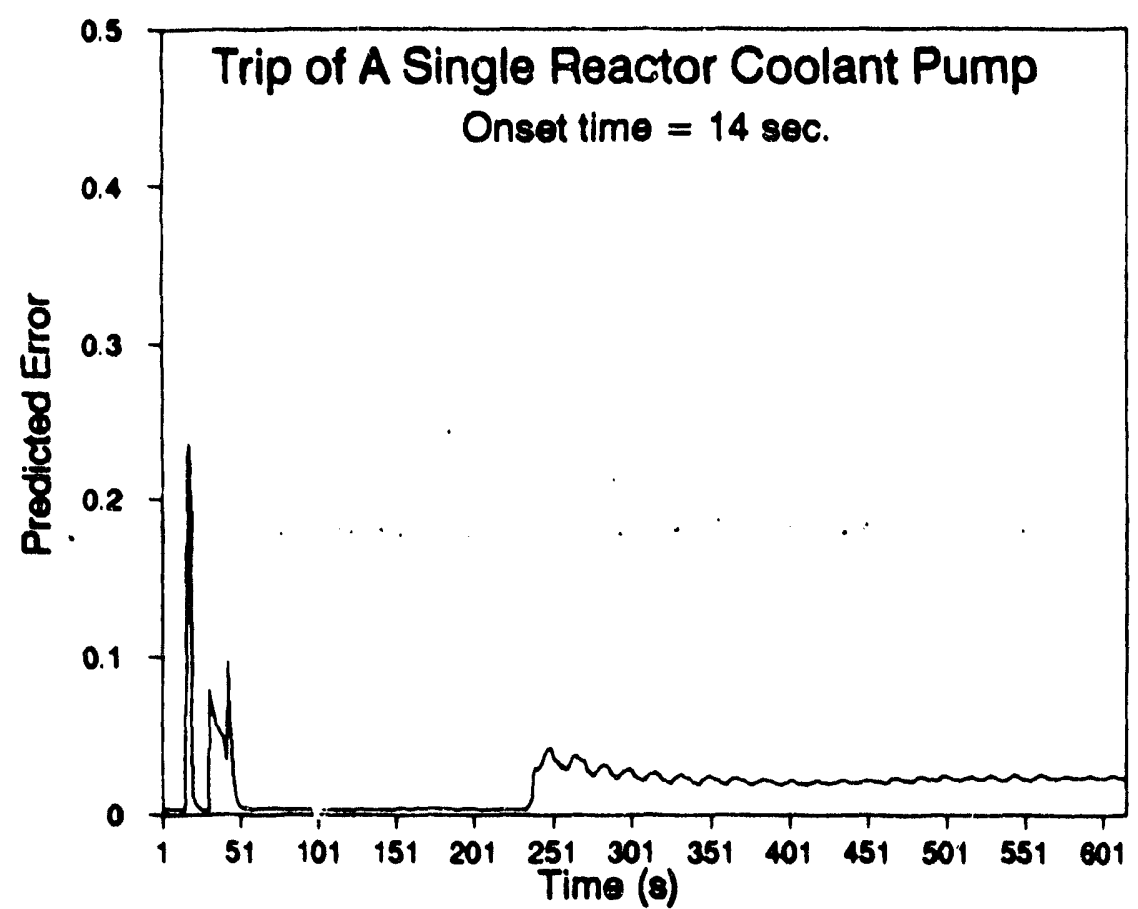

Figure 6.19: Predicted error on the diagnosis for the Trip of a single Reactor Coolant Pump

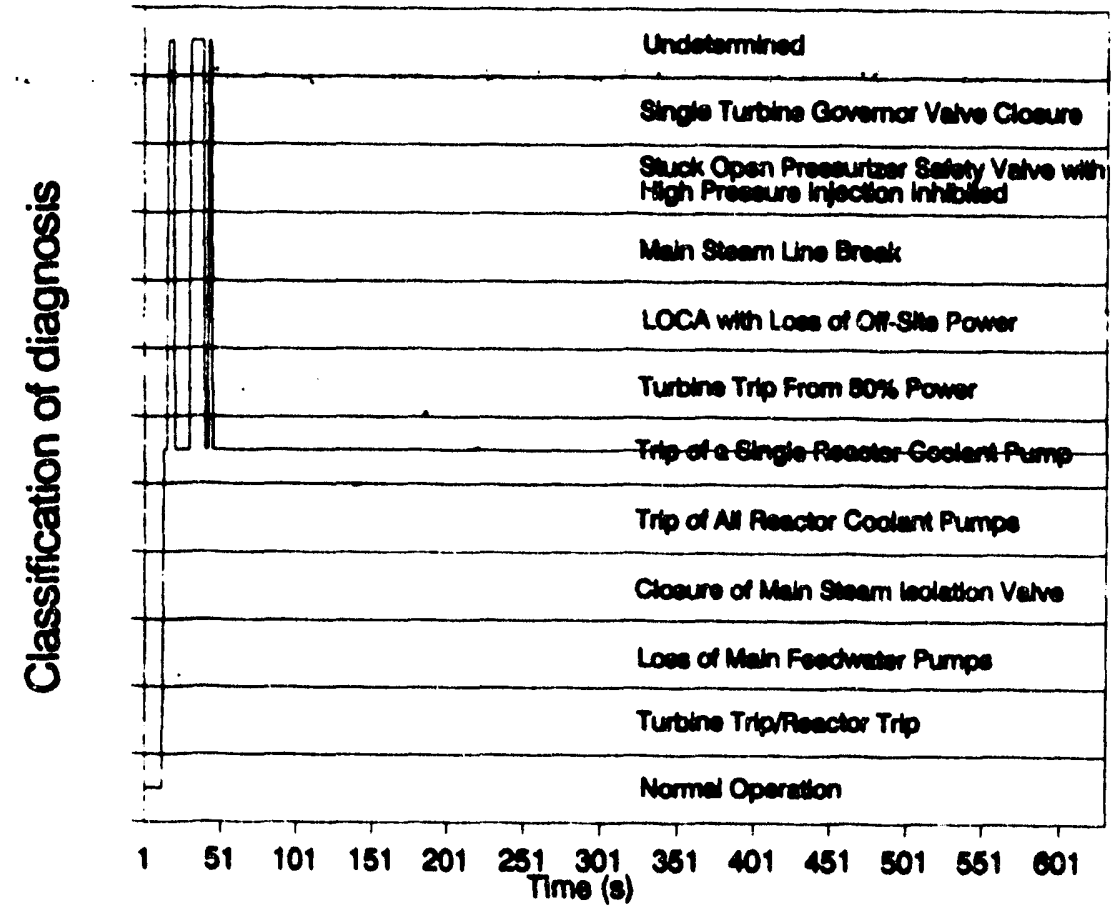

Figure 6.20 : Classification of the diagnosis for the Trip of a single Reactor Coolant Pump 


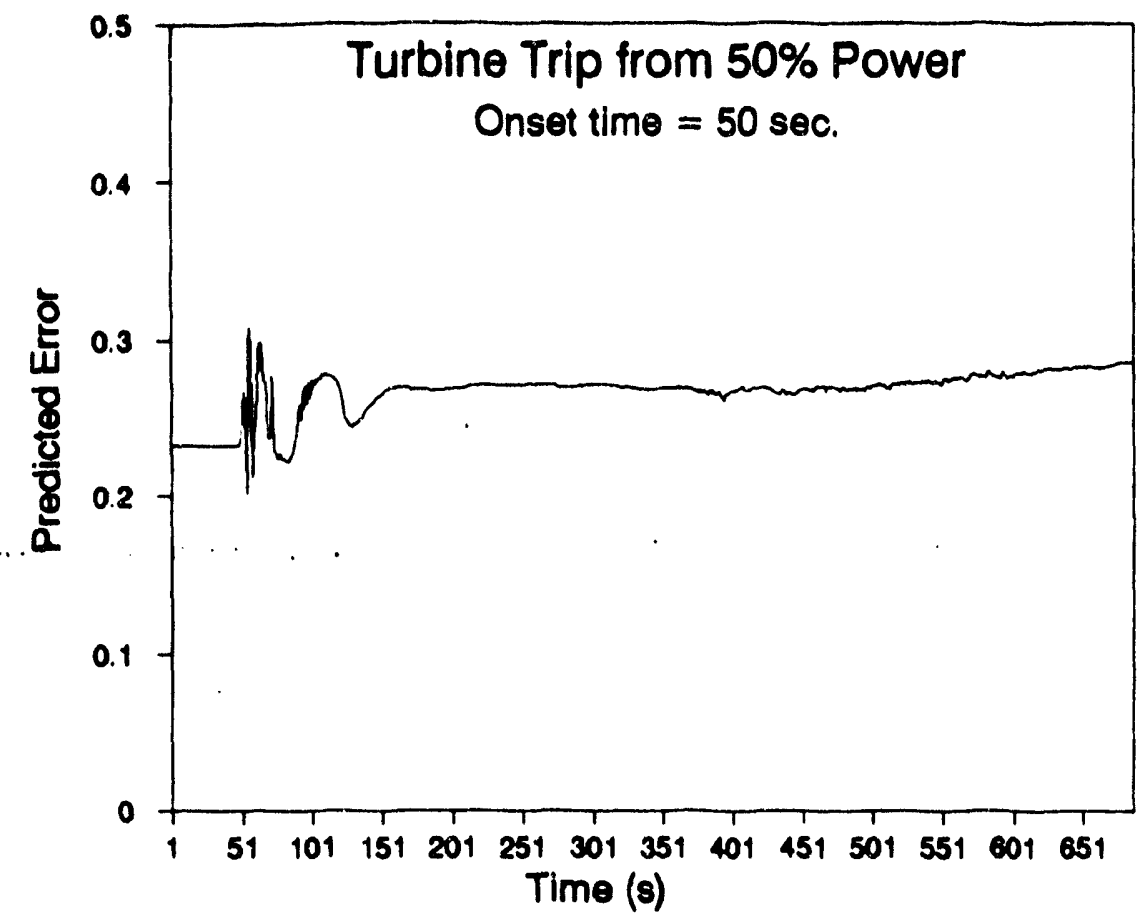

Figure 6.21 : Predicted error on the diagnosis for the Turbine Trip From $50 \%$ Power

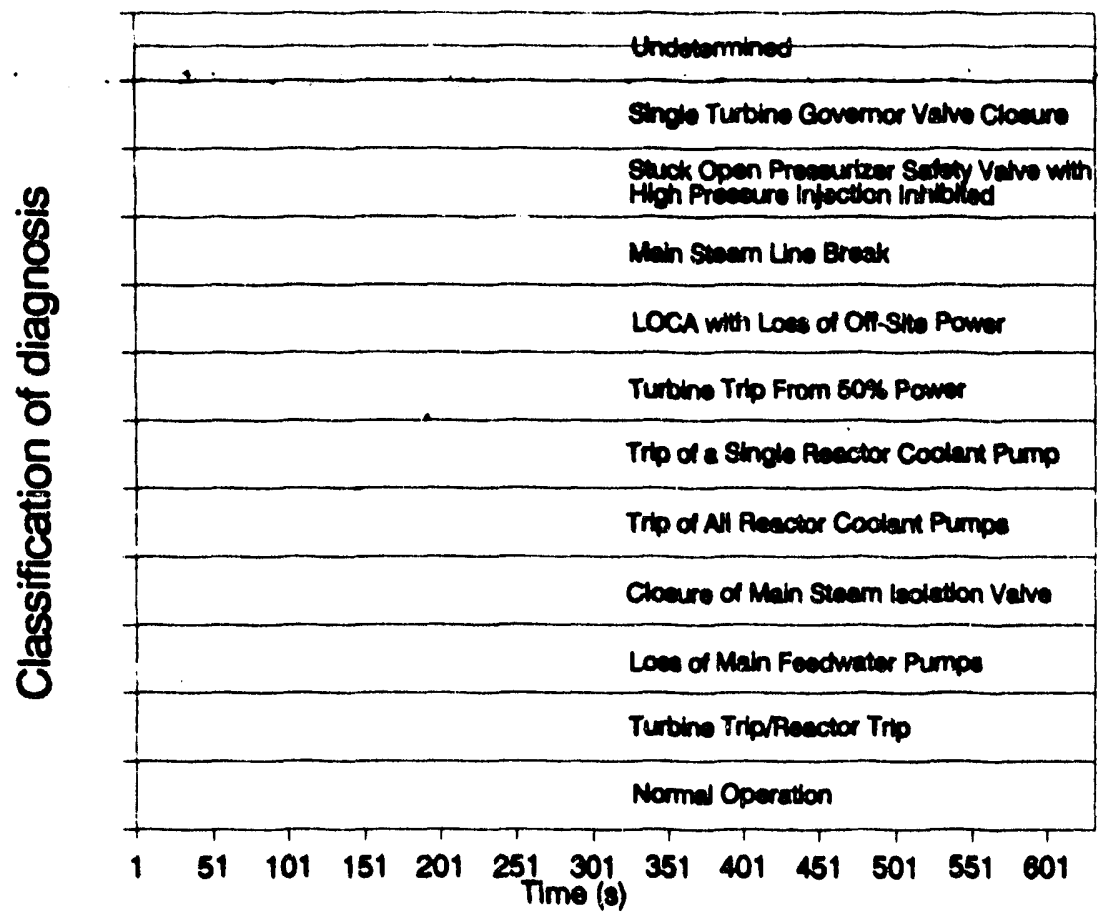

Figure 6.22 : Classification of the diagnosis for the Turbine Trip From 50 \% Power 


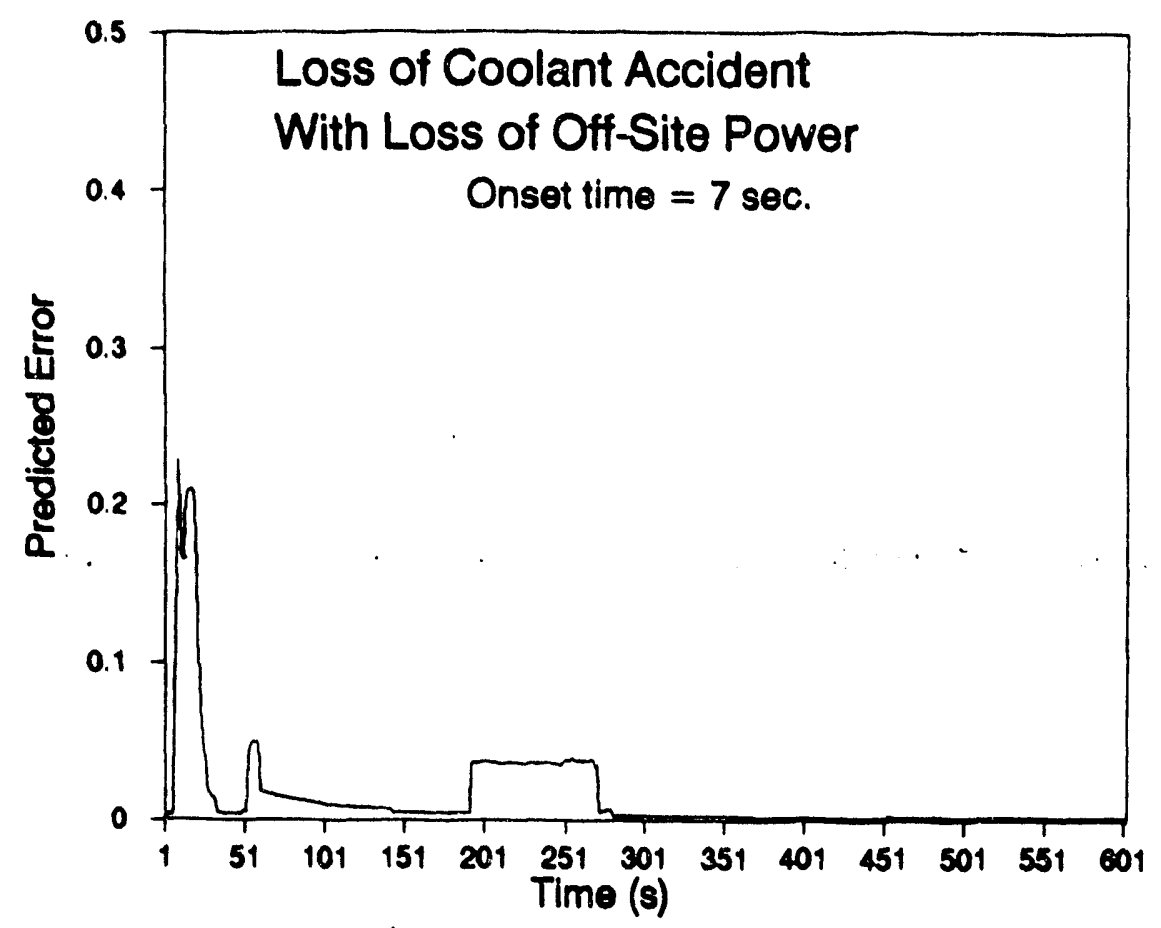

Figure 6.23: Predicted error on the diagnosis for the Loss of Coolant Accident (LOCA) with Loss of offSite Power

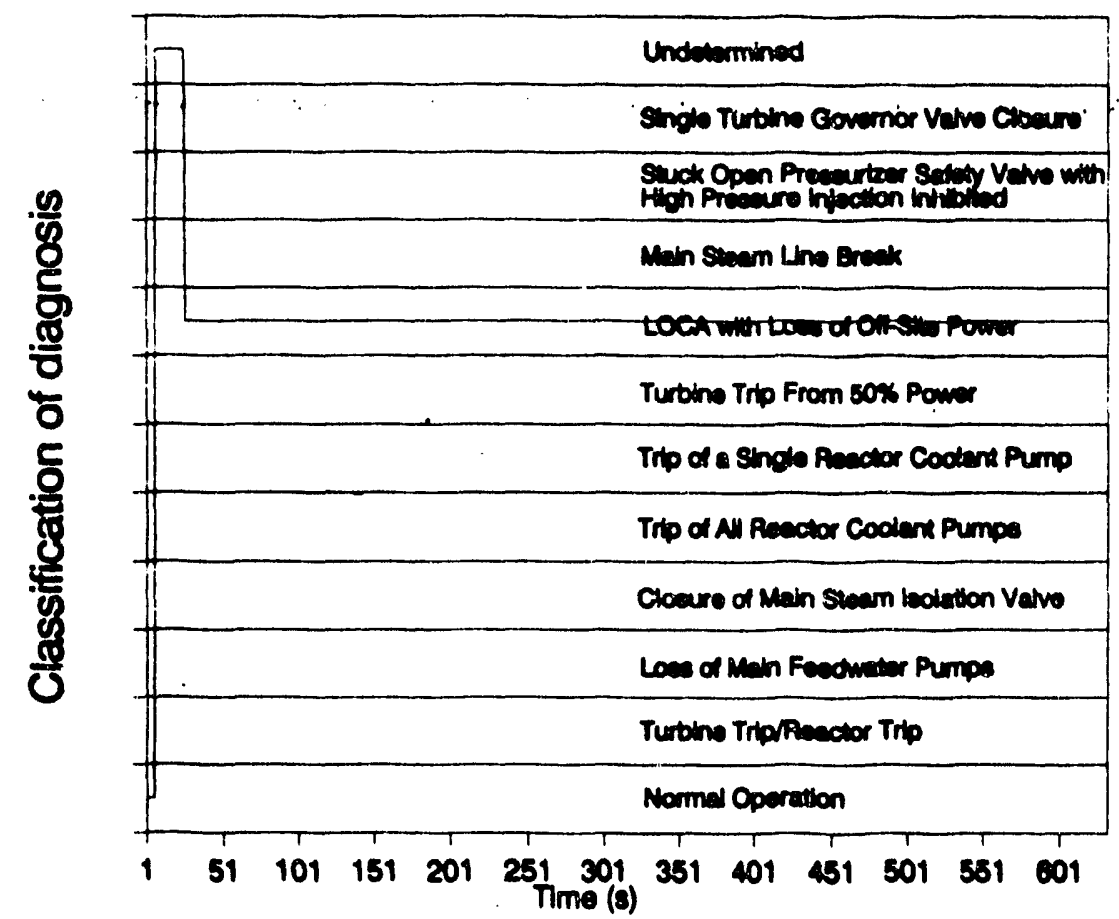

Figure 6.24 : Classification of the diagnosis for the Loss of Coolant Accident (LOCA) with Loss of offSite Power 


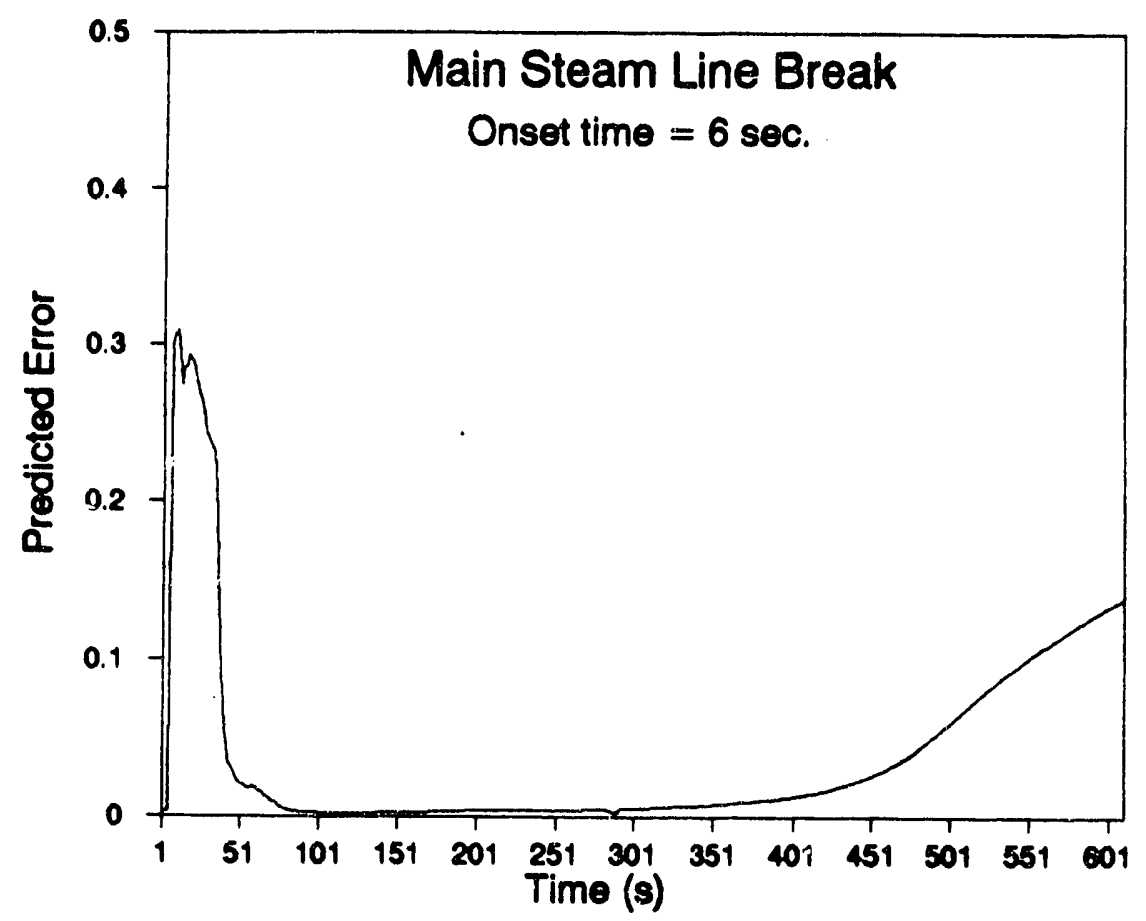

Figure 6.25 : Predicted error on the diagnosis for the Main Steam Line Break

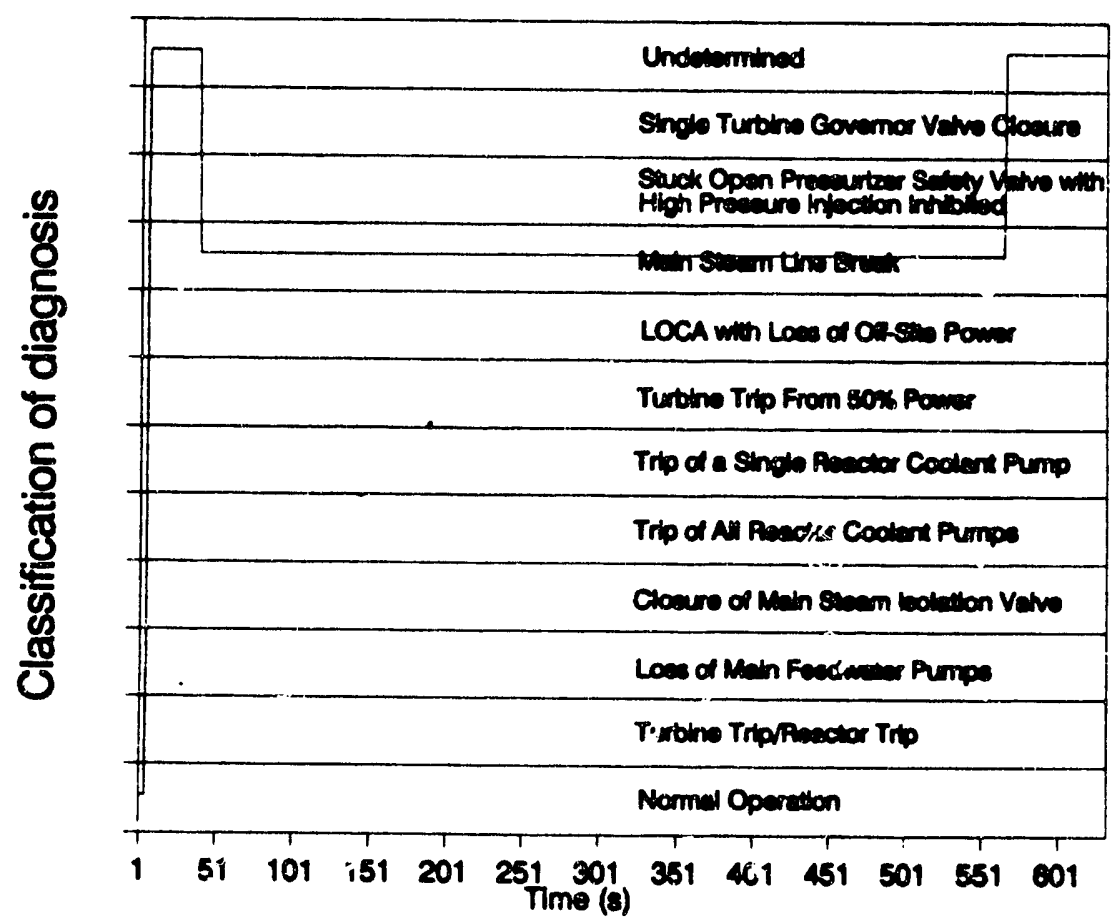

Figure 6.26 : Classification of the diagnosis for the Main steam Iine break 


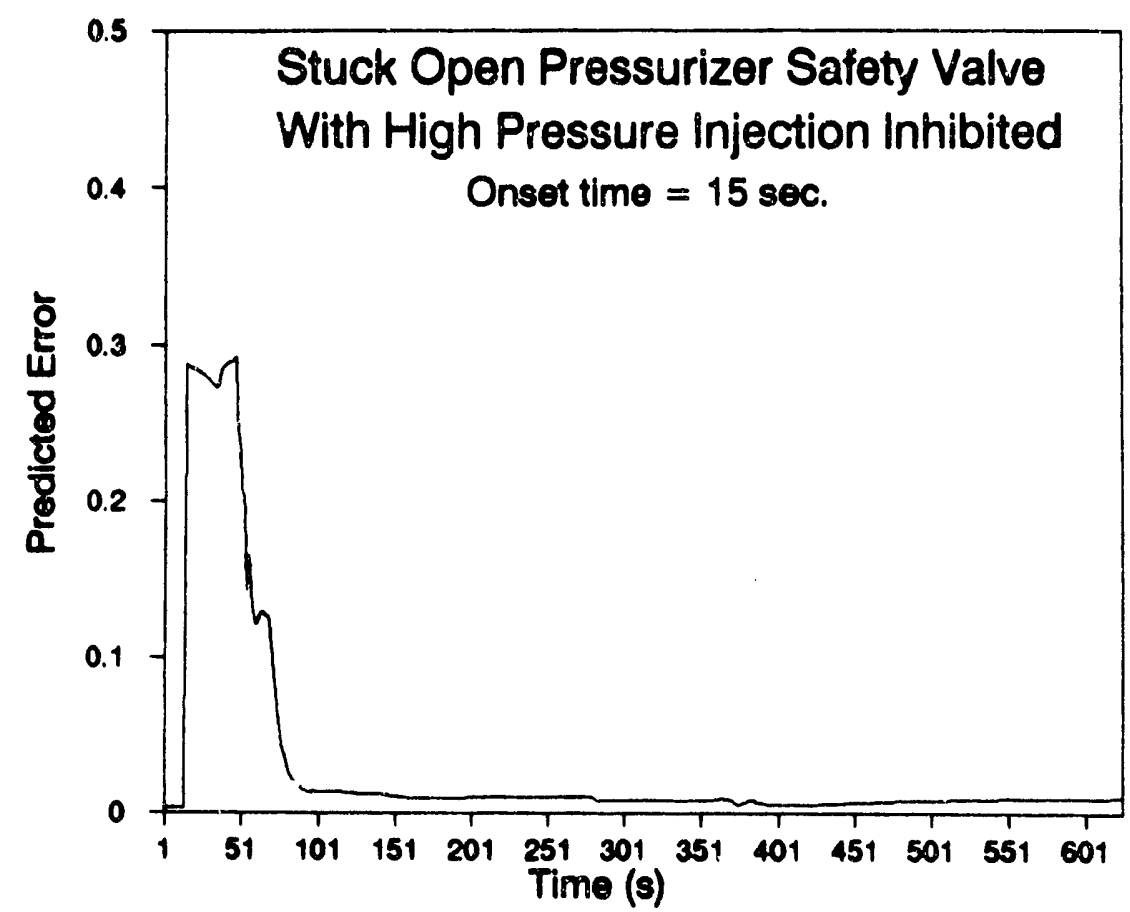

Figure 6.27 : Predicted error on the diagnosis for the stuck open Pressurizer Safety with High Pressure Injection Inhibited

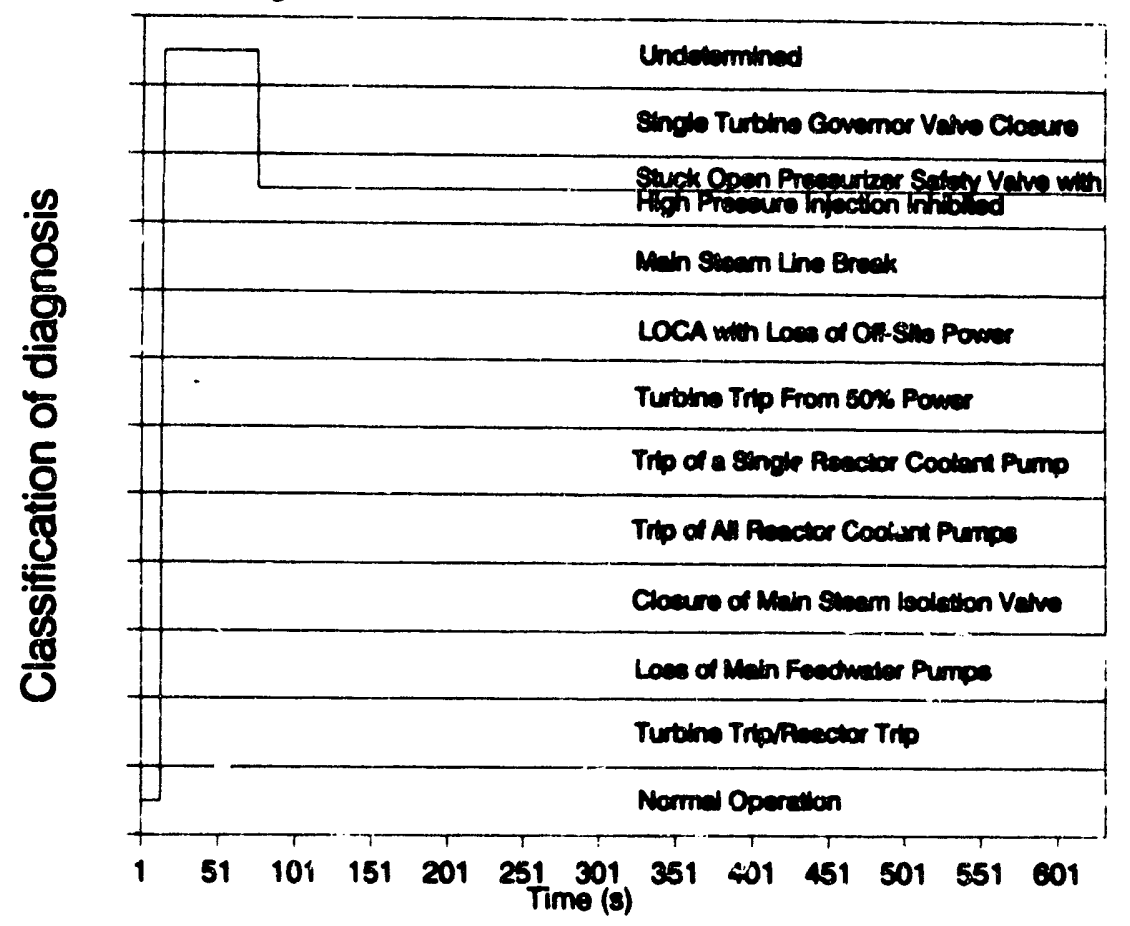

Figure 6.28 : Classification of the diagnosis for the stuck open Pressurizer Safety witin High Pressure Injection Inhibited 


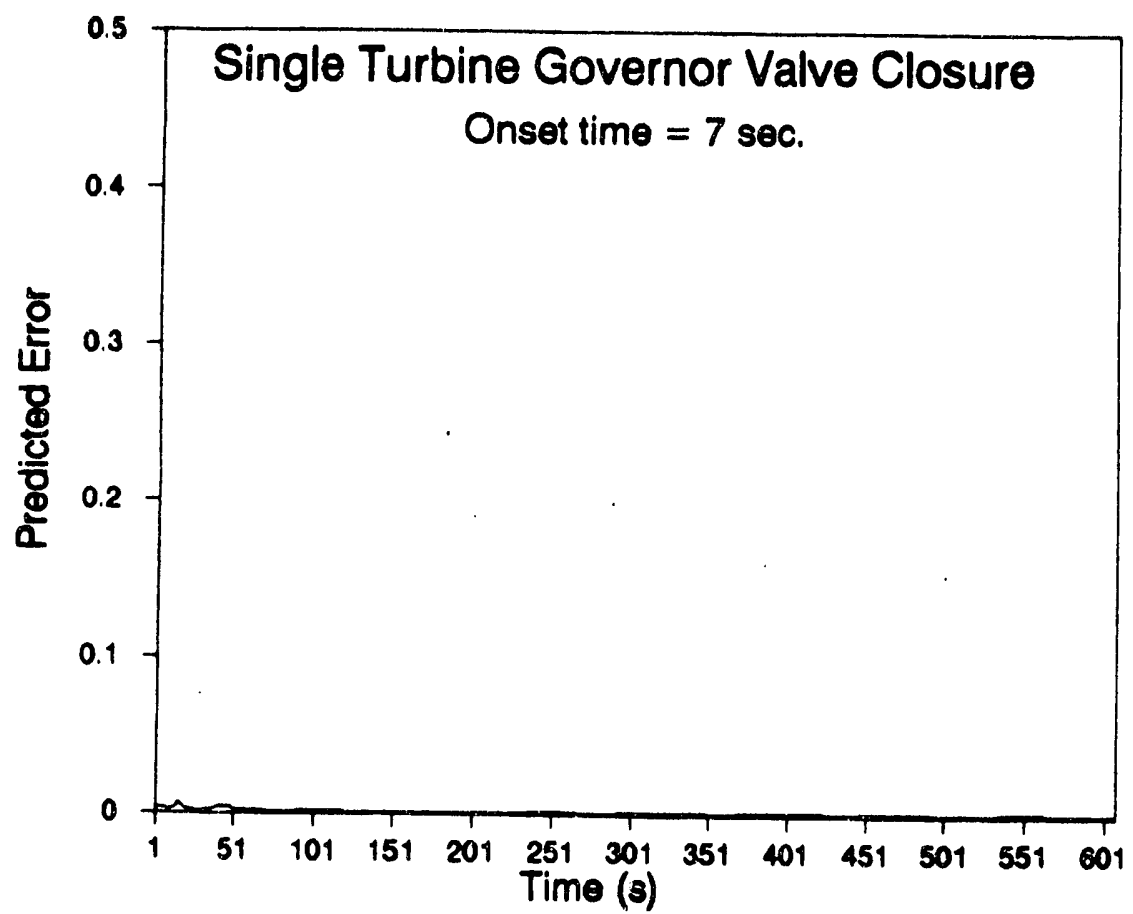

Figure 6.29: Predicted error on the diagnosis for the single Turbine Governor Valve closure

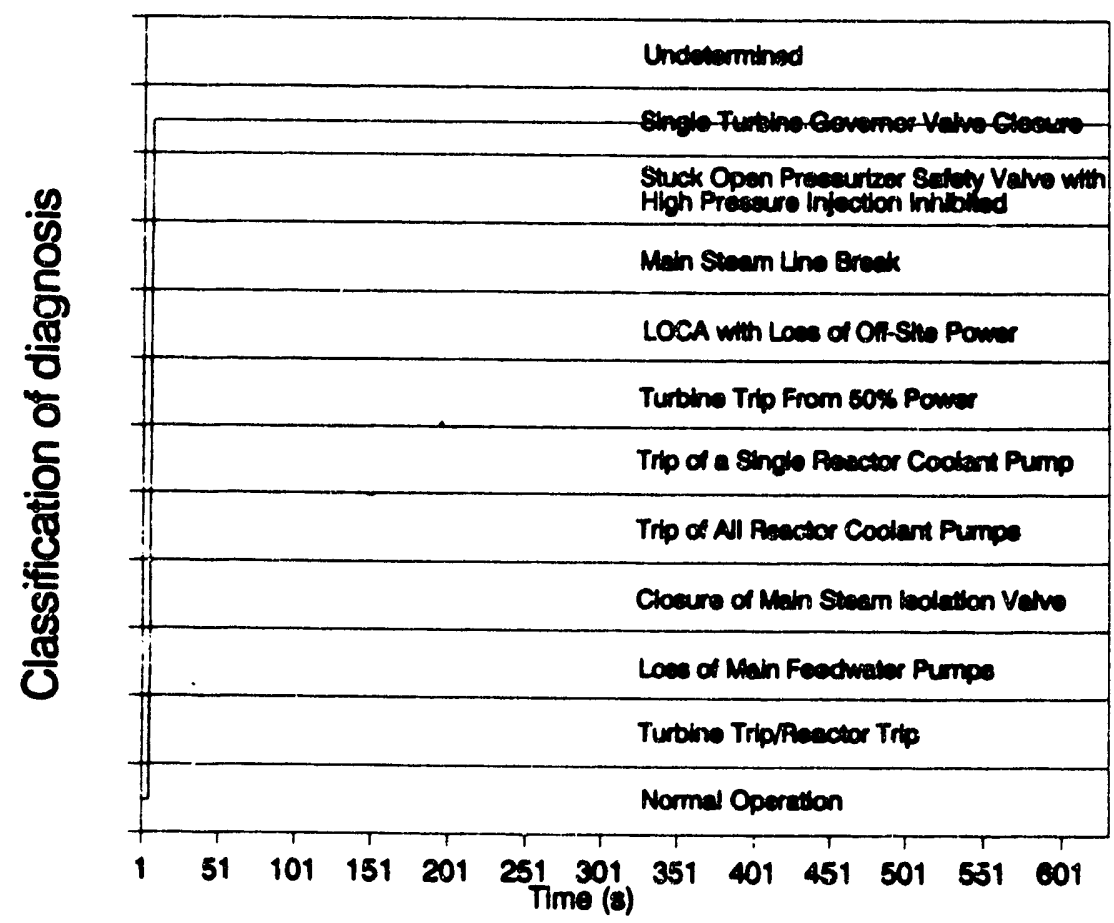

Figure 6.30 : Classification of the diagnosis for the single Turbine Governor Valve Closure 
anomaly .

Another fascinating example is the Turbine Trip From $50 \%$ Power displayed in Figure 6.21 and 6.22. Figure 6.21 shows that the predicted errors on the diagnoses are significantly large for this entire scenario, even over the normal operation period. This indicates that the diagnoses are unreliable for the entire time period. In contrast with this figure, Figure 6.6 shows that the diagnoses are correct for the entire period. This discrepancy looks like an unwanted result of the method used in this research. But it justifies the method. Notice that all the data for the other transients were collected from $100 \%$ power, except for this particular transient where the data were collected from $50 \%$ power. Consequently, from the viewpoint of generalization accuracy as measured by stacked generalization, the adviser was not able to sufficiently generalize this specific scenario of the Turbine Trip From $50 \%$ Power. In other words, the confidence on the diagnoses for this transient cannot help being very low. The assuredness on the diagnoses of this transient can be increased by training the ANN adviser with more transients from this lower reactor power level. This additional training will increase the generalization accuracy for this kind of different power transients. The implication of the above result can be applied as follows.

As seen in the figures of the diagnostic RMS error (Figure 6.1 through Figure 6.10), a recall performance is measured by 
calculating the RMS error. The recall performance is typically used to check the generalization accuracy within a single transient. Hence, the generalization accuracy of the ANN diagnoses within a single specific transient is obtained from the recall performance. However, this generalization accuracy within a single transient cannot provide the generalization accuracy for a unique transient scenario being compared with other transient scenarios. For example, the result in Figure 6.6 could not anticipate the result in Figure 6.21 . Hence, the generalization accuracy for a unique transient scenario being compared with other transient scenarios can only be obtained by applying the stacked generalization error prediction method. In other words, the generalization accuracy for the entire scenario is obtained by applying the error prediction method that was investigated in this thesis. For instance, the result in Figure 6.21 indicates that the transient of the Turbine Trip From $50 \%$ Power needs more training data in order to be generalized from the other transients.

Another illustrative example is shown Figure 6.10 and 6.29 . The predicted errors in the case of the single Turbine Governor Valve closure in Figure 6.29 are very low for the entire period. But the actual diagnostic RMS error in Figure 6.10 shows that the diagnosis for the transitory period (from 7 seconds to 21 seconds) is not correct. Hence, this inconsistency means that the predicted error for this particular transient during this 
transitory period is not appropriate. This is probably due to incomplete training of the level 1 generalizer. This difficulty should be investigated further as future work. 
CHAPTER 7. CONCLUBIONB

The objective of this thesis is to demonstrate a validation technique that provides an estimated error for the diagnosis of an ANN fault-diagnostic adviser for a NPP. To this end, an ANN adviser was successfully developed to detect and classify ten transient scenarios and ten normal conditions in a PWR nuclear power plant. The error prediction was accomplished by applying stacked generalization error analysis to the ANN adviser. The results demonstrate the feasibility of the error prediction method for a nuclear power plant status diagnostics.

If an anomaly occurs, the ANN fault-diagnostic adviser detects and diagnoses the anomaly incipiently. For the diagnosis by the adviser, a predicted error allows the plant operators to obtain an idea of the validity of the diagnosis from the ANN adviser. The operators can act in a timely manner to mitigate or rectify the problems associate with the particular transient at hand once the diagnosis is assured by a low predicted error. Additionally, as mentioned in the preceding chapter, error prediction by stacked generalization can tell us the 
generalization accuracy not only for a single transient, but also for each individual transient scenario as compared with all the other scenarios.

\section{Possible Future Work}

Further refinement of the stacked generalization technique would be the first step, because many aspects of the technique are black art, as Wolpert describes in his paper [41]. Moreover, the technique should be modified so that it may be implemented to solve enormously complex problems, such as an error prediction for 300 NPP transients.

As seen in Figure 6.10 and 6.29 , the predicted errors in Figure 6.29 are low for the entire period although the actual diagnostic error in Figure 6.10 is high during the transitory period. This is probably associated with incomplete training of the level 1 generalizer. Hence, this difficulty should be investigated further as future work.

Fundamentally, the stacked generalization utilizes nonparametric-statistical information in a learning set. Accordingly, each example in a learning set is closely related to generalization accuracy, i.e., the more appropriate selection of examples, the better the generalization. Hence, for the optimized selection of learning examples from data, it is suggested that the stacked generalization may be applied as a 
more suitable method for the selection of examples for the learning set. 


\section{BIBLIOGRAPHY}

[1] T.Ash. "Dynamic Node Creation in Backpropagation Networks." IJCNN International Conference on Neural Networks, vol. 2 , Washington D.C., June 1989. 623.

[2] A.E.Bryson and Y.Ho. Applied Optimal Control, Blaisdell, New York, 1969.

[3] N.Baba. "A New Approach for Finding the Global Minimum of Error Function of Neural Networks." Neural Networks, vol. 2,1989 . 367-373.

[4] E.B.Bartlett, "Nuclear Power Plant Status Diagnostics Using Simulated Condensation: An Auto-Adaptive Computer Learning Technique." The University of Tennessee at Knoxville, University Microfilms, Ann Arbor, Michigan, Ph.D. Dissertation. August 1990.

[5] E.B.Bartlett and R.Uhrir, "Nuclear Power Plant status Diagnostics Using an Artificial Neural Network." Nuclear Technology, Vol. 97, March 1992.

[6] E.B.Bartlett and A.Basu, "A Dynamic Node Architecture Scheme for Backpropagation Neural Networks." Intelligent Engineering Systems Through Nrtificial Neural Networks, $C$. I. Dagli, et al. editors, ASME Press, 1991. 101-106.

[7] M.Caudill, "Neural Networks Primer." Part 1-5, AI Expert, 1987-1988.

[8] M.Caudill, "Using Neural Nets: Representing Knowledge." Part 1-5, AI Expert, 1989-1990.

[9] J.D.Farmer and J.J.Sidorowich, "Exploiting Chaos to Predict the Future and Reduce Noise." Los Alamos, NM, Report LA-UR-88-901, 1988. 
[10] W.J.Freeman, "The Physiology of Perception." Scientific American, February 1991. 78-85.

[11] S.Geisser, "The Predictive Sample Reuse Method with Applications." Journal of the American Statistical Association, vol.70, 1975. 320-328.

[12] Z.Guo and R.Uhrig,"Use of Artificial Neural Networks to Analyze Nuclear Power Plant Performance." Nuclear Technology, vol. 99, July 1992 (36-42).

[13] R.Hecht-Nielsen. "Theory of the Backpropagation Neural Networks." Proceedings of the International Joint Conference on Neural Networks, vol. 1, 1989. 595-605.

[14] J.Holland, Adaption in Natural and Artificial Systems. University of Michigan Press, Ann Arbor, MI, 1975.

[15] Y.Hirose, K.Yamashita, and S.Hijiya. "Backpropagation Algorithm that Varies the Number of Hidden Nodes." Neural Networks, vol. 4, 1991. 61-66.

[16] E.D.Karnin, "A Simple Procedure for Pruning BackPropagation Trained Neural Networks." IEEE Transactions on Neural Networks, vol. 1, no. 2, June 1990. 239-242.

[17] T.L.Lanc. "The Importance of Input Variables to a Neural Network Fault Diagnostic System for NPPs." Iowa state University, M.S. Thesis. Dec. 1991.

[18] K.Li, "From Stein's Unbiased Rigk Estimates to the Method of Generalized Cross Validation." The Annals of Statistics, vol. $13,1985.1352-1377$.

[19] R.P.Lippmann, "An Introduction to Computing with Neural Nets." IEEE Acoustic. Speech and signal Processing Magazine, vol. 4, April 1987. 4-22.

[20] S.Omohundro, "Efficient Algorithms with Neural Network Behavior". Report UIUCSCS-R-87-1331, Urbana, IL., University of Illinois at Urbana-Champaign Computer Science Department.

[21] T.Poggio and staff of MIT AI Lab, "MIT Progress in Understanding Images." In L. Bauman (Ed.), Proceedings of the Image Understanding Workshop, "McLean, VA, 1988. 111129 . 
[22] J.Rissanen, "Stochastic Complexity and Modeling," The Annals of Statistics, vol. 14, 1986. 1080-1100.

[23] M.Roh, S.Cheon and S.Chang, "Thermal Power Prediction of Nuclear Power Plant Using Neural Network and Parity Space Model." IEEE Transactions on Nuclear Science, vol. 38, no. 2, April 1991. 866-872.

[24] D.E. Rumelhart et al., "Learning Internal Representations by Error Propagation." ICS report 8506, Institute for Cognitive Science, University of California at San Diego, September 1985.

[25] D.E.Rumelhart et al., Parallel Distributed Processing: Exploration in the Microstructure of cognition. vol. $1 \& 2$, MIT Press, Cambridge, Massachusetts, 1986.

[26] C.Stanfill and D.Waltz, "Toward Memory-Based Reasoning." Communications of the ACY, vol.29, 1986. 1213-1228.

[27] M.Stone, "Cross-validatory Choice and Assessment of statistical Predictions." Journal of Royal Statistical Society Series B 36, 1974, 111-147.

[28] M.Stone, "Asymptotics For and Against Cross-Validation. Biometrica, vol. 64, 1977. 29-35.

[29] R.E.Uhrig, "Use of Neural Networks in Nuclear Power Plant Diagnostics." presented at Proceedings of International Conference on Availability Improvements in Nuclear Power Plant, Madrid, Spain, April. 1989.

[30] B.R. Upadhyaya and E.Eryurek, "Application of Neural Networks for Sensor Validation and Plant Monitoring." Nuclear Technology, vol. 97, February 1992. 170-176.

[31] G.Wahba and S.Wold, "A Completely Automatic French Curve: Fitting Spline Functions by cross Validation." Communications in statistics 4 , 1975. 1-17.

[32] A.S.Weigend, D.E.Rumelhart, and B.A.Huberman, "Generalization by Weight-Elimination Applied to Currency Exchange Rate Prediction." IJCNN International Conference on Neural Networks, 1991. 837-841.

[33] P.J.Werbos, "Beyond Regression: New Tools for Prediction and Analysis in the Behavioral Sciences." Ph.D. Thesis, Applied Mathematics, Harvard University, November 1974. 
[34] B.Widrow and M.A.Lehr, "30 Years of Adaptive Neural Networks: Perceptron, Madaline, and Backpropagation." Proceedings of the IEEE, vol. 78, September 1990. 1415-1441.

[35] D.H.Wolpert, "A benchmark for how well neural nets generalize." Biological Cybernetics, vol. 61, 1989. 303315 .

[36] D.H.Wolpert, "A Mathematical Theory of Generalization: Part I and Part II." Complex Systems, vol. 4, 151-249.

[37] D.H.Wolpert, "Stacked Generalization." Neural Networks, vol. 5, 1992. 241-259.

[38] Data provided by T.James, S.Olmos, and D.Rogers of San Onofre Nuclear Generating Station, San Clamente, CA. 


\section{Acknowledgment}

The authors would like to thank the staff of the Office of Energy Research with special thanks to H. Alter, L. Barker, T. Dolan, R. Forman, L. Hammun, J. Nadler, R. Stephens, P. Waldman, and T. Williams. The monetary support received from the Office of Energy Research of the US Department of Energy for this project is greatly appreciated.

The authors would like to thank the staff of Iowa Electric Light and Power Company, in particular Don Vest, Dan Berchenbriter, John Franz, Craig Hunt, Phil Meek, and Richard McGauphy of the Duane Arnold Energy Center. We would also like to thank the company for allowing the use of their simulator, supporting this project monetarily, and supporting the Nuclear Engineering program at Iowa State University.

The authors would also like to thank the staff at of Southern California Edison Company, particularly Dr. J. Olmos, T. James, and D. Rogers for supplying us with data from the San Onofre Nuclear Power Station simulator.

The authors also appreciate the monetary support received from Netrologic Inc. and its president, Dan Greenwood.

Thanks are also due to the staff of Iowa State University Office of Editorial Services for their excellent help in preparing this report, the original proposal that landed this grant and made the whole thing possible, and for all the journal articles and reports yet to come. We wish to single out Barbara Munson for her encouragement, guidance, and patience. Thank you. 


\section{Bibliography}

Akiyama, Y.. A. Yamashita, M. Kajiura, and H. Aiso. 1989. Combinatorial Optimization with Gaussian Machines. IJCNN International Conference on Neural Networks 1:533-40.

Ash. T. 1989. Dynamic Node Creation in Backpropagation Networks. IJCNN International Conference on Neural Networks 2:623.

Baba, N. 1989. A New Approach for Finding the Global Minimum of Error Function of Neural Networks. Neural Networks 2: No. 5, 367-73.

Bartlett, E. B. 1992a. Analysis of Chaotic Population Dynamics Using Artificial Neural Networks. Chaos, Soliton, and Fractals: Applications in Science and Engineering 1: No. 5. Elmsford, NY: Pergamon Press.

Bartlett, E. B. 1992b. Neural Network Recognition of Nuclear Power Plant Transients. Annual Report to DOF

Bartlett, E. B. 1992c. Neural Network Recognition of Nuclear Power Plant Transients: Continuation Proposal for Phase II. Continuation Proposal for 2nd Year to DOE.

Bartlett, E. B. 1991. Chaotic Time Series Prediction Using Artificial Neural Networks. Proceedings of the 2nd Government Neural Network Applications Workshop. Huntsville, Alabama.

Bartlett, E. B. 1990. Nuclear Power Plan Status Diagnostics Using Simulated Condensation: An Auto-Adaptive Computer Learning Technique. Ph.D. Dissertation, University of Tennessee, Knoxville.

Bartlett, E. B., and A. Basu. 1991. A Dynamic Node Architecture Scheme for Backpropagation Neural Networks. Intelligent Engineering Systems Through Artificial Neural Networks, edited by C. I. Dagli, et al., New York: ASME Press.

Bartlett, E. B., A. Basu, and K. Kim. 1992. Nuclear Power Plant Diagnostics with Artificial Neural Networks. Final Phase 1 Report to U. S. NRC Subcontract with NETROLOGIC. 
Bartlett, E. B., and R. E. Uhrig. 1992a. A Self-Optimizing Stochastic Dynamic Node Learning Algorithm for Layered Neural Networks. Proceedings of WNN-AIND-92, Auburn University.

Bartlett, E. B., and R. E. Uhrig. 1992b. Nuclear Power Plant Status Diagnostics Using An Artificial Neural Network. Nuclear Technology 97: No. 3, 272-81.

Bartlett, E. B., and R. E. Uhrig. 1991a. A Self-Optimizing Stochastic Dynamic Node Learning Algorithm for Layered Neural Networks. Proceedings of the IEEE INNS International Joint Conference of Neural Networks 2:A947.

Bartlett, E. B., and R. E. Uhrig. 1991b. Nuclear Power Plant Status Diagnostics Using Artificial Neural Networks. Proceedings of the American Nuclear Society Meeting on Frontiers in Innovative Computing for the Nuclear Industry: 655-53.

Basu, A. 1992. Nuclear Power Plant Status Diagnostics Using a Neural Network with Dynamic Node Architecture. M.S. Thesis, Iowa State University.

Bornholt, S., and D. Graudenz. 1992. General Asymmetric Neural Networks, and Structure Design by Genetic Algorithms. Neural Networks 5: No. 2, 327-334.

Caudill, M. 1991. Avoiding the Great Backpropagation Trap. AI Expert July: 29-35.

Caudill, M. 1988. Neural Networks Primer, Part 2. AI Expert Feb.: 55-61.

Chen, R:, and P. Mars. 1990. Step-sizer Variation Methods for Accelerating the Backpropagation Algorithm. in IJCNN-90. Washington, D.C.: Lawrence Erlbaum.

Eaton, H. A. C., and T. L. Olivier. 1992. Learning Coefficient Dependence on Training Set Size. Neural Networks 5: No. 2, 283-88.

Frarey, J. L., D. S. Wilson, N. J. Peterson, and J. A. Bartlett. 1984. An Expert System For On-Line Machinery Diagnostics. Shaker Research Corporation, Final Report.

Gallant, S. I. 1990. A Connectionist Learning Algorithm with Provable Generalization and Scaling Bounds. Neural Networks 3:191-201.

Gould, J. 1991a. Malfunction Cause and Effects Report, Task No. 06000004. Cedar Rapids, IA, Duane Arnold Energy Center.

Gould, J. 1991b. Updated Description of Initiating Events, Task No. 04000103. Cedar Rapids, IA, Duane Arnold Energy Center. 
Hecht-Nielsen, R. 1989. Theory of the Backpropagation Neural Network. IJCNN International Joint Conference on Neural Networks 1:593-60.5.

Hecht-Nielsen, R. 1987. Kolmogorov's Mapping Neural Network Existence Theorem. IJCNN International Conference on Neural Networks 2:11-14.

Hirose, Y., K. Yamashita, and S. Hijiya 1991. Backpropagation Algorithm Which Varies the Number of Hidden Units. Neural Networks 4:61-66.

Hopcroft, J. E. 1984. Turning Machines. Scientific American 250: No. 5, 86-98.

Hyvarinen, L. P. 1970. Information Theory for Systems Engineers. New York: Springer-Verlag.

Ikonomopoulos, A., R. E. Uhrig, and L. Tsoukalas 1991. A Hybrid Neural Network-Fuzzy Logic Approach to Nuclear Power Plant Transient Identification. AI 91 Frontiers in Innovative Computing for the Nuclear Industry. Jackson, WY: 217-226.

Ishikawa, M. 1989. A Structural Learning Algorithm with Forgetting of Link Weights. IJCNN International Conference on Neural Networks 2:626.

Jacobs, R. A. 1988. Increased Rates of Convergence Through Learning Rate Adaption. Neural Networks 1:4.

James, T., and D. Rogers. 1992. Data Provided from San Onofre Nuclear Generating Station.

Judd, J. S. 1990. Neural Network Design and the Complexity of Learning. Cambridge, Mass.: MIT Press.

Judd, J. S. 1987. Learning in Networks is Hard. IEEE First International Conference on Neural Networks 2:685-92.

Kalos, M. H., and P. A. Whitlock. 1986. Monte Carlo Methods, Vol. 1: Basics. New York: John Wiley \& Sons.

Kardos, C. 1991. DAEC Process Computer Points List. Cedar Rapids, IA: Duane Arnold Energy Center.

Karnin, E. D. 1990. A Simple Procedure for Pruning Backpropagation Trained Neural Networks. IEEE Transactions on Neural Networks 1: No. 2.

Kerr, J. P. 1992. The Parallel Implementation of a Backpropagation Neural Network 
and its Applicability to SPECT Image Reconstruction. M.S. Thesis, Iowa State University.

Kerr, J. P., and E. B. Bartlett. 1992. SPECT Reconstruction Using a Backpropagation Neural Network Implemented on a Massively Parallel SIMD Computer. Proceedings of the Fifth Computer-Based Medical Systems Symposium, Los Alamitos, CA: IEEE Computer Society Press.

Kim, K. 1992. An Artificial Neural Network Fault-diagnostic Adviser For a Nuclear Power Plant with Error Prediction. M.S. Thesis, Iowa State University.

Kirkpatrick, S., C. D. Gelatt, JR. and M. P. Vecchi. 1983. Optimization by Simulated Annealing. Science 220:671-80.

Kruschke, J. K. 1989. Improving Generalization in Backpropagation Networks with Distributed Bottlenecks. IJCNN International Joint Conference on Neural Networks 1:443-47.

Kullback, S. 1959. Information Theory and Statistics. New York: John Wiley \& Sons.

Lanc, T. L. 1991. The Importance of Input Variables to a Neural Network Fault-Diagnostic System For Nuclear Power Plants. M. S. Thesis, Iowa State University.

Leitmann, G. (ed.). 1967. Topics in Optimization. New York: Academic Press.

Li, K. C. 1985. From Stein's Unbiased Risk Estimates to the Method of Generalized Cross Validation. The Annals of Statistics 13: No. 4, 1352-77.

Lippmann, R. P. 1987. An Introduction to Computing with Neural Nets. IEEE Acoustics Speech and Signal Processing Magazine 4:4-22.

Matsuba, I. 1989. Optimal Simulated Annealing Method and Its Application to Combinatorial Problems. IJCNN International Joint Conference on Neural Netu'orks 1:541-46.

Matyas, J. 1965. Random Optimization. Automation and Remote Control 26:246-53.

Maxwell, T., C. L. Giles, and Y. C. Lee. 1987. Generalization in Neural Networks: The Contiguity Problem. IEEE First International Conference on Neural. Networks 2:41-46.

McInerney, J. M., K. G. Haines, S. Biafore, and R. Hecht-Nielsen 1989. Backpropa- 
gation Error Surfaces Can Have a Local Minima. IJCNN International Joint Conference on Neural Networks 2:627.

Metropolis, N., A. W. Rosenbluth, M. N. Rosenbluth, A. H. Teller, and

E. Teller. 1953. Equations of State Calculations by Fast Computing Machine.

J. Chem. Phys. 21:1087-91.

Minai, A. A., and R. D. Williams. 1990. Backpropagation Heuristics: A Study of the Extended Delta-Bar-Delta Algorithm. in Proceedings of IJCNN, edited by M. Caudill. Piscataway, NJ: IEEE Press.

Musavi, M. T., A. Rajavelu, S. Sahai, and J. Zhao. 1988. Analysis and Generalization of Backpropagation in Neural Networks. Neural Networks 1: Suppl. 1, 118.

Papadimitriou, C. H., and K. Steiglitz. 1982. Combinatorial Optimization: Algorithms and Complexity. Englewood Cliffs, NJ: Prentice Hall.

Press, W. H., B. P. Flannery, S. A. Teukolsky, and W. T. Vetterling. 1986. Numerical Recipes: The Art of Scientific Computing. New York: Cambridge Univ. Press.

Rigler, A. K., J. M. Irvine, and T. P. Vogl. 1991. Rescaling of Variables in Backpropagation Learning. Neural Networks 4:225-29.

Rubinstein, R. Y. 1986. Monte Carlo Optimization, Simulation, and Sensitivity of Queueing Networks. New York: John Wiley \& Sons.

Rumelhart, D. E., G. E. Hinton, and R. J. Williams. 1986. Learning Internal Representation by Error Propagation. Parallel Distributed Processing, edited by D. E. Rumelhart, et al., Cambridge, Mass: MIT Press.

Shannon, C. E., and W. Weaver. 1971. The Mathematical Theory of Communication. Urbana, IL: Univ. of Illinois Press.

Stone, M. 1977. Asymptotics For and Against Cross-Validation. Biometrika 64: No. $1,29-35$.

Tishby, N., and E. Levin. 1989. Consistent Inference of Probabilities in Layered Networks: Predictions and Generalizations. IJCNN International Joint Conference on Neural Networks, 2:403-409.

Tveter, D. 1991. Getting a Fast Break with Backprop. AI Expert. July: 36-43. 
Uhrig, R. 1990. Enhancing Nuclear Power Plant Performance Through The Use Of Artificial Intelligence. Annual Report to DOE.

Updated Final Safety Analysis Report, 1984. Chapter 15. Cedar Rapids, IA: Duane Arnold Energy Center.

Upadhyaya, B. R., and E. Eryurek. 1992. Application of Neural Networks for Sensor Validation and Plant Monitoring. Nuclear Technology 97.

Vaario, J., and S. Ohsuga. 1991. Adaptive Neural Architectures Through Growth Control. Intelligent Engineering Systems Through Artificial Neural Networks, edited by C. I. Dagli, et al. New York: ASME Press.

Vest, D., and D. Berchenbriter. 1991. Discussions and data collection. Duane Arnold Energy Cienter. Palo, Iowa.

Vogl, T. P. et al. 1988. Accelerating the Convergence of the Backpropagation Method. Biological Cybernetics, 59.

Watanabe, S. 1969. Knowing and Guessing: A Quantitative Study of Inference and Information. New York: John Wiley and Sons.

Watrous, R. L. 1987. Learning Algorithms for Connectionist Networks: Applied Gradient Methods of Nonlinear Optimization. IEEE First International Conference on Neural Networks, 2:619-628.

Weigend, A. S., D. E. Rumelhart, and B. A. Huberman. 1991. Generalization by Weight Elimination Applied to Currency Exchange Rate Prediction. IJCNN International Conference on Neural Networks 1:837-841.

Werbos, P. J. 1989. Backpropagation and Neural Control: A Review and Prospectus. IJCNN International Joint Conference on Neural Networks 1:209-216.

Widrow, B., and M. A. Lehr. 1990. 30 Years of Adaptive Neural Networks: Perceptron, Madaline, and Backpropagation. Proceedings of IEEE 78: No. 9, 1415-41.

Wilson, A. G., J. D. Coelho, S. M. Macgill, and H. C. W. L. Williams. 1981. Optimization in Locational and Transport Analysis. New York: John Wiley and Sons.

Wolpert, D. H. 1992. Stacked Generalization. Neural Network 5:241-259. 
Wolpert. D. H. 1990a. A Mathematical Theory of Generalization Part I. Complex Systems 4:151-200.

Wolpert. D. H. 1990b. A Mathematical Theory of Generalization Part II. Complex Systems 4:200-249.

Won, Y., and R. L. Pimmel. 1991. A Comparison of Connection Pruning Algorithms with Back-Propagation. Intelligent Engineering Systems Through Artificial Neural Networks, edited by C. I. Dagli et al. New York: ASME Press. 11-16.3.2. 


\section{Glossary of Terms}

Accidents: A severe instability in nuclear power plant conditions that might include injury of the personnel, damage of hardware or a release of radioactive materials.

Activation or transfer function: Usually a nonlinear function used in nodes in ANNs that perform computations. The input to the function is the weighted sum of all nodes' inputs. The network passes the output of the function to other nodes or to the outside environment as an output of the network. Examples of these functions are the sigmoidal, the hard limiter, the identity function.

Artificial neural network (ANN): A computing system made up of simple, highly interconnected processing elements which process information.

Artificial neural network architecture: The number of layers and nodes, and the way these nodes are interconnected via weights.

Convergence of weights: The modification of weights during training in order to find a final stable set of values that will give the desired outputs. Backpropagation training algorithm employs this type of convergence.

Generalization: The ability of the network to classify a given novel input based on its relation with known stored knowledge.

Generalizer: A mathematical algorithm that can infer a parent function from given examples (training set). An ANN is one example of a generalizer.

Hidden layer: A set of hidden nodes.

Hidden nodes: Computational elements that do not directly receive data, or send data to, the ANNs external environment.

Input nodes: Elements that receive information from the external environment. Typically they perform no computations.

Learning (training or teaching the network): A mathematical rule for adjusting the interneuron connection weights in order to optimize the ANN performance.

Mapping by a network: Finding the set(s) of weights that will relate a set of inputs with a set of desired outputs.

Nodes (processing or computational elements): The computational elements that make up an ANN. In their typical form they sum their weighted inputs and pass the result through a nonlinearity function.

Output nodes: Computational elements that are capable of sending signals to the network's external environment.

Recall set: A set of patterns which the trained network is used to classify. 
RMS error: The root mean square of the differences of the actual and the desired outputs of the network.

Similar transients: Transients at nuclear power plants that cause groups of the measuring instruments to show similar responses for different instabilities.

Stacked generalization: A technique that can predict the error in the output of a single generalizer.

Supervised learning: Learning that uses information available outside the network to make adjustments in weights, number of times the data is presented, and when to terminate the learning process.

Training algorithm: A mathematical rule for adjusting the interneuron connection weights in order to optimize the ANN performance by providing convergence of weights.

Training patterns: A set the values of the networks inputs and their associated outputs.

Training set: A set of input patterns and their corresponding outputs.

Transient: A severe deviation from the normal operating conditions of nuclear power plants.

Unsupervised learning or self organization: A process that relies only on information available in the input patterns to modify the parameters of the network. Unlike the supervised learning, the outputs in the unsupervised learning scheme are not supplied to the network.

Weights: The interconnections between the nodes of the network. Weights can be real, integers, and complex numbers. 


\section{ISU/DAEC Plant Trip Log Book}

This section is a copy of the daily records of the trips made by the project members to the Duane Arnold energy center 
ISU/DAEC PLANT TRIP

LOG BOOK

Date : April 1991 at ISU
Depart ISU :
Arrive DAEC :
Depart DAEC :
Arrive ISU :

ACCOMPLISHMENTS :

Discussions were held betbeen Don Vest from DAEC and students and faculty of the nuclear engineering program. Topics covered were plant process variables, and transient selection. The discussions lasted for about tro and a half hours.

Present at the meeting were (from ISU):

Dr. E.B. Bartlett

Dr. R.A. Danof sky

John Adams

Anujit Basu

Serhat Alten

Terry Lanc

Keehoon Kim

The list of plant variables and the list of operational transients rere reviewed. A tentative selection was made of the important variables and transients. A brief outline was presented about the capabilitios and restrictions of the operator training simulator at the DAEC training facility. 


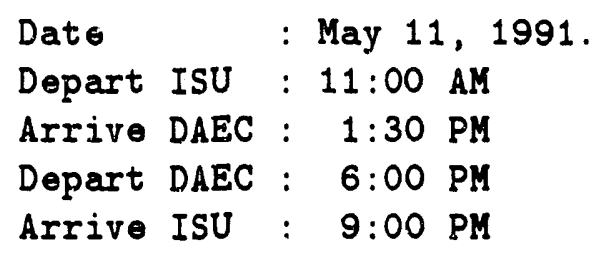

\section{ACCOMPLISHMENTS :}

Discussions vere held with Don Vest and plant personnel. Topics covered included logistics and data collection strategies. A tour of the training facility and the simulator was also carried out.

This trip ras mainly intended to establish contact rith the personnel at the DAEC operator training center. 


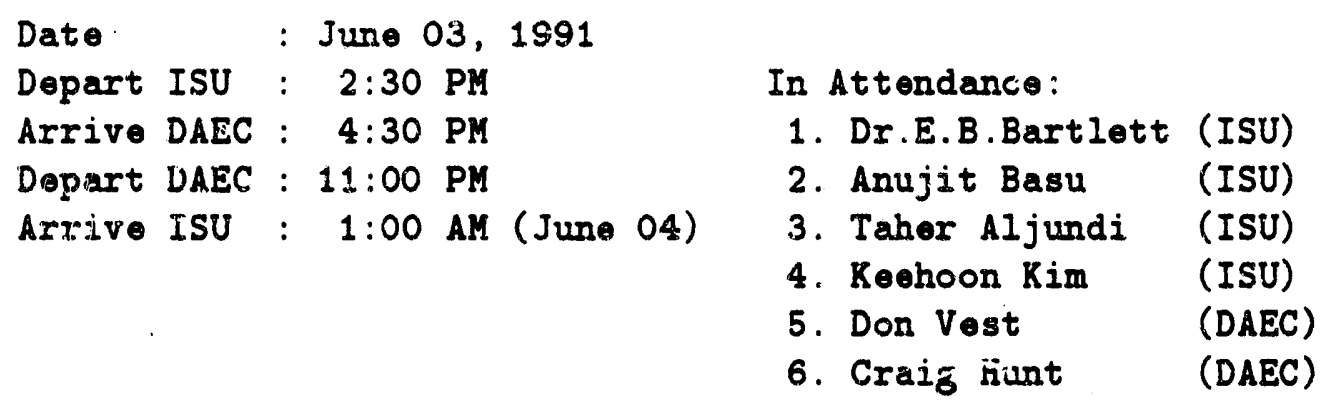

ACCOMPLISHENTS :

Discussions were held with Don Vest and Craig Hunt of DAEC on plant process rariables to be monitored during simulation for transients of geveral interest. A list of 83 variables vere chosen and put in a control file for trending during simulation.

Transiont Simulated : RR15A

Recirculation loop ' $A$ ' rupture

(Design-basis LOCA, 100\% double ended shear - loop A)

Length of simulation : 5 minutes

File Name : RR15A.DAT 


Date : July 20, 1991
Depart ISU : $7: 30 \mathrm{AM}$
Arrive DAEC : $10: 45 \mathrm{AM}$
Depart DAEC : $7: 00 \mathrm{PM}$
Arrive ISU : $9: 00 \mathrm{PM}$

$\begin{array}{ll}\text { In Attendance: } & \\ \text { 1. Dr.E.B.Bartlett } & \text { (ISU) } \\ \text { 2. Terry Lanc } & \text { (ISU) } \\ \text { 3. Anujit Basu } & \text { (ISU) } \\ \text { 4. Keehoon Kim } & \text { (ISU) } \\ \text { 5. Toher Aljundi } & \text { (ISU) } \\ \text { 6. John Kerr } & \text { (ISU) } \\ \text { 7. Don Vest } & \text { (DAEC) } \\ \text { 8. Craig Hunt } & \text { (DAEC) }\end{array}$

\section{ACCOMPLISHMENTS :}

Further discussions were held with Don Vest and Craig Hunt on plant process variables to be monitored for transients of general interest. The 83 variables list from the previous trip vas expanded to 97 variables. Tro variables from the previous list, which were judged to be unimportant, were dropped. The nev list also contained a boolean transient true-false svitch vhich indicated the onset of the transient.

Transients Simulated : MS14 and FW17

MS14 : Loss of feedrater heating to both feedrater heaters $6 \mathrm{~A}$ and $6 \dot{\mathrm{B}}$.

This transient is caused due to loss of extraction steam.

Initial condition is IC24, $100 \%$ porer, Middle of Fuel Cycle (MOC).

Run Time : 5 min $46 \mathrm{sec}$ including $17 \mathrm{sec}$ of normal data

File name : MS14_6.DAT

FW17 : Main feedwater line broak inside primary containment. $100 \%$ break in feedrater line ' $A$ '. Initial condition is IC24, $100 \%$ porer, MOC.

Run Time : 5 min $16 \mathrm{sec}$ including $11 \mathrm{sec}$ of normal data

File name : FW17A.DAT 


\section{ISU/DAEC PLANT TRIP \\ LOG BOOK}

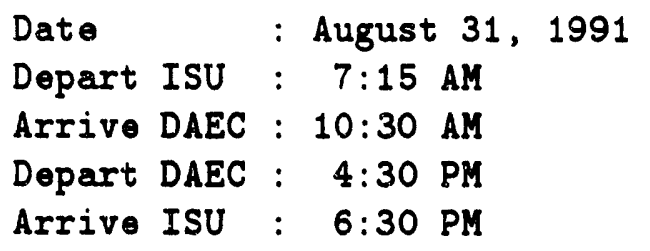

$\begin{array}{ll}\text { In Attendance: } & \\ \text { 1. Dr.E.B.Bartlett } & \text { (ISU) } \\ \text { 2. Anujit Basu } & \text { (ISU) } \\ \text { 3. Terry Lanc } & \text { (ISU) } \\ \text { 4. Don Vest } & \text { (DAEC) } \\ \text { 5. Craig Hunt } & \text { (DAEC) }\end{array}$

ACCOMPLISHMENTS :

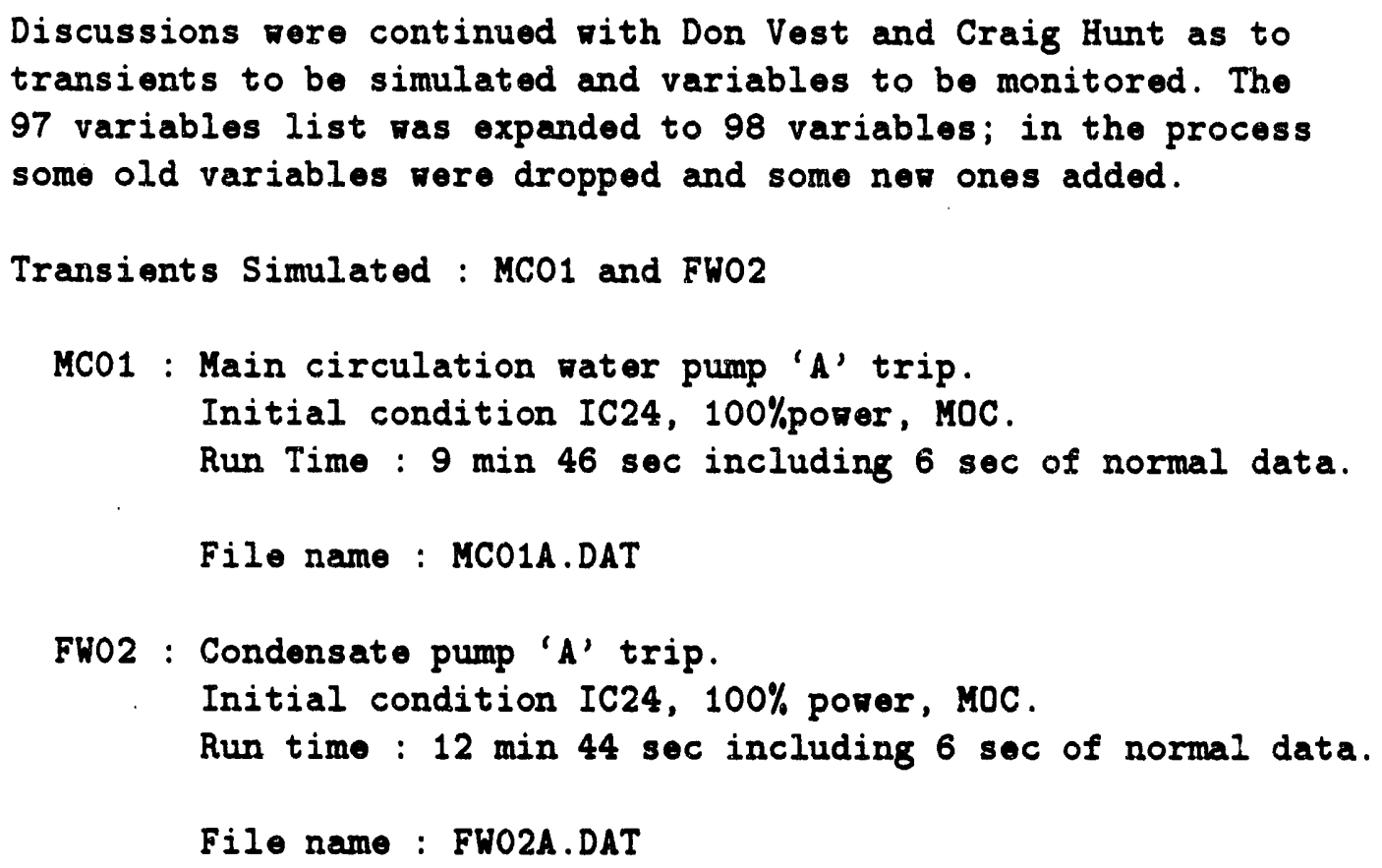




\section{ISU/DAEC PLANT TRIP LOG BOOK}

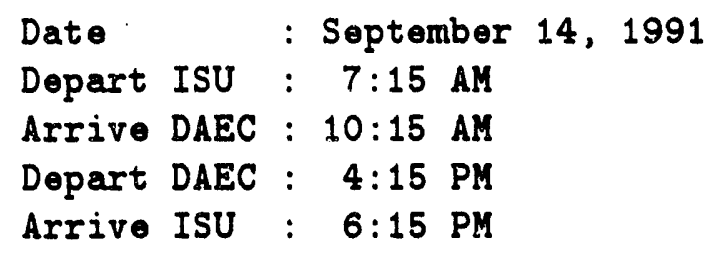
In Attendance :
1. Dr.E.B.Bartlett
2. Anujit Basu
3. Chalapathy Dhanwada (ISU)
4. Terry Lanc
5. Don Vest
(DAEC)

\section{ACCOMPLISHMENTS :}

Discussions were held with Don Vest on ATWS and variables being monitored. In vien of the particular transients to be simulated this day, two more booleans were added, making 100 variables. The softrare on the simulator at the DAEC facility currently has the capability to trend only 100 variables during a simulation.

Transients Simulated : RP05

The first transient simulated was the main turbine trip together with failure to scram and failure of alternate rod injection (ARI). No operator action was involved. Initial condition was IC24, 100\% porer, MOC. The actual plant, as well as the simulator, vould have automatically scrammed after the initiation of this transiont failing which, ARI would initiate, safely shutting down the reactor. The two booleans introduced were the used to supress both of these safety features by holding thoir values at 0.0 .

\section{Filo name : RP5ACTC1.DAT}

The second transient simulated was also the main turbine trip together with failure to scram. But in this case ARI does occur. No operator action was involved. Initial condition was IC24, $100 \%$ pover, MOC. The ARI resulted in a slow scram. As the ARI did not need to be over-ridden at this time, the corresponding boolean was removed, and so only 99 variables vere used in this simulation.

File name: RP05TC01.DAT 
Date : September 28, 1991

Depart ISU : 7:00 AM

Arrive DAEC : 10:00 Alf

In Attendance :

Depart DAEC : 3:00 PM

1. Anujit Basu (ISU)

Arrive ISU : 5:00 PM

2. Terry Lanc

(ISU)

3. Don Vest

(DAEC)

ACCOMPLISHMENTS :

Discussions vere held with Don Vest on various initial conditions. The proposed adviser will be able to detect both normal and abnormal conditions. So it is important to collect data concerning various normal conditions too. It ras decided to simulate all the standard initial conditions available on the . simulator, and to follow oach simulation by a spurious scram.

An attempt was made to simulate a condition, but the system was inoperative. No data ras obtained on this trip.

Photographs were taken for publicity of the project. An instructional tour of the simulator complex ras undertaken. 


\section{ISU/DAEC PLANT TRIP \\ LOG BOOK}

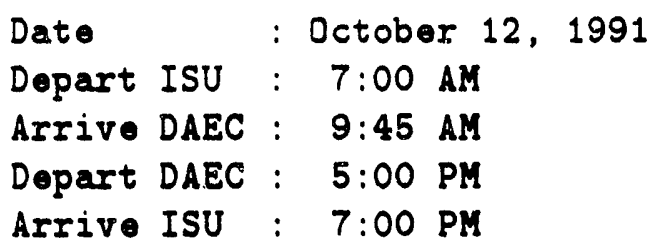

2. Chalapathy Dhanzada (ISU)

3. Taher Aljundi

4. Don Vest (DAEC)

\section{ACCOMPLISHMENTS :}

Tro initial conditions vere simulated with spurious scram.

IC22 : This is 25\% Porer, Beginning of Cycle (BOC) 98 variables tronded.

File name : IC22SCRA.DAT

IC14 : This is 100\% Porer, Beginning of Cyclo (BOC) 98 variables tronded.

File name: IC14SCRA.DAT 


\section{ISU/DAEC PLANT TRIP}

LOG BOOK

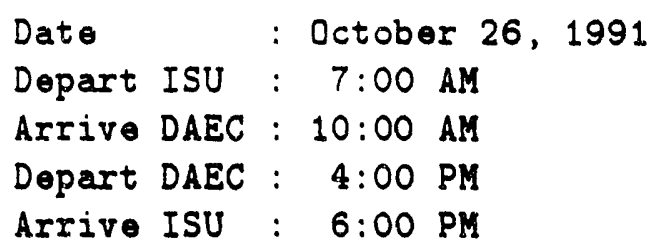

3. Keohoon Kim

4. Don Vest

(DAEC)

\section{ACCOMPLISHMENTS :}

Further initial conditions with spurious scrams were simulated.

IC23 : This is 75\% Power, Beginning of Cycle (BOC) 98 variables trended.

File name : IC23SCRA.DAT

IC20 : This is 100\% Power, End of Cycle (EOC) 98 variables trended.

File name : IC2OSCRA.DAT

IC24 : This is 100\% Power, Middle of Cycle (MOC) 98 variables trended.

Filo name: IC24SCRA.DAT 


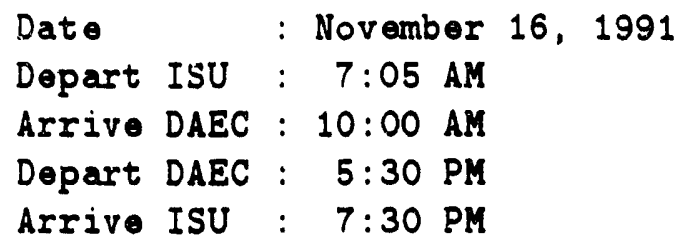

In Attendance:

1. Dr.E.B.Bartlett

2. Anujit Basu

3. Chalapathy Dhanwada (ISU)

4. Terry Lanc

5. Don Vest

ACCOMPLISHMENTS :

Transients Simulated : HPO5 and HPO8

HP05 : High Pressure Coolant Injection (HPCI) steam line break in HPCI room. 100\% severity. Initial condition IC20, $100 \%$ porer, EOC.

Filo name: IC2OKP05.DAT

HP08 : HPCI steam line break in Torus room. 100\% severity. Initial condition IC20, 100\% porer, EOC.

File name : IC2OHP08.DAT

Discussions wer held with Don Vest about anticipated operator action. All provious accidents did not have any operator sction. But during a prolonged transient in a roal plant, tho operator rill bo taking proventive and/or corrective action. The proposed adviser should be able to recognize the transient in spite of such interventions by the operators. For this reason, it was decided to simulate some transients with oporator action.

Transients Simulated : RPO3

RPO3 : Spurious scram with operator action. Initial condition IC20, 100\% porer, EOC. The operators vere not able to successfully control the Reactor Pressur. Vessel (RPV) levels which led to the trip of feed pumps.

File name: IC2OSCR1.DAT 
RPO3 : Spurious scram rith operator action. Initial condition IC20, $100 \%$ pover, EOC. This time the operators vere able to successfully control the RPV lovels to prevent trip of feed pumps.

File name: IC2OSCR2.DAT 
ISU/DAEC PLANT TRIP

LOG BOOK

Date : December 14, 1991

Depart ISU : 7:05 AM

In Attendance:

Arrive DAEC : 10:10 AM

1. Dr.E.B.Bartlett

Depart DAEC : 5:20 AM

2. Anujit Basu

Arrive ISU : 7:30 AM

3. Terry Lanc

4. Taher Aljundi

5. Chalapathy Dhanwada (ISU)

6. Don Vest

7. Dan Berchenbriter

\section{ACCOMPLISHMENTS :}

Discussions rere held with Don Vest and Dan Berchenbriter on agenda for the next several months.

Transients Simulated : CU10

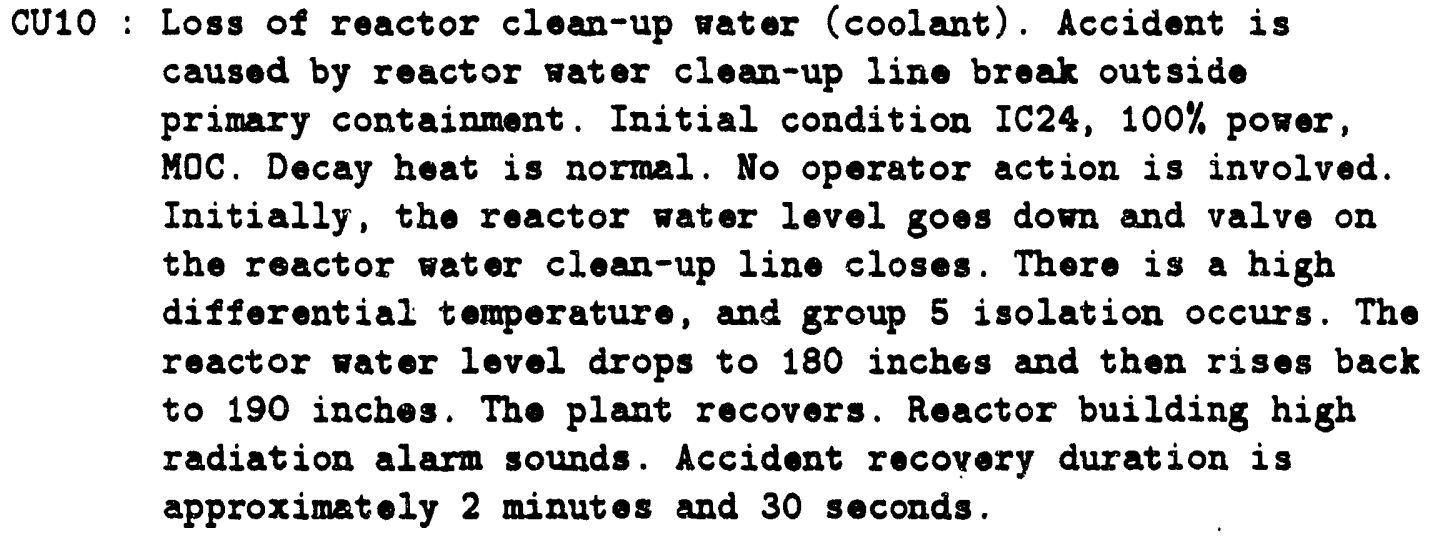
MOC. Decay heat is normal. No operator action is involved. Initially, the reactor water level goes down and valve on the reactor vater clean-up line closes. There is a high differential tomperature, and group 5 isolation occurs. The reactor nater level drops to 180 inches and then rises back to 190 inches. The plant recovers. Reactor building high radiation alarm sounds. Accident recovery duration is approximately 2 minutes and 30 seconds.

File Name : CU10.DAT

Talked about schedule. The next trip was planned on Jan. 18, 1992.

Went on a trip through the plant. Visited the reactor building, the turbine building, the spent fuel storage pool area and the control room. The plant nas boing propared for a rofueling outago. 


\section{ISU/DAEC PLANT TRIP \\ LOG BOOK}

$\begin{array}{lllll}\text { Date } & : \text { December 15, } 1991 & & \\ \text { Depart ISU : } & -- & \text { In Attendance: } \\ \text { Arrive DAEC : } & -- & \text { 1. Don Vest } & \text { (DAEC) } \\ \text { Depart DAEC : } & -- & \text { 2. Dan Berchenbriter (DAEC) } \\ \text { Arrive ISU : } & -- & \end{array}$

ACCOMPLISHMENTS :

The previous accident, loss of reactor clean-up rater (CU10), was repeated. This time, failure of group 5 isolation valves ras added to the scenario. This vork was performed without an ISU cren present, and the data was sent over. 
ISU/DAEC PLANT TRIP

LOG BOOK

Date : January 18, 1992

Depart ISU : 7:00 AM

In Attendance:

Arrivo DAEC : 9:45 AM

1. Taher Aljundi

(ISU)

Depart DAEC : $4: 20$ PM

2. Terry Lanc

Arrive ISU : $6: 30 \mathrm{PM}$

3. Chalapathy Dhanrada (ISU)

4. Dan Berchenbriter

(DAEC)

5. Criag Hunt

(DAEC)

\section{ACCOMPLISHMENTS :}

Discussions vere held about the transients to be simulated. The trend file was modified a bit and nor contained 100 variables.

Transionts Simulated : FW18 and MS19

FW18 : Main feodwater line A break outside primary containment in the ground floor of turbine building. Thick 360 crnck on 16" line, single-ended shear broak. Tro phase flov limits loss. There is loss of pressure in the common line behind the feedvater pumps. This cause the feedvater pumps to trip.

File Name: FW18A.DAT

MS19 : Group 1 isolatica caused by failure of relays. The valves fail closed on both logs A B. Leg A alone vould have resulted in only an alarm sounding. Reactor vessel level drops. Relief valve allows vessel to blow down to torus.

File Name: MS19.DAT

RR30 : This transiont was simulated but data was not collected due to hardware probloms. Soe $\log$ from the next trip for a description of the transient. 
ISU/DAEC PLANT TRIP

LOG BOOK

$\begin{array}{llcll}\text { Date } & \text { February 1, } 1992 & & \\ \text { Depart ISU : } & 6: 55 \mathrm{AM} & \text { In Attendance: } & \\ \text { Arrive DAEC : } 9: 15 \mathrm{AM} & \text { 1. Anujit Basu } & \text { (ISU) } \\ \text { Depart DAEC : } 3: 45 \mathrm{PM} & \text { 2. Chalapathy Dhanrada (ISU) } \\ \text { Arrive ISU : } 5: 45 \mathrm{PM} & \text { 3. Rodney Schuler } & \text { (ISU) } \\ & & \text { 4. Taher Aljundi } & \text { (ISU) } \\ & & \text { 5. Dan Birchenbriter } & \text { (DAEC) } \\ & & \text { 6. Criag Hunt } & \text { (DAEC) }\end{array}$

ACCOMPLISHMENTS :

Transients Simulated : RR3O, MSO3, MSO4, and FWO9

RR30 : Coolant leakage inside primary containment. The simulation was a $100 \%$ double ended shear in a 2 " diameter pipo. This transient is caused by weld failure in the reactor vessel bottom drain pipe. Initial condition IC24, $100 \%$ porer, MOC.

File Name : RR30.DAT

MSO3 : Main steam line (MSL) rupture inside primary containment. Steam line A was selected for the simulation. The break was of 100\% severity, i.e. a double-ended shear in the 20" diameter steam line. This transient is caused by piping failure or flov restriction at the high pressure instrument tap that feed control room monitor stean flow instrumentation. Initial condition IC24, $100 \%$ power MOC.

File Name: MSO3A.DAT

MSO4 : This transient is the same as MSO3 except that it is caused by piping failure at main steam common header. This results in a rupture outside the primary containment at the tube inlet header.

File Namo : MSO4A.DAT

FW09 : Reactor feedwater purn trip. The simulation was a trip of pump A. This transient is caused by a spurious trip signal. Initial condition IC24, $100 \%$ porer, MOC. This malfunction 
causes the selected main foedwater pump to trip in standby due to a spurious trip signal. The pump motor breaker will trip open and annunciation vill activate. The pump pressure and flor will decrease and the recirculation valve, if open, will close.

File Name: FW19A.DAT 


\section{ISTJ/DAEC PLANT TRIP \\ LOG BOOK}

Date : Fobruary 15, 1992

Depart ISU : 7:00 AM

Arrive DAEC : 10:00 AM

In Attendance:

1. Anujit Basu

Depart DAEC : $2: 30 \mathrm{PM}$

2. Taher Aljundi

Arrive ISU : $4: 30 \mathrm{PM}$

3. Dan Berchenbriter (DAEC)

4. Criag Hunt

(DAEC)

\section{ACCOMPLISGMENTS :}

Transionts Simulatod: MSO2, FH12, and MS32

MSO2 : Steam loak anside primary containment. This transient is caused by main steam leak at RCIC line elbor. Initial condition IC24, 100\% porer, MOC. Main steam flow rill increas are reactor pressure illl decrease. High drynoll pressure at 2 PSIG $\mathbf{\text { will }}$ trif the reactor.

File Name : :502A.DAT

FW12 : Feodrater regulator valve cortroller failure. This transiont is caused by the failure of the controller of the fordvater regulator valvo, causing the valve to be stuck at a particular position. Tro simulations were carried out, one for the valve stuck fully open and the other for the valve stuck fully closed. Both simulations had initial conditions IC? 4 , 100\% power, MOC.

(a) High : This is the scenerio when the valve is stuck open all the ray.

File Name: FW12H.DAT

(b) Lon : This is the scenario when the valve is stuck in the fully closed position.

Filo Namo: FW12L.DAT

MS32 : Spurious group 7 isolation. Short circuit causes rolay CR4841 to rip close. Closure will cause the Iryvell to onorgize. This causes the group 7 isolation

valve to trip close. Closure will cause the dryvell to 
loose cooling; dryoell temperature and pressure will increase. At 2 PSIG dryøell pressure, the reactor vill scram, Emergency Core Cooling System (ECCS) vill be initiated and group $2,3,4$, and 5 isolation $\nabla i 11$ be initiated. Initial condition IC24, 100\% porer, MOC.

File Name: MS32.DAT 


\section{ISU/DAEC PLANT TRIP \\ LOG BOOK}

Date : February 29, 1992
Depart ISU : $7: 00$ AM
Arrive DAEC : $9: 20$ AM
Depart DAEC : $2: 05$ PM
Arrive ISU : $4: 15 \mathrm{PM}$
In Attendance:
1. Anujit Basu
2. Tahei Aljundi
3. Dan Berchenbriter (DAEC)
4. Criag Hunt
(DAEC)

\section{ACCOMPLISHMENTS :}

Transients Simulated : RX01, RR10, TCO2, and FWO4

RX01 : Fuel cladding failure. Simulation was for $100 \%$ severity which ras 30\% fuel clad damage. As the damage increases, the amount of activity in the reactor recirculation loop and the main steam system vill increase. This activity aill propagate throughout the plant and the radiation monitoring system vill indicate the same. At $100 \%$ severity, the main steam line radiation monitors will cause main steam isolation and reactor scram at sot point. Initial condition IC24, $100 \%$ porer, MOC.

File Name : RX01.DAT

RR10 : Recirculation pump speed feedback signal failure. For the simulation, $100 \%$ of the feodback signal to pump A vas lost. This caused fluctuations in the steam flor and porer generated. Initial condition IC24, $100 \%$ poøer, MOC.

File Name : RR1OA.DAT

TCO2 : Emergency Hydraulic Cooling (EHC) system hydraulic pump trip. Both pumps A B rere mado to trip in tho simulation. The EHC pumps fail and trip on ovorload. Turbine trip follors as the EHC systom pressure roaches 1300 PSIG. Initial condition IC24, 100\% porer, MOC.

File Name : TCO2.DAT

FW04 : Condensate filter demin resin injection. At 100\% severity, 
(a) The transient was simulated at $60 \%$ severity. File Name : FW17A_2.DAT

(b) The transient was simulated at $30 \%$ severity.

File Name: FW17A_3.DAT 
Dato : April 25, 1992

Depart ISU : 7:20 AM

In Attendance:

Arrive DAEC : $10: 10$ AM

1. Anujit Basu

2. Taher Aljundi

Depart DAEC : 2:15 PM

3. Chalapathy Dhanwada

Arrive ISU : 4:15 PM

4. Dan Berchenbriter

5. Criag Hunt

\section{ACCOMPLISHMENTS :}

Further simulation were carriod out for proviously simulated transients but at different severities.

Transients Simulated : HPO5 and HPO8

HPO5 : For a description of this transient, see ontry dated November 16, 1991. Initial condition IC20, 100\% porer, EOC.

(a) The transiont was simulated at $60 \%$ severity.

File Name: HPO5_2.DAT

(b) The transient ras simulated at 30\% soverity.

Fil. Name : HP05_3.DAT

HPO8 : For a description of this transiont, see ontry dated November 16, 1991. Initial condition IC20, 100\% power, EOC.

(a) The transient ras simulated at $60 \%$ severity.

File Name : HP08_2.DAT

(b) The transient was simulated at $30 \%$ severity.

File Name : HPO8_3.DAT 


\section{ISU/DAEC PLANT TRIP \\ LOG BOOK}

$\begin{array}{ll}\text { Date } & \text { March } 14,1992 \\ \text { Depart ISU }: & 7: 10 \mathrm{AM} \\ \text { Arrive DAEC : } 9: 40 \mathrm{AM} \\ \text { Depart DAEC : } 2: 20 \mathrm{PM} \\ \text { Arrive ISU : } 4: 30 \mathrm{PM}\end{array}$
In Attendance:
1. Anujit Basu
(ISU)
2. Taher Aljundi
(ISU)
3. Rodney Schuler
4. Chalapathy Dhanrada (ISU)
5. Dan Berchenbriter
(DAEC)

\section{ACCOMPL ISHMENTS :}

Talked to Dan Berchenbriter about present variables being monitored and addition to that list in the noar future. Also talked about "similar" accidents. Reviered goals and progress to date.

The simulator ras down for upgradation. Took an educational tour of the plant. The plant ras down for a refueling outage at the time. 
Date : March 28, 1992

Depart ISU : $7: 15 \mathrm{AM}$

In Attendance:

Arrive DAEC : $9: 50$ AM

1. Anujit Basu

Depart DAEC : 2:00 PH

2. Taher Aljundi

(ISU)

Arrive ISU : 4:00 PM

3. Dan Berchenbriter (DAEC)

4. Craig Hunt

(DAEC)

ACCOMPLISHMENTS :

On this trip, some of the earlier transients were repeated at different saverities. This is because the adviser rould be expected to recognize a transiont irrespective of it's soverity. It is expected that if severities of $100 \%, 60 \%$ and $30 \%$ are used to train the adviser, it will be able to generalize the transient over the entire range of severities.

Transients Simulated : RR15 and FW17

RR15 : For a description of this transient, seo entry dated June 3, 1991.

(a) The transient at $100 \%$ soverity is repeated as the variables boing monitored had changed since the last time this transiont had boen simulated.

File Name: RR15A_1.DAT

(b) The transiont was simulated at $60 \%$ severity.

File Name : RR15A_2.DAT

(c) The transiont was simulated at 30\% soverity. Filo Name : RR15A_3.DAT

FW17 : For a description of this transient, seo ontry dated July 20, 1991. 


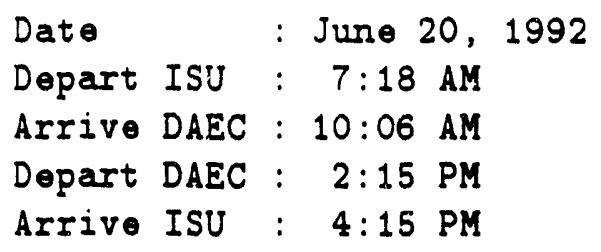

In Attendance:

1. Taher Aljundi

2. Chalapathy Dhanwada (ISU)

3. Criag Hunt

\section{ACCOMPLISHMENTS :}

Further simulation vere carried out for previously simulated transients but at different severities.

Transients Simulated : FW18, MSO3 and RR3O

FW18 : For a description of this transient, seo entry dated January 18, 1992. Initial condition IC24, 100\% porer, MOC.
(a) The transient was simulated at $60 \%$ severity.
Filo Name: FW18A_2.DAT
(b) The transient was simulated at $30 \%$ severity.
File Name : FW18A_3.DAT
MS03 : For a description of this transient, seo ontry dated February 1, 1992. Initial condition IC24, 100\% pover, MOC.
(a) The transient was simulated at $60 \%$ severity.
Filo Name: MSO3A_2.DAT
(b) The transient ras simulated at $30 \%$ severity.
File Name : MSO3A_3.DAT


RR30 : For a description of this transient, see entry dated February 1, 1992. Initial condition IC24, 100\% porer, MOC.

(a) The transient was simulated at $60 \%$ severity.

File Name : RR30_2.DAT 


\section{ISU/DAEC PLANT TRIP \\ LOG BOOK}

$\begin{array}{ll}\text { Date } & \text { July } 18,1992 \\ \text { Depart ISU }: & 7: 00 \mathrm{AM} \\ \text { Arrive DAEC }: & 10: 05 \mathrm{AM} \\ \text { Depart DAEC : } & 2: 10 \mathrm{PM} \\ \text { Arrive ISU : } & 4: 10 \mathrm{PM}\end{array}$

In Attendance:

1. Anujit Basu

2. Chalapathy Dhanrada (ISU)

3. Criag Hunt
(ISU)

(DAEC)

\section{ACCOMPLISHMENTS :}

Discussions were held with Craig Hunt about steady states, system noise, errors in the data over the first fer seconds of simulation, etc.

--> Steady state variations are due to computations based on physics, and is not o random or computer generated noise..

--) The only simulated noise is on the meter readouts.

--) Boiling noise is not built into the system and so is not simulated.

Further simulation vere carried out for previously simulated transients but at different severities.

Transients Simulated : RR3O, MSO2 and MSO4.
RR30 : For a description of this transient, seo entry dated February. 1, 1992. Initial condition IC24, 100\% porer, MOC.

(a) The transient was simulated at $30 \%$ severity.

File Name : RR30_3.DAT

MSO2 : For a description of this transient, seo entry dated Fobruary 15, 1992. Initial condition IC24, 100\% porer, MOC.

(a) The transient was simulated at $60 \%$ severity.

File Name : MSO2_2.DAT

(b) The transient pas simulated at $30 \%$ severity. 
File Name: MSO2_3.DAT

MSO4 : For a description of this transient, seo entry dated February 1, 1992. Initial condition IC24, 100\% pover, MOC.

(a) The transient ras simulated at $60 \%$ severity.

Fil. Name: MSO4A_2.DAT

(b) The transient was simulated at $30 \%$ soverity.

Filo Name : MSO4A_3.DAT 


\section{ISU/DAEC PLANT TRIP \\ LOG BOOK}
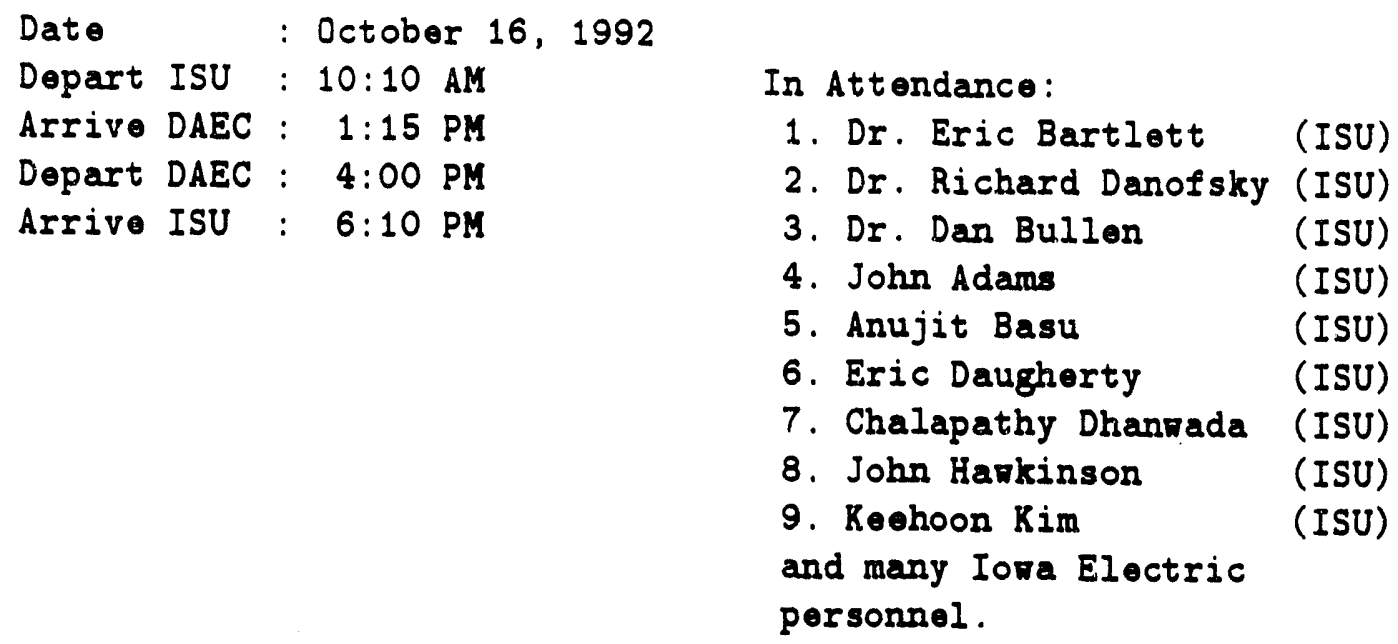

ACCOMPLISHMENTS :

This trip was mainly an effort to update the oxecutives and plant personnel about the advances being made on this project. This ras important as Iora Electric Light and Porer company is donating substantially to the project by way of simulator time and simulator personnel overtime.

The main agenda of the trip was a presentation by Anujit Basu. This presentation was an account of Basu's Master's thesis. Anujit Basu finished his Master's in August 1992, and is supported by the DOE grant.

The attondees were also introduced to other projects being investigated by faculty and graduate students in the Nuclear Engineoring program at Iowa State University. 
Date : October 23, 1992

Depart ISU : 7:00 AM In Attendance:

Arrive DAEC : 10:05 AM 1. Anujit Basu

Depart DAEC : 2:10 PM 2. Chalapathy Dhanrada (ISU)

Arrive ISU : 4:10 PM 3. Criag Hunt

ACCOMPLISHMENTS :

Discussions with Craig Hunt about the work to be done over the next fev trips. Also discussed about the distinct transients that caused almost identical offects in the various plant paramoters, and how noural netrorks can identify and differentiate these transients.

Transients Simulated : RXO1 and FW04.

RX01 : For a description of this transiont, see ontry dated Fobruary 29, 1992. Initial condition IC24, 100\% porer, MOC.

(a) The transient ras simulated at $60 \%$ sevority.

File Name : RXO1_2.DAT

(b) The transient was simulated at $30 \%$ severity.

File Name : RX01_3.DAT

Note: The wait time in the batch file C.ISUBAT was changed to 120 frames (about $10 \mathrm{sec}$ ). This gives us a little more normal operating time at the beginning of each simulation.

FW04 : For a description of this transient, seo ontry dated Fobruary 29, 1992. Initial condition IC24, 100\% porer, MOC.

(a) The transiont ras simulated at $60 \%$ soverity.

File Name: FWO4_2.DAT 
(b) The transient was simulated at $30 \%$ severity.

File Name: FWO4_3.DAT 


\section{Description of Collected Malfunction Data}

This section contains the descriptions of the various malfunctions that were simulated at the DAEC sim"lator. These descriptions were provided by the DAEC simulator personnel (Gould 1987a \& 1987b). 


\section{MALFUNCTION CU10}

C'oolant leakage outside the primary containment. Severity is variable: $\mathrm{O} \cdot 100 \%=$ O - 4" diameter pipe (single-ended shear). Reactor Water Cleanup System (RWCS) expansion joint failure at $100 \%$ power. This malfunction will cause a leak to occur at the cleanup system inlet expansion joint. The leak rate will be determined by the specified severity.

A low-severity leak will cause the ambient temperature to increase and will actuate the leak detection system isolation and annunciation at setpoint. As severity increases the leak detection system will be actuated by area temp/temp differentials. Prior to isolation, a brief decrease in pressure and flow will indicate mass loss on the inlet to the RWCS pumps. The pump discharge pressure will decrease proportional to leak severity and the cleanup system return temperature will decrease. When the reactor water cleanup system leak detection system activates, motor valves (MO-2700, 2701, 2740) will close, and the RWCU pumps will trip. The motor valve position indicating lights will indicate the valves are closed, and the RWCU pump motor breaker will indicate the breaker is open. The RWCU leak will cause the system pressure to decrease to atmospheric pressure. The system flow will decrease resulting in appropriate annunciation. The cleanup holding pumps will start automatically from the system low flow. System temperature will slowly decay to ambient, and the heat load on Reactor Building Closed Coolant Water (RBCCW) will decrease rapidly.

Malfunction removal will restore the effected components to normal. Operator action may be required to restore the plant to normal.

Datafiles:

culO.dat: Accident is reactor water cleanup line break outside primary containment $100 \%$ break. IC24, 100\% power, Middle of Cycle (MOC). Malfunction is YP:MCU10 at 100\%. Decay heat is normal. No operator action.

culOgp5.dat: Accident is reactor water cleanup line break outside primary containment $100 \%$ break. IC24, $100 \%$ power, Middle of Cycle (MOC). Malfunction is YP:MCU10 at $100 \%$. Decay heat is normal. No operator action. Automatic group 5 isolation is overridden. Valves M02700, 2701, 2740 do not close feedwater pumps run out trip on delayed overload. 


\section{MALFUNCTION FW02}

Malfunction is condensate pump trip.

a. pump a

b. pump b

Generic, breaker overcurrent device (50) failure, $100 \%$ power. This malfunction will cause the selected main condensate pump breaker to trip from a faulty overcurrent device $(50)$. The condensate pump breaker will indicate open, motor current will decrease, and annunciation from the trip will occur.

When the condensate pump motor breaker trips, the pump will stop, and pump discharge pressure and flow will decrease. The corresponding reactor feedwater pump will trip and the recirculation system will run back low water level of 186 " to $45 \%$ speed.Condensate header pressure will decrease, and flow will increase as the remaining condensate pump capacity is exceeded.

If both condensate pumps are tripped, the reactor feedwater pumps will trip. The recirculation pumps will start to run back at 186" Reactor Pressure Vessel (RPV) water level to $45 \%$ speed.

The reactor will scram when level reaches $170 "$.

Malfunction removal will restore the effected components to normal. Operator action may be required to restore the plant to normal.

Datafiles:

fwO2a.dat: Accident is trip of condensate pump A. No loss of power. When a condensate pump trips, the associated feedwater pump trips automatically. Reactor trips on low level. The turbine then trips on reverse power. IC24, $100 \%$ power, Middle of Cycle (MOC). Malfunction is YP:MFW02(A) the runback of recirculation pumps delays the reactor scram. 


\section{MALFUNCTION FW04}

Malfunction is condensate filter demineralization resin injection.
a. filter a
b. filter $b$
c. filter $c$
d. filter $d$
e. filter e

Generic, variable. $1-100 \%=1-5 \%$ resin release, resin retention element failure, $100 \%$ power. This malfunction will cause the release of resin from the selected demineralizer filter to the severity selected. Any release of resin into the condensate system will cause a buildup in the reactor vessel. Irradiation and carryover into the main steam system will cause the radiation monitoring system to respond to increased radiation levels and annunciation. High temperature and radiation cause a large increase in reactor vessel conductivity and a decrease in water $\mathrm{pH}$.

Malfunction removal will restore the affected components to normal. Operator action may be required to restore the plant to normal.

Datafiles:

fwO4a.dat: Accident is condensate filter demin resin injection causes increase in vessel conductivity and steam line radiation $\mathrm{IC} 24,100 \%$ power, Middle of Cycle (MOC). 


\section{MALFUNCTION FWO9}

Malfunction is reactor feedwater pump trip.

a. pump a

b. pump b

Generic, spurious trip signal, $100 \%$ power. This malfunction will cause the selected main feedwater pump to trip instantly from a spurious trip signal. The pump motor breaker will trip open and annunciation will activate. The pump pressure and flow will decrease and the recirculation valve will close, if open.

The main feedwater pump trip will cause a partial loss of feedwater to the reactor, the level will decrease, and speed is runback to $45 \%$ at the recirculation pump. Reactor and turbine power are reduced accordingly. The feedwater control valves will modulate and maintain reactor water level in the control band at the reduced power level. The plant will stabilize at a new lower power. It is possible for low water level scram because of too high a power level or load line.

Malfunction removal will restore the affected components to normal. Operator action may be required to restore the plant to normal.

Datafiles:

fwO9a.dat: Accident is reactor feedwater pump 'a' trip. IC24, 100\% power, Middle of Cycle (MOC). 


\section{MALFUNCTION FW17}

Malfunction is main feedwater line break inside primary containment.

a. Feed line a

b. Feed line $b$

Generic, variable, $0-100 \%=0-16 "$ diameter double-ended shear weld failure on outlet of check valve, $100 \%$ power. This malfunction will cause the selected feed line inside the primary containment to shear at the outlet of the check valve to the size specified by severity. This malfunction is unisolable from the reactor vessel through the selected feedwater line.

At $100 \%$ severity, the rupture will cause a rapid depressurization of the reactor vessel and feedwater line. The reactor water level will initially increase resulting in a high-level trip of the main turbine, reactor feed pumps, High Pressure Coolant Injection (HPCI) and Reactor Core Isolation Cooling (RCIC). Low-Pressure Coolant Injection (LPCI) and Core Spray (CS) will initiate on the resulting containment pressure of 2 psig and inject into the reactor vessel when reactor pressure decreases below the shutoff head of the pumps. (Inject valves for LPCI and CS will not open until reactor pressure decreases below 400 PSIG).

Drywell pressure and temperature will increase rapidly, and at 2 PSI group isolations $2,3,4,8,9$ and reactor scram will occur. Suppression pool temperature and level will increase in response to the rupture severity. The reactor water level will decrease rapidly actuating reactor trip, and turbine reactor water low,low-low,low-low-low isolation signals for groups $1,2,3,4,5,7,8$, seal purge.

The core spray, HPCI and LPCI systems will actuate and begin to flood the reactor with water. The unisoltated rupture will continue to cause mass loss from the reactor to the drywell and suppression pool. HPCI and RCIC will receive initiation signals on lo-lo reactor water level. If the reactor pressure is greater than 100 PSIG, these systems will initiate.

Depending on which feedwater line is broken, HPCI or RCIC will inject to the reactor vessel. ('A' feedwater line break, RCIC injects to vessel, portion of HPCI bay inject and rest through break, and the opposite is true of ' $\mathrm{B}$ ' feedwater line breaks).

The reactor will cooldown in response to the Emergency Core Cooling System (ECCS), and the event will eventually stabilize. Reactor pressure and drywell pressure will equalize on large break in very short period of time.

This malfunction is unrecoverable, and the simulator will have to be reinitialized for malfunction removal.

Datafiles:

fwl7a_2.dat: Accident is main feed water line break. $60 \%$ single-ended shear loop $A$ IC $24,100 \%$ power, MOC.

fwl7a_3.dat: Accident is main feed water line break. $30 \%$ single-ended shear - loop A IC24, $100 \%$ power, MOC. 


\section{MALFUNCTION FW18}

Malfunction is main feedwater line break outside primary containment.

a. feed line a

b. feed line $b$

Generic, variable, $0-100 \%=0-16$ " diameter double-ended shear weld failure on outlet of feed reg valve $100 \%$ power. This malfunction will cause the selected feed line outside the primary containment to shear at the outlet of the feedwater regulator valve to the size specified by severity.

At $100 \%$ severity, the rupture will cause the feedwater header pressure to decrease rapidly to less than reactor pressure. Header flow will increase rapidly to maximum, and the feedwater pumps capacity will be exceeded and trip on low suction pressure of 250 PSIG. Initially the feedwater regulator valves will modulate open from steam/feedwater mismatch, then open when the decreasing reactor water level overrides control.

A reactor scram will occur when reactor water level decreases from lack of feedwater, the low water level causes High Pressure Coolant Injection (HPCI), and Reactor Core Isolation Cooling (RCIC) actuation and begin to flood the reactor with water and eventually recover the level. Group isolations will occur at the respective setpoints.

The reactor will cool down in response to the Emergency Core Coolant System (ECCS), and the event will eventually stabilize. This malfunction is unrecoverable, and the simulator will have to be reinitialized for malfunction removal.

Datafiles:

fwl8a.dat: Accident is main feedwater line break outside primary containment $100 \%$ break. 


\section{MALFUNCTION HP05}

Malfunction is High Pressure Coolant Injection (HPCI) steam supply line break (HPCI room). Variable, exponential. 0-100\% =0-10" diameter single-ended shear weld failure on HPCI steam supply line any, HPCI in operation. This malfunction will cause the HPCI turbine steam supply line to break at the drain pot inlet. The break size will be specified by severity.

A low severity steam line break will cause the HPCI turbine speed to decrease. The turbine speed controller will cause the throttle valve to open and return the speed to setpoint.

As severity increases, the steam flow will increase and the turbine speed/pumping capacity will decrease. The emergency area cooler will detect a high differential temperature, high room temperature or high steam flow $(300 \%)$ caused by the steam line break and actuate an auto-isolation signal, closing the sieam isolation valves $\mathrm{MO}-2238$, $\mathrm{MIO}-2239$, torus suction valves close, and tripping the turbine. The room fire suppression system may activate at high severities.

The HPCI turbine steam inlet valve HV-2201 will close, the turbine speed will decrease, and exhaust pressure will go to minimum. The HPCI pump discharge pressure and flow will decrease as pump capacity is lost. Reactor water level will not increase from the HPCI system. Without a manual reset the turbine will not attempt a restart at $119.5 "$.

Malfunction removal will restore the affected components to normal. Operator action may be required to restore the plant to normal.

Datafiles:

hpO5_2.dat: Accident is High Pressure Coolant Injection (HPCI) steam line break in HPCI room. $60 \%$ single-ended shear IC20, $100 \%$ power, End of Cycle (EOC).

hpO5_3.dat: Accident is High Pressure Coolant Injection (HPCI) steam line break in HPCI room. $30 \%$ single-ended shear IC20, 100\% power, End of Cycle (EOC). 


\section{MALFUNCTION HP08}

Malfunction is High Pressure Coolant Injection (HPCI) steam supply line break (torus room), variable, $0-100 \%=0-10$ " diameter single-ended shear, weld failure on HPCI supply line at M0-2298 any, HPCI in operation. This malfunction will cause the HPCI turbine steam supply line to break in the torus room at the outlet of M0-2298. The break size will be specified by severity. A low-severity steam line break will cause the HPCI turbine speed to decrease, and the turbine speed controlle: will cause the throttle valve to open and return the speed to setpoint. $\mathrm{HPCI}$ isolation can result if the torus area temperature increases to the high setpoint or has a high $\mathrm{D} / \mathrm{T}$ for greater than 15 minutes.

As severity increases, the steam flow will increase, and the turbine speed/pumping capacity will decrease. The excessive steam flow will cause a high steam line $D / P$ isolation signal to be generated, closing the steam isolation valves $\mathrm{MO}-2238$, MO-2239, torus suction valves close and tripping the turbine.

The HPCI turbine steam inlet valve MO-2202 will close, the turbine speed will decrease, and exhaust pressure will go to minimum. The HPCI pump discharge pressure and flow will decrease as pump capacity is lost. Reactor water level will not increase from the HPCI system. Without a manual reset the turbine will not attempt a restart at 119.5 ".

Malfunction removal will restore the affected components to normal. Operator action may be required to restore the plant to normal.

Datafiles:

hpO8_2.dat: Accident is High Pressure Coolant Injection (HPCI) steam line break in torus room. $60 \%$ single-ended shear IC20, $100 \%$ power, End of Cycle (EOC).

hpO8_3.dat: Accident is High Pressure Coolant Injection (HPCI) steam line break in torus room. $30 \%$ single-ended shear IC20, $100 \%$ power, End of Cycle (EOC). 


\section{MALFUNCTION MCOI}

Malfunction is main circulating water pump trip.

a. pump a. $\operatorname{lp} 4 a$

b. pump b. lp4b

Generic. upper motor bearing failure, $100 \%$ power. This malfunction will cause the selected main circulating water-pump motor upper bearing to fail, resulting in a motor breaker trip on overcurrent.

The circulating water-pump upper motor bearing will fail causing the motor speed or current to fluctuate. After approximately one minute the motor bearing will seize and cause a very high current to be drawn by the motor, and the supply breaker will trip on overcurrent. As the circulating water pump discharges pressure, flow will decrease, and the pump discharge valve will close. The cooling tower basin level will increase slightly then return to normal as the system mass rebalances.

With a circulating water pump tripped the circulating water temperatures will increase across the condensers. Condenser vacuum will decrease, and annunciation and a turbine trip will result, causing a reactor scram and Reactor Pump Trip (RPT). The plant protection system will respond appropriately to the turbine trip, and the plant will stabilize in a post trip condition with Electro-hydraulic Control $(E H C)$ maintaining reactor pressure with the bypass valves.

Malfunction removal will restore the affected components to normal. Operator action may be required to restore the plant to normal.

Datafile:

mcOla.dat: Accident is main circulation water pump "a" trip. No loss of power IC 24, $100 \%$ power, Middle of Cycle (MOC). Malfunction is YP:MMCOI(A). 


\section{MALFUNCTION MSO2}

Steam leak inside the primary containment. Variable $0 \cdot 100 \%=0 \cdot 4$ " diameter single ended shear. Caused by RCIC steam line weld failure at elbow instrument tap (unisolable). $100 \%$ power. This malfunction will cause a main steam leak at $\mathrm{RCIC}$ line elbow instrument tap at a rate specified by severity. Very small severities will cause local heating inside the drywell, a very slight pressure increase, and an increase in leakage to the drywell floor drain system.

The main steam flow will increase and $x x$ pressure will decrease. The turbine Electro-Hydraulic Control (EHC) system will detect the pressure decrease and respond to maintain pressure. With the decreased steam flow the feed flow will decrease causing the reactor vessel water level to decrease until the level dominates and stablizes the level.

The drywell pressure and temp will respond quickly to the leak and the high drywell pressure trip at 2 psig. The HPCI, LPCI, CS and DG's will start, group 2, 3, 4, 5 isolations will activate. If the rx pressure decreases to 850 psig, group 1 isolation will occur and isolate the turbine bypass system. The rx will continue to blow. down and the rx pressure and level will decrease consistant with the severity. Reactor pressure and temperature will decrease rapidly. The torus level and temperature will increase in response to the rupture.

Malfunction removal will restore the effected components to normal. Operator action may be required to restore the plant to normal.

Datafile:

ms02_2.dat: RCIC line break inside primary containment. The simulation was a $60 \%$ single ended shear in a 4" dia pipe. Initial condition is $\mathrm{IC} 24,100 \%$ power, Middle of Cycle (MOC). $60 \%$ severity.

ms02_3.dat: RCIC line break inside primary containment. The simulation was a $30 \%$ single ended shear in a 4" dia pipe. Initial condition is IC24, $100 \%$ power, Middle of Cycle (MOC). $30 \%$ severity. 


\section{MALFUNCTION MS03}

Malfunction is .Main Steam Line (.MSL) rupture inside primary containment.
a. steam line a
b. steam line $b$
c. steam line $c$
d. steam line $d$

Generic, variable, $0 \cdot 100 \%=0 \cdot 20$ " diameter double-ended shear piping on flow restricter at the high pressure instrument tap that feed CRM steam flow instrumentation, $100 \%$ power. This malfunction will cause the selected main steam line to rupture at the flow restricter inlet at a rate specified by severity.

At very low severities, local drywell temperatures will increase. Drywell pressure increase will be small. The drywell floor drain sump will fill up faster, and the drywell cooling system will indicate temperature increases. At lower severities, the main steam flow will increase, measured flow will decrease, and reactor pressure will decrease. The turbine bypass and control valves will modulate close, if open, in an attempt to increase steam pressure.

The feedwater control system will increase feedflow to control the increased demand. The hotwell level control system will begin to makeup from the condensate storage tank to maintain the hotwell level in the normal control band, compensating for the system mass loss. The drywell temperature/pressure will increase at an appropriate level consistent with severity.

At higher severities, the excessive main steam pressure decrease will cause the main turbine control valves to close, attempting to maintain steam pressure. Whenever the steam line pressure decreases to 850 PSIG, the main steam isolation signal and group I isolation will activate and the Main Steam isolation Valve (MSIV) will close, the reactor will scram, and the turbine bypass system will isolate. The reactor will continue to blow down, and the reactor pressure and level will decrease consistent with the severity. The drywell temperature/pressure increase will cause the ECCS to activate at 2 PSIG, and group isolation II,III \& IV will occur. Reactor pressure and temperature will decrease rapidly.

Malfunction removal will restore the affected components to normal. Operator action may be required to restore the plant to normal.

Datafile:

msO3a.dat: Accident is main steam line header double ended shear, $100 \%$. (20" line). IC 24, 100\% power, Middle of Cycle (MOC). 


\section{MALFUNCTION MS04}

Malfunction is Main Steam Line (MSL) rupture outside primary containment.
a. steam line a
b. steam line $b$
c. steam line c
d. steam line $d$

Generic, variable, $0-100 \%=0-20$ " diameter double-ended shear, piping failure at ms common header, $100 \%$ power. This malfunction will cause the selected main steam line to rupture outside the containment at the turbine inlet header at a rate specified by severity. At lower severities, the main steam flow will increase, and reactor pressure will decrease. The turbine bypass and control valves will modulate close, if open, in an attempt to increase steam pressure to control the increased demand. The hotwell level control system will begin to makeup from the condensate storage tank to maintain the hotwell level in the normal control band, compensating for the system mass loss. A Primary Containment Isolation System (PCIS) group I isolation is possible on steam line high temp (200 DEG F), and probability increases with severity.

At $100 \%$ severity, the PCIS group I isolation will be initiated on steam line low-pressure (850 PSIG in the run mode) with the steam line flow (140\%) as a backup. The reactor will scram on MSIV closure. Because of the rapid steaming rate, the reactor water level will rapidly increase causing the main turbine and both reactor feed pumps, HPCI and RCIC, to trip. As the MSIVs close, steam flow through the break will cease, voids will collapse, and reactor water level will stabilize at some new lower level. Emergency Core Cooling System (ECCS) will respond to maintain adequate core cooling. The pressure rise in the turbine building will cause the blowout panels to function, releasing the steam cloud to the environment.

Malfunction removal will restore the affected components to normal. Operator action may be required to restore the plant to normal.

Datafile:

msO4a.dat: Accident is main steam line header double ended shear, $100 \%$. (20" line). Outside primary containment. IC24, $100 \%$ power, Middle of Cycle (MOC). 


\section{MALFUNCTION MSI9}

Malfunction is spurious group I isolation.

a. logic ' $A$ '

b. $\operatorname{logic} \cdot B^{\prime}$

Generic, relay failure, $100 \%$ power. This malfunction will cause the selected group I isolation relay to fail and cause the isolation signal to be generated.

The failure of logic ' $A$ ' will cause the group I isolation annunciator to actuate without valve response.

The failure of logic ' $\mathrm{B}$ ' will cause the group I isolation annunciator to actuate without valve response.

The failure of both logic ' $\mathrm{A}$ ' and ' $\mathrm{B}$ ' will cause the below listed inboard/ont buard isolation valves to trip closed. The valve positions will be displayed at the hand-switches and IC03. The valves are listed below:

M0-4423 M0-4424 CV-4639 CV-4640 CV-4412 CV.4415

CV.4418 CV.4420 CV-4413 CV.4416 CV-4419 CV.4421

The closing of the Main Steam Isolation Valve (MSIV) inboard or outboard will result in a reactor scram, turbine trip, and plant shutdown. Reactor high pressure will activate the Low Low Set (LLS), and reactor pressure will be controlled at about 900 to 1020 PSIG.

Malfunction removal will restore the affected components to normal. Operator action may be required to restore the plant to normal.

Datafile:

ms19ab.dat: Accident is feedwater relay failures A and B logic causing a group I isolation. IC24, $100 \%$ power, Middle of Cycle (MOC). 


\section{MALFUNCTION RP05}

Malfunction RPS scram circuit failure (ATWS).

a. auto-scram failure

b. manual-scram failure

c. ARI failure

d. RPS fuse removal failure

e. all individual rod-scram switches fail

f. hydraulic lock-scram discharge volume

Discrete, RPS scram circuit internal short circuit in wiring (A,B,C,D,E) scram discharge volume blockage $(\mathrm{F}), 100 \%$ power. This malfunction will cause the selected RPS scram circuit to fail to cause a reactor scram when actuated. $(A, B, C, D, E)$ selection of the hydraulic lock malfunction will reduce the scram discharge volume to simulate flow blockage.

If the auto-scram is selected for failure, the plant will respond to the effects of the condition that generated the scram signal. The annunciators and indications will respond to auto-scram inputs as they are generated. However, the plant will remain operating until a protection feature or injection of sodium pertaborate causes the plant to shutdown. The reactor has the manual-scram capability functional, and the operator can utilize this mode as desired.

With an active auto-scram, the plant will scram as required by logic whenever the appropriate condition exists.

A failure of ARI to cause a scram will also cause a failure of the RPT breakers to trip on lo-lo reactor water level, high reactor pressure, or manual initiation of ARI.

The effects of the manual-scram feature failures would be the response failure of the function to respond when activated manually.

RPS fuse removal failure simulates a failure of the RPS fuse removal to work.

Failure of the rod-scram switches simulates a failure of all 89 scram switches to work.

The hydraulic lock malfunction reduces the volume and will allow the rods to partially insert, with each scram signal/reset applied.

Insertion of all (6) generic failures will result in a "ATWS" condition.

Malfunction removal will restore the affected components to normal. Operator action may be required to restore the plant to normal.

Datafiles:

rpO5tcOl.dat: Accident is trip of main turbine together with failure to scram (ATWS). No operator action. IC24, 100\% power, Middle of Cycle (MOC). Malfunction is YP:MTCOl (turbine trip) followed by YP:MRF05(A) (failure to automatically scram). Scram will be delayed and slow. Scram is from alternate rod 
insert (ARI). Recirculation pumps also trip on ARI. ARI is triggered at 119 " vessel level or 1140 PSIG vessel pressure. Recirculation pump trips at turbine control valves fast closure or stop valves less than $90 \%$ open.

rp5actcl.dat: Accident is trip of main turbine together with failure to scram (ATWS), and Alternate Rod Insert (ARI). No operator action. IC24, 100\% power, Middle of Cycle (MOC). Malfunction is YP:MTCOl (turbine trip) followed by YF:MRP05(A) (failure to automatically scram) and YP:MRP05(C) (failure of $A R I)$. Recirculation pump trips on turbine control valves fast closure or stop valves less than $90 \%$ open. 


\section{MALFUNCTION RR10}

Malfunction recirculation pump speed feedback signal failure.

a. pump a

b. pump b

Generic. variable, $0-100 \%=0-100 \%$ of feedback signal, speed control circuit failure, $50 \%$ power. This malfunction will cause the selected recirculation pump speed-control feedback circuit to fail to the specified severity. The pump speed indicator will fail to the specified severity. With the tacho-generator signal failing below the speed demand/manual pot position signal, the recirculation pump actual speed will increase, and the scoop tube will increase to maximum or auto lock if auto-lock conditions are met. With the tacho-generator signal failing above the speed demand/manual pot position signal, the recirculation actual speed will decrease to minimum.

The resulting effect on the plant will be the increase in power for an increased recirculation flow and a decrease in power for a decreased recirculation flow. Turbine generator power and control valve positions will respond as appropriate. Annunciator response to flow limits and control failures will actuate at setpoint.

Reactor water level will respond to the opposite of the recirculation speed initially until feedflow and steam flow can get matched at the proper water level.

Malfunction removal will restore the affected components to normal. Operator action may be required to restore the plant to normal.

Datafile:

rrlO.dat: Accident is recirculation pump speed feedback signal failure caused by speed circuit control failure IC24, 100\% power, Middle of Cycle (MOC). 


\section{MALFUNCTION RR15}

Malfunction is recirculation loop rupture (design basis Loss of Coolant Accident (LOCA) at $100 \%$ ).

a. loop a

b. loop b

Generic, variable, $0 \cdot 100 \%=0-22$ " diameter double-ended shear piping failure at recirc pump suction, $100 \%$ power. This malfunction will cause the selected recirculation loop, inside the primary containment, to shear at the recirculation pump suction to the size specified by severity.

At $100 \%$ severity, the rupture will cause the recirculation loop and reactor pressure to decrease rapidly. The affected loop recirculation pump will cavitate and flow will be lost. Reactor water level will decrease rapidly as the reactor blows down through the rupture into the containment. The reactor water level decrease will actuate reactor scram, and reactor water level low, low-low, low-low-low isolation signals for groups $1,2,3,4,5,7,8$, seal purge. The Core Spray (CS), High-Pressure Coolant Injection (HPCI), Low-Pressure Coolant Injection (LPCI), DG, and ADS systems will actuate and begin to flood the reactor with water. The RR pump discharge valves will close on the non-broken loop on the LPCI loop select signal. Reactor feed pumps will trip on overcurrent.

At $100 \%$ severity, the HPCI and RCIC will receive initiation signals. However, the reactor pressure will decrease so fast that they will trip and isolate on low pressure before they will have any noticeable effect. Drywell pressure and temperature will increase rapidly and at 2 PSI group isolations $2,3,4,8,9$ will occur. Suppression pool temperature and level will increase in response to the rupture severity. The reactor will cooldown in response to the Emergency Core Coolant System (ECCS), and the event will eventually stabilize.

This malfunction is unrecoverable, and the simulator will have to be reinitialized for malfunction removal.

Datafiles:

rrl5a_2.dat: Accident is recirculation loop rupture. $60 \%$ double-ended shear - loop a IC24, $100 \%$ power, Middle of Cycle (MOC).

rrl5a_3.dat: Accident is recirculation loop rupture. $30 \%$ double-ended shear - loop a IC24, 100\% power, Middle of Cycle (MOC). 


\section{MALFUNCTION RR30}

Malfunction is coolant leakage inside primary containment. Variable (exponential), $0 \cdot 100 \%=0.2 "$ diameter pipe (double-ended shear) reactor vessel bottom drain weld failure. $100 \%$ power. This malfunction will cause reactor coolant to leak from the reactor vessel bottom drain failed weld at a rate specified by severity. As severity increases the mass loss from the reactor will easily be made up for by the hotwell level control system. In fact, at $100 \%$ severity the effects on reactor level/hotwell level will be very small. The most effective display of mass loss will be at hot standby.

At $100 \%$ severity, drywell pressure, temperature, and activity will increase. At 2 PSI, group isolations $2,3,4,5,8$ will occur. Suppression pool temperature and level will increase in response to the rupture severity. The reactor scram will result from the 2 PSIG drywell pressure, and a turbine trip will result from reserve power.

The shutdown plant will cooldown in response to the Emergency Core Cooling (ECC) and will stabilize. The longterm effect of the leak will be the transfer of the Condensate Storage Tanks (CST) mass to the suppression pool via the leak in the reactor vessel.

At small severities where the drywell pressure remains below 2 PSIG, the floor drain equipment system will see a high leak (in excess of the 5 GPM tech spec limit). The drywell cooler heat load will increase as seen on the cooler temperatures on IC25.

Malfunction removal will restore the affected components to normal. Operator action may be required to restore the plant to normal.

Datafile:

rr30.dat: Accident is reactor bottom head drain $100 \%$ single-ended shear (2" line). IC24, $100 \%$ power, Middle of Cycle (MOC). 


\section{MALFUNCTION RXOI}

Malfunction is fuel cladding failure. Variable, exponential, $0-100 \%=0 \cdot 30 \%$ fuel clad damage, fuel cladding degradation, $100 \%$ power. This malfunction will cause the fuel cladding to fail to a value specified by severity.

As the fuel failure increases, the amount of activity in the reactor recirculation and main steam system will increase. This activity will propagate throughout the plant and the radiation monitoring system will detect, indicate, and alarm as the activity increases. At low severities, offgas post-treat radiation monitors will cause offgas to isolate (without a group isolation) resulting in a loss of condenser vacuum, main turbine trips, and reactor scram. As the severity increases, the main steam line radiation monitors will cause main steam line isolation and reactor scram at setpoint. As the normal power dependent background radiation levels decrease, the additional radiation levels will be more evident on area and process monitors. At high severities the before mentioned will occur faster with more dramatic increases. Various system trips and isolations will occur, protecting the environment from excessive discharges.

The sequence of the fuel failure indication will be as follows:

1. Offgas pretreat and post-treat radiation monitors increase

2. Offgas stack release will start to increase

3. Offgas system isolates on post-treat hi-hi radiation level

4. Main steam line radiation monitors respond:
a. MSL high radiation alarm
b. Group I isolation
c. Reactor scram

5. Drywell monitors increase

6. Torus radiation monitors increase from relief valve discharge or $\mathrm{HPCI}$ and/or RCIC exhaust.

7. Reactor building area radiation increases from Emergency Core Cooling System (ECCS) system operation. (HPCI, RCIC, LPCI, CS).

NOTE: Malfunction severity will cause some of the above items to be "passed over" or will result in a delayed response.

Datafile:

rxOl.dat: Accident is $30 \%$ fuel clad failure. Causes high radiation alarm to go off IC24, 100\% power, Middle of Cycle (MOC). 


\section{MALFUNCTION TC02}

Malfunction is EHC hydraulic pump trip.

a. pump a

b. pump b

Generic, motor failure, $100 \%$ power. This malfunction will cause the selected EHC pump motor to fail and trip on overload. The starter will open, and an annunciator will actuate.

The unaffected EHC pump will start when the low pressure annunciator actuates at 1300 PSIG EHC system pressure.

If the unaffected EHC pump is unavailable or both EHC pumps are failed, the turbine will trip at 1100 PSIG EHC system pressure. When the turbine trip is initiated, the turbine stop valves, control valves, and combined intermediate valves will rapidly close. The reactor/main steam pressure increases rapidly activating the turbine bypass system. The turbine bypass system will modulate as necessary to control the steam pressure by dumping steam to the main condenser. A reactor scram will occur as a result of the turbine trip. Recirculation pumps will trip when the RPT breakers open from a turbine trip.

$4 \mathrm{KV}$ bus close-circuit transfer is initiated. The main generator $286 / \mathrm{B}$ lockout relay will actuate from the anti-motoring trip protection. The main generator output breakers $352-\mathrm{H}$ and/or 352-I will trip open and lockout. The generator exciter field breaker will open. Generator indication of current, voltage, megawatts, megavars, etc. will decrease to zero. Appropriate annunciators for generator trip will actuate.

The plant will stabilize in a post shutdown condition.

Malfunction removal will restore the affected components to normal. Operator action may be required to restore the plant to normal.

Datafile:

tcO2.dat: Accident is EHC hydraulic pump trip causes pump motors to fail and trip on overload. IC24, 100\% power, Middle of Cycle (MOC). 


\section{INITIAL CONDITIONS IC}

The fuel cycle of a reactor is defined as the preparation, utilization, and ultimate disposal after use of the fuel. The fuel cycle may be divided into three categories depending the time for which the fuel was in the reactor. They are:

1. Beginning of $\mathrm{Cycle}(\mathrm{BOC})$

2. Middle of Cycle (MOC)

3. End of Cycle (EOC)

Conditions pertaining to $\mathrm{BOC}, \mathrm{MOC}$ or EOC can be simulated. The reactor response to a malfunction can differ for these conditions. The following data files were obtained for spurious scram with various initial conditions.

Datafiles:

ic 14scra.dat: Accident is spurious scram. No operator action. IC14, $100 \%$ power, BOC. Malfunction is YP:MRP03.

ic20scrl.dat: Accident is spurious scram with operator action. IC20, $100 \%$ power, EOC. Malfunction is YP:MRP03. Decay heat is $10 \%$ of full power. Operator action is according to integrated plant operating instruction (IPOI) NO. 5 - reactor scram. Actions include: mode switch to shutdown position, feedwater level controller to 175 inches, use reactor water cleanup to maintain RPV level, trip 'A' feed and condensate pumps, manually control feed regulator valves, insert all Source Range Monitor (SRM) and Intermediate Range Monitor (IRM) detectors. Level was not adequately controlled, and both feed pumps and turbine tripped on high RPV level (212 inches).

ic20scr2.dat: Accident is spurious scram with operator action. IC20, $100 \%$ power, EOC. Malfunction is YP:MRP03. Decay heat is $10 \%$ of full power. Operator action is according to Integrated Plant Operating Instruction (IPOI) NO. 5 - reactor scram. Actions include: mode switch to shutdown position, feedwater level controller to 175 inches, use reactor water cleanup to maintain RPV level, trip 'A' feed and condensate pumps, manually control feed regulator valves, insert all SRM and IRM detectors. Level was manually controlled to prevent the trip of feed pumps and turbine.

ic20scrm.dat: Accident is spurious scram. No operator action. IC20, $100 \%$ power, EOC. Malfunction is YP:MRP03.

ic22scrm.dat: Accident is spurious scram. No operator action. IC22, $25 \%$ power, BOC. Malfunction is YP:MRP03.

ic23scrm.dat: Accident is spurious scram. No operator action. IC23, $75 \%$ power, BOC. Malfunction is YP:MRP03.

ic24scrm.dat: Accident is spurious scram. No operator action. IC24, $100 \%$ power, MOC. Malfunction is YP:MRP03. 

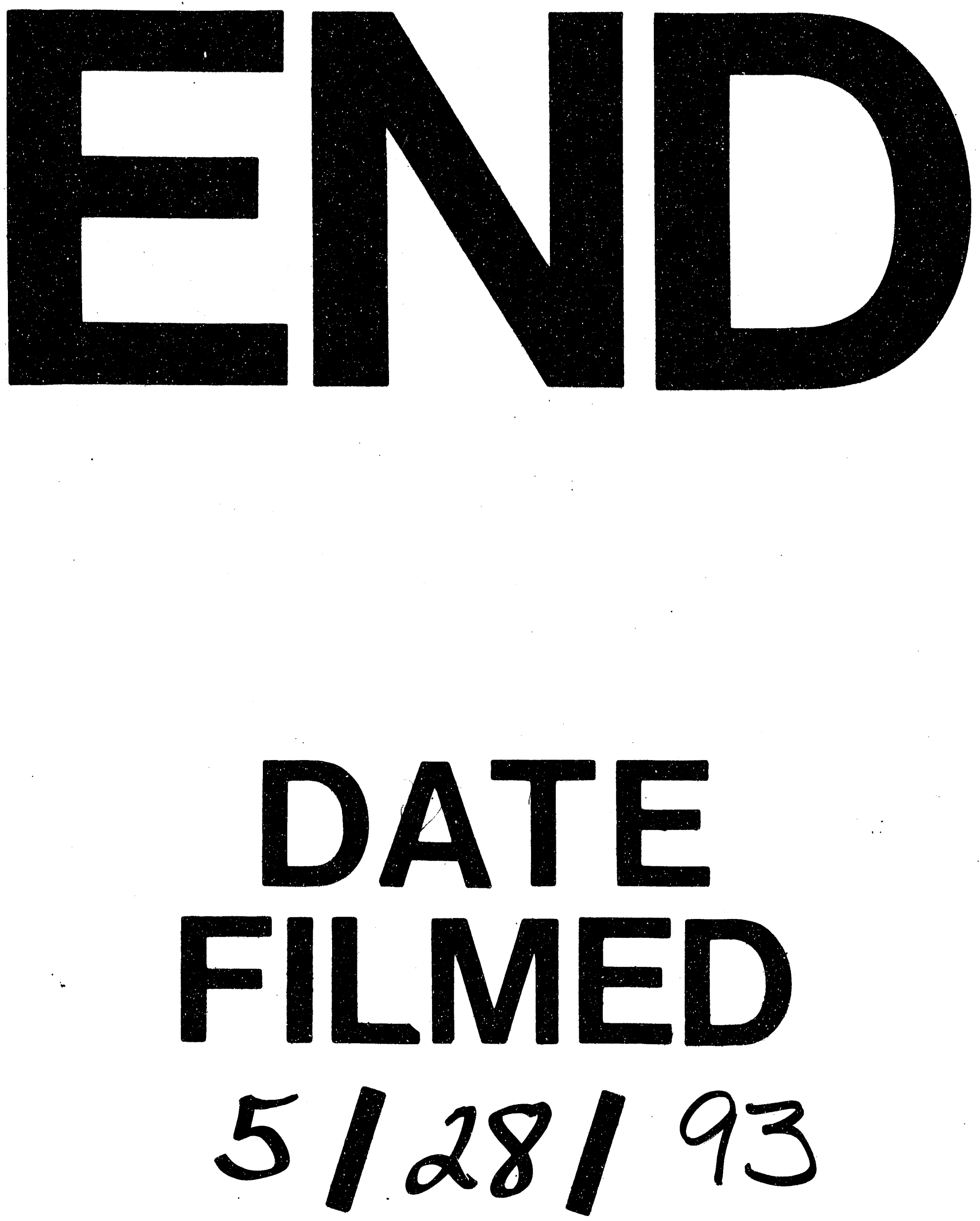
